MONTHLY VARIABILITY IN UPPER OCEAN BIOGEOCHEMISTRY DUE TO MESOSCALE EDDY ACTIVITY IN THE SARGASSO SEA

By

Erin N. Sweeney

B.S., Chemicai Ligineering, Virginia Polytechnic Institute and State University (1994)

Submitted in partial fulfillment of the requirements for the degree of

MASTERS OF SCIENCE, at the MASSACHUSETTS INSTITUTE OF TECHNOLOGY and the WOODS HOLE OCEANOGRAPHIC INSTITUTION

May 2001

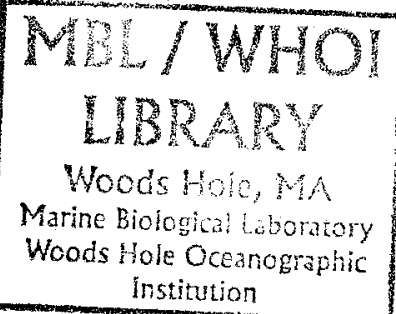

(C) Erin N. Sweeney, 2001. All rights reserved.

The author hereby grants MIT and WHOI permission to reproduce and to distribute mnies of this thesis document in whole or in part. 


\section{Table of Contents}

Abstract $\quad$................................................. 4

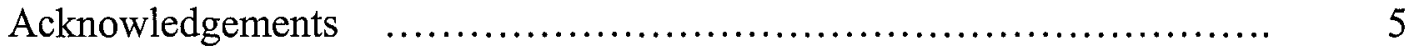

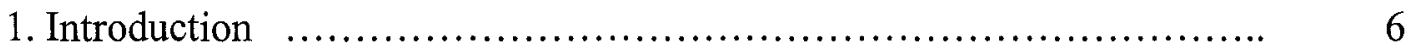

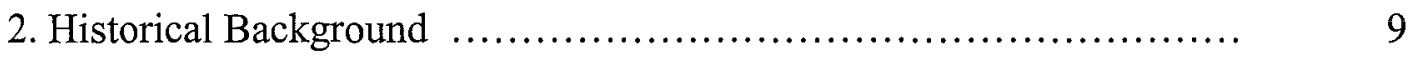

2.1 The Sargasso Sea

2.1.1 The Bermuda Atlantic Time-series Study Site

2.1.2 The Seasonal Cycle

2.1.3 The Budget of Nitrogen and Carbon

2.2 Mesoscale Eddies

2.2.1 Satellite Observations

2.2.2 Isopycnal Displacement

2.2.3 Fundamental Concepts Regarding Mesoscale Eddies

2.2.4 The Relevance of Mesoscale Eddies

2.3 Ecosystem Dynamics

2.3.1 $\mathrm{CO}_{2}$ Drawdown, Population Dynamics, and Export

2.3.2 Pigments and Community Structure

3. Methods

3.1 Satellite Altimetry and Eddy Field Animations

3.1.2 Objective Analysis

3.1.3 Eddy Field Animations

3.2 Thorium Measurements

3.2.1 Thorium-234 Flux Calculation

3.2.2 Thorium-234 Activity Measurements

3.3 Bermuda Area Times Series Measurements

3.3.1 Nitrate and Nitrite Measurements

3.3.2 Productivity Measurements

3.3.3 Chlorophyll Samples and Pigment Measurements

3.3.4 Plotting Procedures

4. Results and Discussion

4.1 Introduction

4.2 Eddy Events

4.2.1 Mode-Water Eddies

July 1995

May 1993

October 1995

4.2.2 Cyclones

July 1993

August 1994 
November 1993

January 1993

4.2.3 Anticyclones

September 1994

March 1994

5. Summary and Significance of Work

5.1 Overview

5.2 The Conceptual Model

5.3 Summary

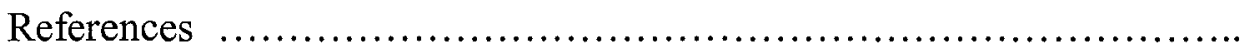




\title{
MONTHLY VARIABILITY IN UPPER OCEAN BIOGEOCHEMISTRY DUE TO MESOSCALE EDDY ACTIVITY IN THE SARGASSO SEA
}

\author{
by \\ Erin N. Sweeney
}

Submitted in May 2001 in partial fulfillment of the requirements for the degree of Masters of Science at Massachusetts Institute of Technology and the Woods Hole Oceanographic Institution.

\begin{abstract}
A comparison of monthly biogeochemical measurements made from 1993 to 1995 , combined with hydrography and satellite altimetry, was used to observe the impacts of nine eddy events on primary productivity and particle flux in the Sargasso Sea. Measurements of primary production, thorium-234 flux, nitrate+nitrite, and photosynthetic pigments made at the US JGOFS Bermuda Atlantic Time-series Study (BATS) site were used. During the three years of this study, four out of six high thorium234 flux events over $1000 \mathrm{dpm} / \mathrm{m}^{2} / \mathrm{d}$ occurred during the passage of an eddy. Primary production nearly as high as the spring bloom maximum was observed in two modewater eddies (May 1993 and July 1995). The 1994 spring bloom at BATS was suppressed by the passage of an anticyclone. Distinct phytoplankton community shifts were observed in mode-water eddies, which had an increased percentage diatoms and dinoflagelletes, and in cyclones, which had an increased percentage cyanobacteria (excluding Prochlorococcus). The difference in the observations of mode-water eddies and cyclones may result from the age of the eddy, which was very important to the biological response. In general, eddies that were one to two months old elicited a large biological response; eddies that were three months old may show a biological response and were accompanied by high thorium flux measurements; eddies that were four months old or older did not show a biological response or high thorium flux. Our conceptual model depicting the importance of temporal changes during eddy upwelling and decay fit the observations well in all 7 upwelling eddies. Additional information is needed to determine the importance of deeper mixed layers and winter mixing to the magnitude of the eddy impacts. Also, sampling generally captured only the beginning, end, and /or edge of an eddy due to the monthly to semi-monthly frequency of the measurements made at BATS. Lagrangian studies, higher resolution time-series, and/or more spatial coverage is needed to provide additional information for improved $\mathrm{C}$ and $\mathrm{N}$ budgets in the Sargasso Sea and to complete our understanding of the temporal changes that occur in an eddy.
\end{abstract}

Thesis Supervisors:

Ken O. Buesseler

Senior Scientist, Department of Marine Chemistry and Geochemistry

Woods Hole Oceanographic Institution

Dennis J. McGillicuddy, Jr.

Associate Scientist, Department of Applied Ocean Physics and Engineering

Woods Hole Oceanographic Institution 


\section{Acknowledgements}

This thesis was made possible through the support and contributions of my thesis advisors Dr. Ken Buesseler and Dr. Dennis McGillicuddy. They were a source of great feedback, suggestions, and ideas regarding this work and were able to balance the complicated task of co-advising with ease. The comparison of data made in this work would not have been possible without the data gathered by the staff of the Bermuda Biological Station for Research. A special thank you should be extended to Rod Johnson for helping me in accessing the online database. In addition, thorium-234 measurements were supplied by Ken Buesseler and Café Thorium. SLA animations were generated primarily by Valery Kosnyrev who also provided me with much help and instruction on how to work with the data used to generate the animations. Olga Kosnyreva helped expand my knowledge of Matlab and in generating the nitrate+nitrite contour plot. Dr. S. Doney from NCAR contributed information on the heat flux at BATS to aid in identifying non-eddy related mixing events. Dr. T. Dickey from UCSB contributed data collected by the Bermuda Testbed Mooring that aided in our interpretation of some eddy events. I would also like to thank my fellow graduate students in the Joint Program for their general support and friendship.

This thesis is dedicated to my family; I hope that my son enjoys a world that is healthy and diverse. My husband, Jason, provided vital support with childcare in the last months of writing my thesis, including many brief trips with our son so I could focus on my work. In addition, he provided help in editing and thesis preparation that was very kind and thoughtful. Also, I certainly would not be here today without the encouragement of my parents.

Funding for this work was provided by NASA and NSF through the JGOFS Synthesis and Modeling Program. 


\section{Introduction}

Recent concern regarding anthropogenic effects on atmospheric $\mathrm{CO}_{2}$ concentration have made the exchange of carbon dioxide gas between the oceans and atmosphere a matter of increased interest. The importance of the ocean to atmospheric $\mathrm{CO}_{2}$ concentration is determined by complex interactions between physics, chemistry, and biology. Large-scale ocean circulation processes play a significant role in transporting energy from the equator to the poles and vary on time scales of decades to millennia. Small-scale ocean physics such as mesoscale eddy flows (ten to hundreds of kilometers in width and continuing for days to years) are ubiquitous in the ocean, are an order of magnitude stronger than mean ocean currents, and also contribute significantly to the transport of momentum and heat within the ocean (Flierl and McGillicuddy, in press). Variability in these long and short time scale physical processes impact global climate. In terms of ocean chemistry, the ocean contains fifty times as much $\mathrm{CO}_{2}$ as the atmosphere, and the $\mathrm{pH}$ and $\mathrm{pCO}_{2}$ of the oceans are buffered by vast reserves of carbon stored as calcium carbonate in oceanic sediments over hundreds of thousands of years (Archer et al., 2000). In addition, evidence of anthropogenic $\mathrm{CO}_{2}$ infiltrating the ocean is apparent; thus short time scale impacts are already occurring. Biological pumping of carbon to the deep ocean also provides a sink for atmospheric $\mathrm{CO}_{2}$, maintaining a lower concentration of $\mathrm{CO}_{2}$ in the atmosphere than would exist above a lifeless ocean. The phytoplankton community structure significantly impacts the effectiveness of this biological pumping. Hence the ocean exerts some control of the atmospheric $\mathrm{CO}_{2}$ concentration, on both long and short time scales.

Such complex and interacting processes are very difficult to model, however, ocean and atmospheric modelers continue their attempts to describe and understand the dynamics of this system. Despite the ubiquitous nature of mesoscale eddies, there is still not enough information to accurately parameterize their effects and the current limits in computing power make it difficult to include them explicitly in ocean circulation models. Therefore, more information is needed to increase our ability to model ocean physics and biogeochemistry. This information is gained both through biogeochemical measurements and through model experiments. 
Eddies introduce a spatial heterogeneity to a study area that is superimposed on any existing temporal variability in the region. Ideally, to study the way the ecosystem responds to this heterogeneity we would follow the progress of a given water mass as it moves through a region, a Lagrangian approach. In this study, however, we have selected Eulerian measurements taken at the Bermuda Atlantic Time-series Study (BATS) site located in the Sargasso Sea. The BATS program was designed to measure seasonal and interannual variability and biogeochemical measurements have been taken there since 1988 (Michaels et al., 1994; Michaels and Knap, 1996). We are using this existing data set, recorded at a fixed point in space, to determine useful insights on eddies that are already recorded in the monthly or semimonthly measurements. Eddies have been demonstrated to be important and prevalent features in the Sargasso Sea (Doney, 1996; McNeil et al., 1999; McGillicuddy et al., 1999). In addition, the N (McGillicuddy et al., 1998; Siegel et al., 1999) and C budgets of the Sargasso Sea may be balanced only by consideration of the impact of mesoscale eddies. If this is the case, it is essential to understand the impact of these eddies in order to parameterize them in general circulation models and thus to predict the effects of anthropogenic $\mathrm{CO}_{2}$.

This thesis examines measurements of ${ }^{234} \mathrm{Th}$ flux, nitrate + nitrite concentration, primary productivity, and photosynthetic pigments taken at the BATS site between January 1993 and December 1995. Eddy activity is predicted from dynamic height, potential density, and satellite altimetry data. The eddy activity is then compared to the biogeochemical measurements taken at BATS over the three-year period of this study. Following this Introduction, we present background information, including the seasonal cycle in the Sargasso Sea, the $\mathrm{C}$ and $\mathrm{N}$ budgets, a primer on mesoscale eddies, information on ecosystem dynamics as it relates to $\mathrm{C}$ export. The Methods section then describes the use of satellite altimetry to generate eddy field animations and their use in this thesis, the calculation of ${ }^{234} \mathrm{Th}$ flux, the determination of ${ }^{234} \mathrm{Th}$ activity, the BATS measurement techniques, and plotting procedures. The Results and Discussion are combined in section four, where a conceptual model depicting eddy impacts in the euphotic zone is introduced, and each of the nine eddy events is presented and discussed. Section five summarizes the eddy-generated responses observed in the time series and 
reflects on the use of the conceptual model introduced in section four. The goal of this work is to better understand the way eddies impact ocean biogeochemistry. 


\section{Historical Background}

\subsection{The Sargasso Sea}

\subsubsection{The Bermuda Atlantic Time-series Study Site}

The BATS station is located near Bermuda in the North Atlantic subtropical gyre at $31^{\circ} 50^{\prime} \mathrm{N}, 64^{\circ} 10^{\prime} \mathrm{W}$. The monthly to semimonthly sampling program commenced in October 1988. The period from 1993-1995 included 36 "core" cruises and 13 "bloom" cruises. A series of 30 measurements, listed in Michaels and Knap (1996) table 3, were made on the core cruises. Bloom cruises differ in that they did not include sediment trap fluxes and measurements were made only from the surface to $250 \mathrm{~m}$. They also took place 2 weeks after a BATS core cruise in January, February, March, and April. BATS measurements of dissolved nitrate+nitrite, primary productivity, photosynthetic pigments, and hydrography were utilized in this thesis. The ${ }^{234} \mathrm{Th}$ fluxes are ancillary to the BATS program and were made only on BATS cruises between 1993 and 1995. The time period of January 1993 to December 1995 is selected for our study to correspond to the ${ }^{234} \mathrm{Th}$ data set because an important emphasis of this thesis is on the impact of mesoscale eddies on particle flux.

\subsubsection{The Seasonal Cycle}

The BATS site is in an area of strong meridional gradients in which seasonal effects have a significant influence on the biogeochemistry. This seasonal cycle was outlined well in Michaels et al. (1994a) and contour plots depicted that seasonal cycle are shown here in figure 2.1. The region south of the BATS site is characterized by weak mixing which leads to a permanently stratified water column. This stratification separates surface waters from dissolved nutrients found at higher concentrations at depth and leads to an oligotrophic ecosystem throughout the year (Michaels and Knap, 1996). Therefore, nitrate is rarely present at the surface and the ecosystem is dominated by picoplankton with nitrogen-fixing cyanobacteria present (Carpenter, 1983; Olson et al., 1990a,b; Siegel et al., 1990). To the north of Bermuda, the deep winter mixed layers result in blooms of larger phytoplankton including diatoms and coccolithophores with a complex transition to oligotrophy in the summer (Siegel et al., 1990). Both of these seasonal patterns can occur at the BATS site depending on the intensity of winter mixing. 

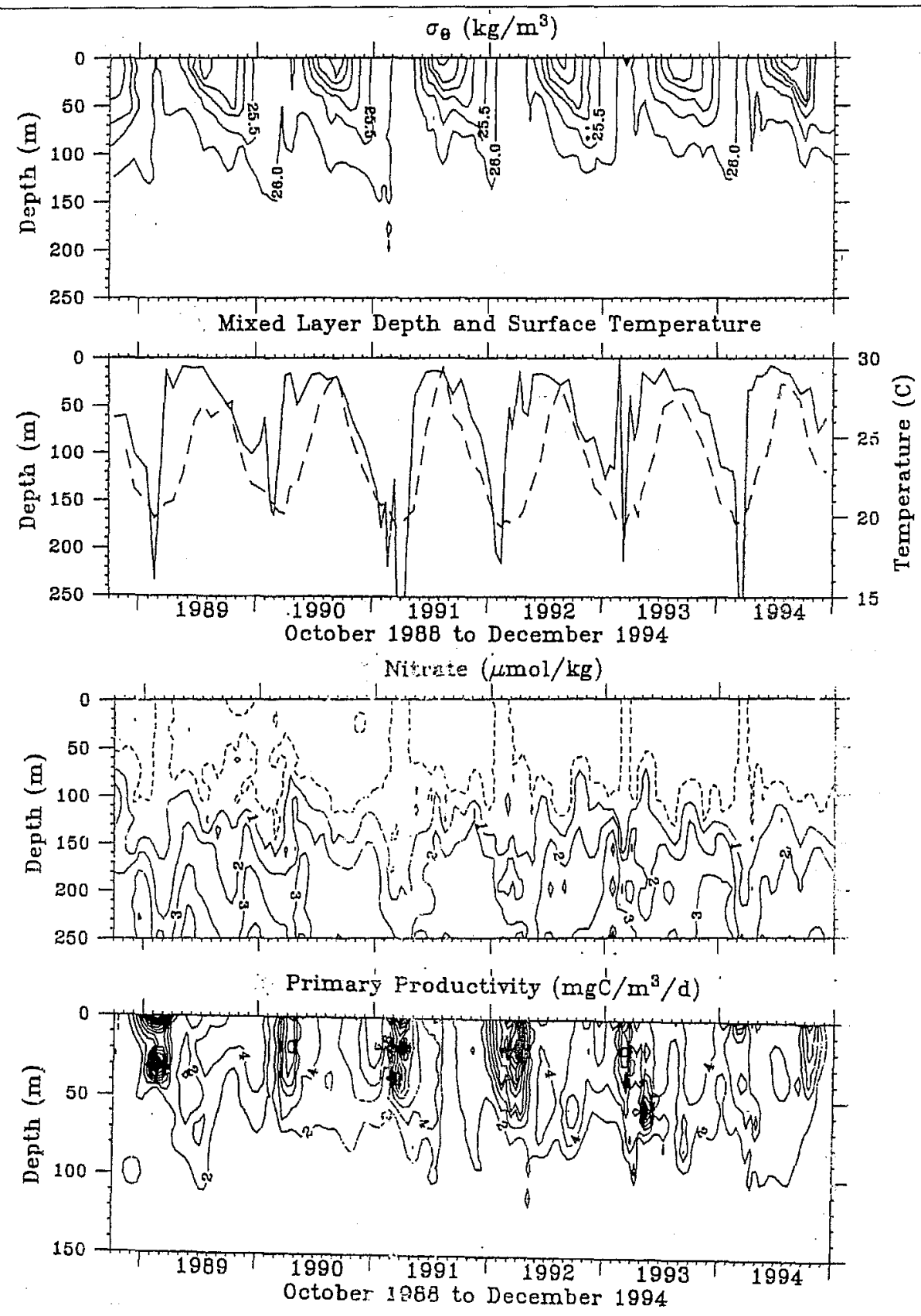

Figure 2.1. The seasonal cycle at BATS depicted in sigma theta (a.), mixed layer depth (b.), nitrate concentration (c.), and primary production (d.) (figures from Michaels and Knap, 1996).

Typically, the formation of a deep mixed layer of $\sim 150$ to $250 \mathrm{~m}$ occurs in February or March of each year (Michaels et al., 1994a; Michaels and Knap, 1996). The entrainment of the deeper nutrient rich waters sparks a subsequent phytoplankton bloom that occurs in March and is characterized by increased pigments, biomass, primary production, and particulate matter. A shallow, well stratified mixed layer is present in the 
summer and fall, until cooling reinitiates the process of deep mixing. As mentioned above, significant variability occurs in the depth of winter mixing and this impacts the strength of the spring bloom in terms of pigment concentration, particulate carbon, nutrient concentrations, and primary production (Lohrenz et al., 1992; Michaels and Knap, 1996).

\subsubsection{The Budget of Nitrogen and Carbon}

A significant motivation behind this work comes from failure to balance the $N$ and $\mathrm{C}$ budgets in the Sargasso Sea. It is possible that the presence of mesoscale eddies, at least in part, provides an explanation for these imbalances. Annual nutrient requirements have been estimated from three independent techniques; $\mathrm{O}_{2}$ utilization (Jenkins et al., 1985; Jenkins and Wallace, 1992), $\mathrm{O}_{2}$ production (Jenkins and Goldman, 1985; Spitzer and Jenkins, 1989), and a ${ }^{3} \mathrm{He}$ flux gauge (Jenkins, 1988). These techniques yield an average estimate of $0.5+/-0.14 \mathrm{~mol} \mathrm{~N} / \mathrm{m}^{2} / \mathrm{yr}$ (McGillicuddy et al., 1998). However, only $0.09-0.17 \mathrm{~mol} \mathrm{~N} / \mathrm{m}^{2} / \mathrm{yr}$ of annual nutrient requirements can be supplied by entrainment during winter deep mixing (Michaels et al., 1994a). Other mixing events, such as diapycnal diffusion and Ekman flows, provide minor contributions $\left(0.08 \mathrm{~mol} \mathrm{~N} / \mathrm{m}^{2} / \mathrm{yr}\right)$ (Lewis et al., 1986; Ledwell et al., 1993; Williams and Follows, 1998). Therefore, half of the nitrogen budget must be introduced from other sources.

Additional sources of nitrogen to balance this budget include atmospheric deposition, nitrogen fixation, and eddy pumping. Estimates of atmospheric deposition are still very poorly constrained, especially with regards to water soluble organic nitrogen and dry deposition, however, it is likely very small in the open ocean; estimates are approximately $0.03 \mathrm{~mol} \mathrm{~N} / \mathrm{m}^{2} / \mathrm{yr}$ (Prospero et al., 1996). Nitrogen fixation could represent a large source of new nitrogen into the euphotic zone; geochemical estimates range from 0.19-0.32 mol N/m²/yr (Michaels et al., 1996) to 0.07 (Gruber and Sarmiento, 1997). Direct determinations from the growth of Trichodesmium, a nitrogen fixing species found in the Sargasso Sea, yielded a very low estimate of $0.01 \mathrm{~mol} \mathrm{~N} / \mathrm{m}^{2} / \mathrm{y}$ (Lipschultz and Owens, 1996). The uncertainty of these nitrogen fixation estimates makes the importance of this source of new nitrogen inconclusive. Eddy pumping is a final potential method of balancing the nutrient budget, yielding estimates of 
approximately $0.25 \mathrm{~mol} \mathrm{~N} / \mathrm{m}^{2} / \mathrm{yr}$ (McGillicuddy et al., 1998; McGillicuddy and Robinson, 1997; Siegel et al., 1999).

The difficulty in balancing the carbon budget at Bermuda further complicates the attempt to balance the nitrogen budget as discussed above. Michaels et al. (1994b) documented a decrease in total carbon stocks from Spring to Autumn of $3.17 \mathrm{~mol}$ $\mathrm{C} / \mathrm{m}^{2} /$ period, three times larger than can be accounted for in the biotic and abiotic flux estimates. Carbon can leave the euphotic zone through air-sea gas exchange, biomass migration, mixing, downwelling, advection and particle flux. The estimates of air-sea gas exchange, biomass, mixing, and downwelling are small and/or relatively well constrained at a net value of around $1.01 \mathrm{~mol} \mathrm{C} / \mathrm{m}^{2} /$ period (Michaels et al., 1994b). This leaves an imbalance of $2.2 \mathrm{~mol} \mathrm{C} / \mathrm{m}^{2} /$ period. This discrepancy has been attributed to either inaccuracies in sediment trap measurements or a failure to account properly for advection (Michaels et al., 1994b).

Inaccuracies in flux estimates from sediment traps clearly exist; for example, traps can fail to record episodic events due to the short 3-day deployment, over or under collect due to swimming heterotrophs (swimmers), lose material through solubilization, and be strongly influenced by hydrodynamic forces. Because of the magnitude of the discrepancy, it is difficult to explain the $2.2 \mathrm{~mol} \mathrm{C} / \mathrm{m}^{2} /$ period imbalance through episodic events alone (Michaels et al., 1994b). The BATS methods account for swimmers and solubilization; thus these sources of error also seem unlikely (Michaels et al., 1994b). Sediment traps have, however, been shown at the BATS site to under collect at highfluxes and over collect at low fluxes (Buesseler et al., 1994). Also, different classes of sinking particles appear to be collected at different efficiencies in the traps (Buesseler et al., 2000). By using the ${ }^{234} \mathrm{Th}$-scavenging method, a Particulate Organic Carbon (POC) flux of 0.4 to $1.9 \mathrm{~mol} \mathrm{C} / \mathrm{m}^{2} /$ period is estimated (Buesseler et al., 2000). Then increasing this value by another $20 \%$ for Particulate Inorganic Carbon (PIC) allows $85 \%$ of the carbon discrepancy to be explained (Buesseler et al., 2000). The use of the ${ }^{234} \mathrm{Th}$ scavenging method as a general particle flux proxy in this thesis is intended to avoid the difficulty of trap biases and inaccuracies.

Horizontal advection of dissolved inorganic carbon (DIC), another proposed solution to the budget imbalance, is not supported by DIC variations in north-south 
transects of the Sargasso Sea or by variations in eddy activity and DIC in the time series measurements (Michaels et al., 1994b). For these reasons, it does not appear to be a likely solution to the calculated carbon budget imbalance.

Not only does the carbon budget in the Sargasso Sea fail to balance, but specifically, the observation of euphotic zone DIC depletions is complicated by high (non-Redfield) ratios of C to N in DIC concentrations (Michaels et al., 1994b). Because they occur in the absence of measurable nutrients, nitrogen fixation is a possible solution to explain this imbalance. Although nitrogen fixation may explain the non-Redfield stoichiometry seen in carbon uptake, it does not specify the fate of the carbon and thus fails to explain the carbon imbalance itself. As mentioned above, mesoscale eddies may provide the added nutrients needed to produce additional biomass, however because upwelled nitrate would be accompanied by additional carbon, eddy upwelling amplifies the already existing carbon uptake imbalance in the euphotic zone by requiring additional unaccounted for uptake and/or export of carbon. Therefore, the exact source of the imbalances is still unclear and this difficulty in balancing the nitrogen and carbon budgets of the Sargasso Sea highlights our need to better constrain the estimates of nitrogen fixation and to better understand the magnitude of the nutrient inputs by mesoscale eddies.

\subsection{Mesoscale Eddies}

\subsubsection{Satellite Observations}

Satellite altimetry measurements were used in this study to detect mesoscale eddies. Both the TOPEX/POSEIDON (T/P) satellite and the European Remote Sensing satellites (ERS) provide altimetric data over the Sargasso Sea. T/P completes its global coverage once every ten days with ground tracks approximately $250 \mathrm{~km}$ apart at the latitude of Bermuda. ERS-1 and ERS-2 complete their cycle of global coverage every 35 days but provide much closer spacing of approximately $70 \mathrm{~km}$.

Observations of the MODE and POLYMODE programs documented eddy sizes in the Sargasso Sea of 100 to $150 \mathrm{~km}$ with the minimum time period for significant changes in mesoscale flows (synoptic dynamical time scale) of 10 to 15 days (Richman et al., 1977; The MODE Group, 1978; Harrison and Heinmiller, 1983). Thus the 
capabilities of the two satellite types in resolving mesoscale eddies using altimetry differs (Table 2.1). The T/P satellite provides adequate temporal coverage to capture mesoscale eddy variations but inadequate spatial coverage, while the ERS satellites provide adequate spatial coverage and inadequate temporal coverage. Therefore, measurements from both $\mathrm{T} / \mathrm{P}$ and ERS satellites were interpolated using objective analysis to provide daily eddy fields and to diagnose mesoscale fluctuations in the BATS measurements.

Table 2.1. T/P and ERS satellites capabilities in resolving mesoscale eddies.

\begin{tabular}{|l|l|l|}
\hline & \multicolumn{1}{|c|}{$\begin{array}{c}\text { Spatial scale or coverage } \\
(\mathrm{km})\end{array}$} & \multicolumn{1}{|c|}{$\begin{array}{c}\text { Temporal scale or } \\
\text { frequency (days) }\end{array}$} \\
\hline Mesoscale Eddies & $100-150$ & $10-15$ \\
\hline T/P satellite & 250 & 10 \\
\hline ERS satellites & 70 & 35 \\
\hline
\end{tabular}

\subsubsection{Isopycnal Displacement}

There are at least three types of mesoscale eddies common in the Sargasso Sea (McGillicuddy, 1998): cyclones, anticyclones, and mode-water eddies (figure 2.2). Cyclones are marked by cold water anomalies; they elevate the isopycnals but depress the sea surface due to the higher density of the water circulating with the eddy. Anticyclones have the opposite effect; they are marked by warm water anomalies, depress the isopynals, and elevate the sea surface due to the lower density of the water circulating with this eddy type. Mode-water eddies appear as elevations of the sea surface but have lens shaped isopycnals. These eddies are anticylonic but, in contrast to other anticyclones, they are associated with a cold water anomaly at the surface. 

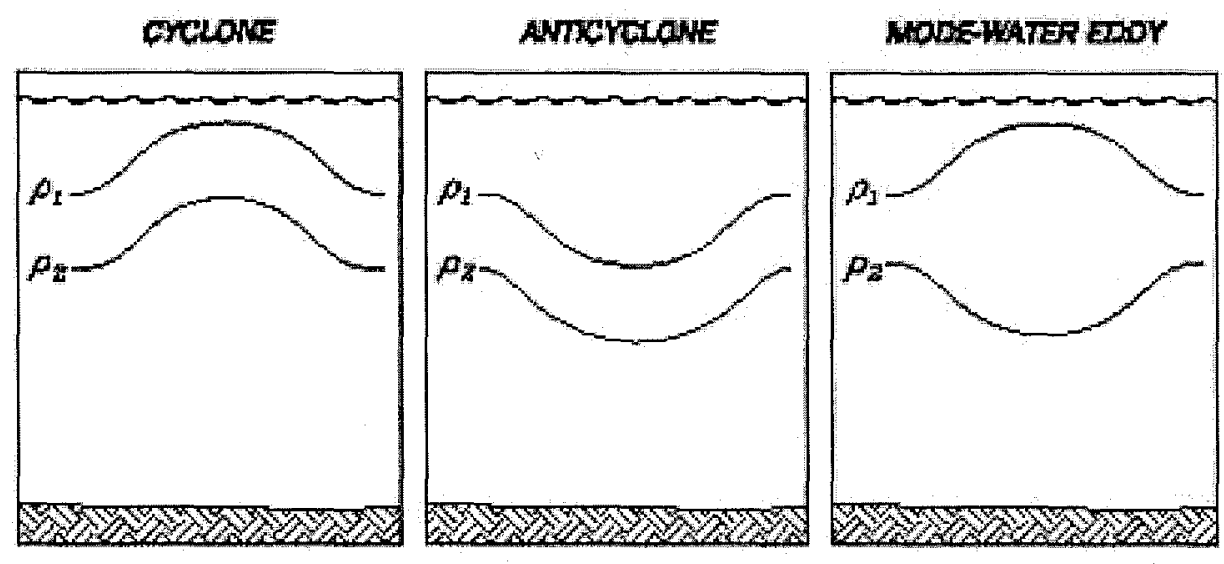

Figure 2.2. Schematic depiction of the isopycnal displacements, $\rho_{1}$ is the seasonal thermocline and $\rho_{2}$ is the main thermocline, of three eddy types encountered in the Sargasso Sea (figure from McGilluddy et al., 1999).

In the mode-water eddies observed at the BATS site, the sense of the isopycnal displacement in the upper ocean is the same as in a cyclonic eddy. Therefore, the cyclone and mode-water eddies both elevate isopycnals in the upper ocean and cause upwelling into the euphotic zone. However, both mode-water eddies and anticyclones are marked by an elevated sea surface. A cartoon representation of the mechanism of nutrient injection in upwelling is shown in figure 2.3 (McGillicuddy and Robinson, 1997). Shoaling isopycnals deliver nitrate into the euphotic zone during upwelling, and deepening isopycnals displace nutrient depleted waters downwards. The upward flux of nutrients should balance a downward flux of organic material from which nutrients are remineralized through decay. 


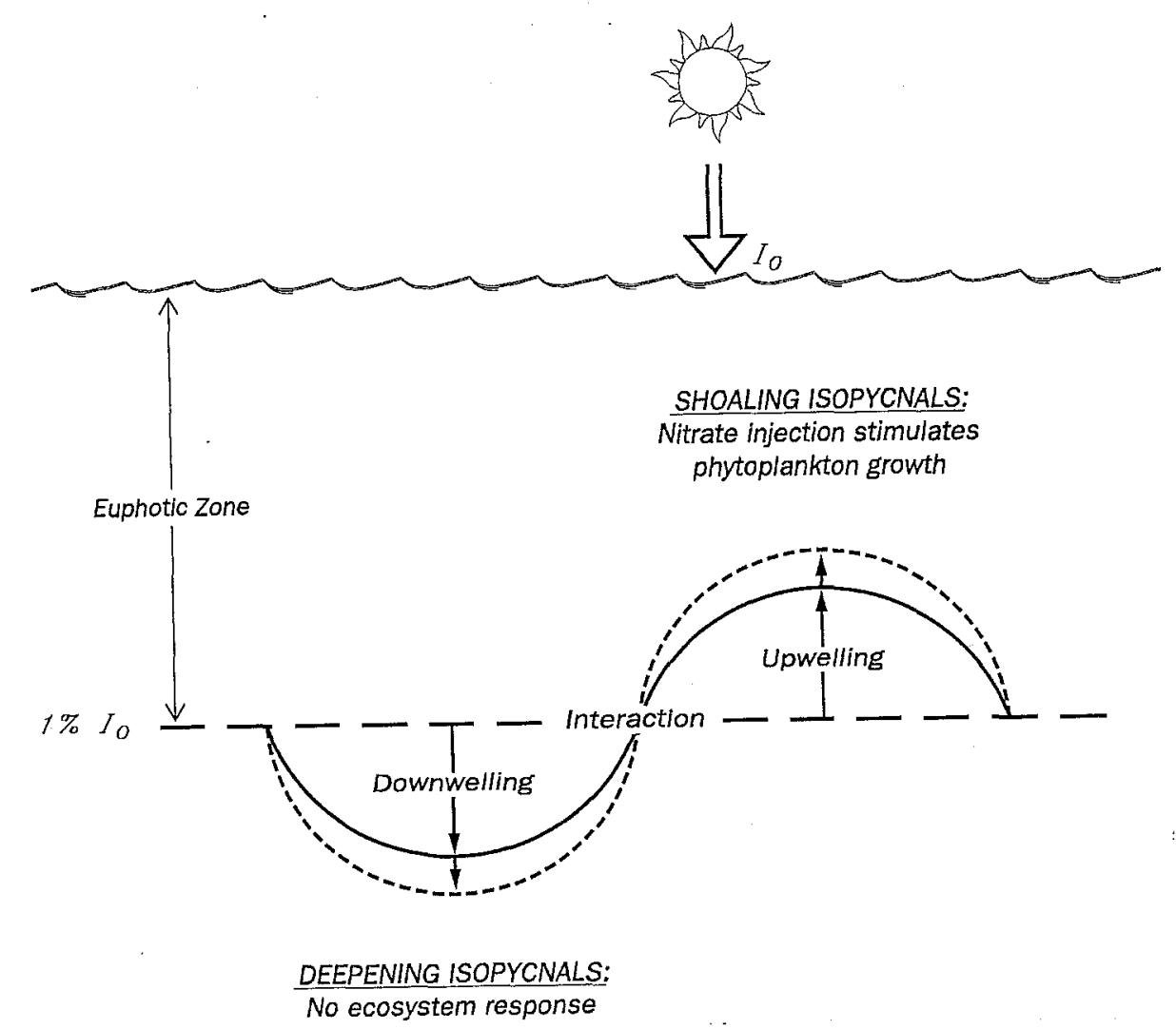

Figure 2.3. A schematic representation of the eddy upwelling mechanism. The solid line depicts the vertical deflection of an individual isopycnal caused by the presence of two adjacent eddies of opposite rotation. The dashed line indicates how the isopycnal might be subsequently perturbed by the interaction of the two eddies. (Figure from McGillicuddy and Robinson, 1997)

\subsubsection{Fundamental Concepts Regarding Mesoscale Eddies}

There are two relevant questions regarding the issue of mesoscale motions. The first is the method of fluid parcel transport; specifically is it by coherent structures or wave motions. The second is the importance of nutrient injections in the interior or on the edges of an eddy (edge effects).

A long standing question regarding fluid transport is whether the mesoscale features are coherent structures, stirring and displacing water parcels through an eddy's lifetime, or planetary waves, simply displacing isopycnal surfaces as they propagate through a region (Seigel et al., 1999). There is much evidence to support the viewpoint that eddy motions carry a water mass with them as they move. SOFAR floats often move in circular motions for months to years (Richardson, 1993). Looping trajectories of these 
floats comprise $25 \%$ of the float observations in the Sargasso Sea, and $60 \%$ of these looping trajectories are cyclonic with radial scales of 90-100 km (Richardson, 1993). These results match well with altimetric sea level anamoly (SLA) fields (Seigel et al., 1999). The foundation of this thesis is based on the premise that eddies carry water masses with them as they propagate westward in the Sargasso Sea. Samples taken in the same eddy over subsequent monthly or semimonthly sampling periods are expected to reflect the passage of that eddy, and samples taken in a new water mass are not expected to reflect it. If the eddies were propagating waves their injection of nutrients into the euphotic zone might be more than previously estimated, and the concept of following an eddy as a water mass would be inaccurate.

The importance of interior flow versus edge effects is still an open question. Upwelling can occur both in the interior and on the edges of an eddy. In the center it is considered slow and of long duration, while on the edges it is rapid but of shorter duration moving along the oscillating edges of the eddy (Woods, 1988; Mahadevan and Archer, 2000; Levy et al., 1999). Using simulations of mesoscale eddies, McGillicuddy and Robinson (1997) determined that the dominant mechanism of nitrate transport associated with a mesoscale eddy arises from internal dynamics. A biological response has been observed due to the passage of an eddy in this study as well as others. Edge effects may be responsible for some of these observations. In this study, eddies rarely passed directly over the site and measurements were often in the edge of the features, therefore, it is sometimes difficult to distinguish between a biological response due to upwelling in the center of an eddy, but observed on the edge, and a response due to edge effects.

\subsubsection{The Relevance of Mesoscale Eddies}

There is a significant body of evidence supporting the contribution of nutrients to the euphotic zone by the passage of mesoscale eddies and showing the prevalence of mesoscale eddy activity in the Sargasso Sea. The BATS record reflects variability that can not be explained by seasonal effects and local air-sea fluxes, and these fluctuations are likely in large part due to mesoscale advection (Doney, 1996). Since the onset of the BATS sampling program, observations of the passage of different water masses have been documented through fluctuations in the nutrient inventories and primary 
productivity (Malone et al., 1993; Roman et al., 1993). In addition, analysis of CZCS ocean color data from the Sargasso Sea shows patches of phytoplankton abundance at the eddy length scale (McGillicuddy and Robinson, 1997). In the summer of 1986, Jenkins (1988) observed upwelled nutrients by comparing two hydrographic profiles sampled one month apart and documented an eddy-driven nutrient injection event that led to the conclusion that eddies could account for $20-30 \%$ of the annual new production in the Sargasso Sea. Work by Goldman $(1988 ; 1993)$ also suggests that eddies are capable of significantly impacting new production in the Sargasso Sea. His work shows that a very small initial population of diatoms can achieve growth rates in culture experiments that would contribute enough new production in a period of days to weeks to equal the annual new production estimates of Jenkins and Goldman (1985) for the Sargasso Sea. Blooms of this type could result from an eddy driven injection of nutrients and might be missed in the BATS monthly to semi-monthly fixed point sampling scheme due to their short duration but which would significantly alter estimates the $\mathrm{C}$ and $\mathrm{N}$ budgets (Goldman, 1988; 1993).

Recently, much progress has been made in modeling the impact of eddy events. McGillicuddy and Robinson (1997) used a regional eddy-resolving model to simulate the potential nutrient injection from upwelling in cyclonic eddies. They estimated eddies to be the dominant source of dissolved inorganic nitrogen into the euphotic zone. An inorganic nitrogen flux estimate, due to upwelling in both cyclones and mode-water eddies, of $0.24+/-0.1 \mathrm{~mol} \mathrm{~N} / \mathrm{m}^{2} / \mathrm{yr}$ (half the nitrogen budget for the Sargasso Sea) was estimated in a kinematic model by Siegel et al. (1999) that linked satellite altimetry to subsurface isopycnal displacements. In addition to modeling, recent progress has been made in making measurements that resolve mesoscale processes. The Bermuda Testbed Mooring (BTM) program (Dickey et al., 1998) documented a nutrient addition that corresponded to increased chlorophyll, particulate matter, and productivity in the presence of a mode-water eddy (McNeil et al., 1999). As part of a BATS validation cruise, eddy injected nutrients were observed to result in accumulated biomass (McGillicuddy et al., 1999). Therefore, mesoscale eddy activity is relevant at the BATS site in two ways; through aliasing onto the time-series observations and in contributing significantly to the nutrient budget of the Sargasso Sea. 


\subsection{Ecosystem Dynamics}

\subsection{1 $\mathrm{CO}_{2}$ drawdown, Population Dynamics, and Export}

Both productivity and plankton community structure impact biological export of carbon to the deep ocean, therefore, the factors that control the dynamics of the upper ocean are essential to understanding the efficiency of the biological carbon pump. Sinking particles can be comprised of aggregated small organisms and material, the biomass of larger organisms, and fecal pellets. By effecting the quantity and composition of surface particles, the size distribution of phytoplankton appears to be of great importance in controlling the carbon export from the surface ocean (Archer, 1995).

Carbon export does not appear to be related directly to the rate of primary production. The decoupling of primary productivity and export has been observed in the central North Pacific (Karl et al., 1995; 1996), in the Arabian Sea (Buesseler et al., 1996), and at the BATS site (Michaels and Knap, 1996). Small phytoplankton groups, $<5 \mu \mathrm{m}$ in size, are the most abundant primary producers in the open ocean but do not appear to contribute significantly to export (Goldman, 1993). They may contribute little to export because they are effectively grazed by protozoa within the microbial loop (Glover et al., 1988), they have extremely low sinking rates (Takahashi and Bienfang, 1983), and they are only slightly associated with larger sinking detrital particles (Silver et al., 1986). Large phytoplankton probably contribute significantly to export, thus episodic nutrient injections (such as from the presence of mesoscale eddies) that change the species composition could significantly impact export and alter the observed relationship between export and primary production.

Large phytoplankton groups such as diatoms and dinoflagellates are believed to be very important to the rate of carbon export. Boyd and Newton (1995) attributed marked interannual variability in the POC flux associated with 1989 and 1990 spring blooms in the North East Atlantic to the absence of large diatoms in 1990. Also, in a study of biogenic silica production in the upper water-column at BATS, export of diatoms was estimated to account for $30 \%$ of the organic carbon (Brzezinski and Nelson, 1995 ) even though they are only estimated to contribute $8 \%$ of the primary production (Boyd and Newton, 1999). Table 2.2 shows common algal groups and their size classes. 
In general, diatoms and dinoflagellates are considered the major contributors to the large size fraction at the BATS site (Savidge et al., 1995; Anderson et al. 1996).

The importance of diatoms and other large phytoplankton to flux is due to many factors. First, larger organisms have higher sinking rates. In addition to their larger size, diatoms produce a silica frustule which gives them a higher density than other phytoplankton and causes them to sink more rapidly. Also, two fast-growing diatoms isolated from the Sargasso Sea were observed to produce giant flocculent masses that would be expected to further increase the size and thus the sinking rate (Goldman, 1993). Second, larger phytoplankton promote short food webs that lead from large suspended organisms to larger grazers and thus larger sinking particles (Michaels and Silver, 1988). Also, large phytoplankton cells contain many times the carbon content of small cells; for example, $\sim 5 \times 10^{4}$ cyanobacteria equal the carbon content of one $100 \mu \mathrm{m}$ round diatom (Goldman, 1988).

Table 2.2. Algal groups and associated size classes (Jeffrey et al., 1997; Sieburth and Smetacek, 1978).

\begin{tabular}{|l|l|l|}
\hline Algal Group & Typical Size & Size Class \\
\hline Prochlorophyte & $0.5 \mu \mathrm{m} ; 1 \mathrm{~mm}$ filaments & picoplankton \\
\hline Cyanobacteria & $1 \mu \mathrm{m} ; 2 \mathrm{~mm}$ filaments & picoplankton \\
\hline Prymnesiophyte & $5-20 \mu \mathrm{m}$ & nanoplankton \\
\hline $\begin{array}{l}\text { Prasinophyte (includes } \\
\text { coccolithophorids) }\end{array}$ & $1-40 \mu \mathrm{m}$ & nano-microplankton \\
\hline Chrysophyte & $\begin{array}{l}2-3 \mu \mathrm{m} \text { coccoid; 20-100 } \mathrm{mm} \\
\text { silicaflagellates }\end{array}$ & $\begin{array}{l}\text { pico-nanoplankton; } \\
\text { microplankton }\end{array}$ \\
\hline Dinoflagellate & $\begin{array}{l}2-200 \mu \mathrm{m} \\
\text { (some up to } 2 \mathrm{~mm} \text { ) }\end{array}$ & $\begin{array}{l}\text { nano-microplankton } \\
\text { (some mesoplankton) }\end{array}$ \\
\hline $\begin{array}{l}\text { Bacillariophyte } \\
\text { (diatoms) }\end{array}$ & $\begin{array}{l}2-200 \mu \mathrm{m} \\
\text { (some up to 2 - 4 mm) }\end{array}$ & $\begin{array}{l}\text { nano-microplankton } \\
\text { (some mesoplankton) }\end{array}$ \\
\hline
\end{tabular}

In addition to phytoplankton biomass, an average of $39 \%$ of the carbon flux at BATS is comprised of fecal pellets (Roman et al., in press). This is unlike the oligotropic Pacific (Hawaiian Ocean Time-series Study site) where fecal pellets appear to comprise $\sim 100 \%$ of the carbon flux (Roman et al., in press). Therefore, aggregated small organisms, larger plankton biomass, and fecal pellets may all be important to particle flux at BATS. 


\subsubsection{Pigments and Community Structure}

Photosynthetic pigment data can be used to infer phytoplankton community composition. Table 2.3 shows pigments useful as taxonomic markers. The pigments we have selected for this study are chlorophyll a, chlorophyll b, 19'-butanoyloxyfucoxanthin, fucoxanthin, 19'-hexanoyloxyfucoxanthin, peridinin, prasinoxanthin, and zeaxanthin + lutein. From these pigment measurements, information can be deduced about the organism(s) present during a bloom. Chlorophyll a is present in all groups; most groups contain monovinyl chlorophyll a, however, Prochlorococcus contains divinyl chlorophyll a. In addition, the presence of both chlorophyll $b$ and zeaxanthin indicates prochlorophytes. Chlorophyll b without zeaxanthin indicates euglenophytes and/or prasinophytes. Zeaxanthin without a peak in chlorophyll b would indicate cyanobacteria. Increases in fucoxanthin with corresponding increases in 19'-hexanoyloxyfucoxanthin and/or 19'-butanoyloxy-fucoxanthin indicates prymnesiophytes and/or chrysophytes respectively. For the pigment data to indicate the presence of diatoms, fucoxanthin must increase without corresponding increases in 19'-hexanoyloxyfucoxanthin and 19'butanoyloxyfucoxanthin (Michaels et al., 1994).

Table 2.3. Phytoplankton pigments useful as diagnostic markers (Jeffrey et al., 1997).

\begin{tabular}{|l|l|}
\hline Pigment & Algal Group(s) \\
\hline Chlorophyll a & All groups (Prochlorococcus contains divinyl chl a) \\
\hline Chlorophyll b & Green algae (Chlorophytes, Prasinophytes, Euglenophytes) \\
\hline 19 '-hexanoyloxyfucoxanthin & Chrysophytes, Prymnesiophytes \\
\hline Fucoxanthin & Diatoms, Chrysophytes, Prymnesiophytes, Raphidophytes \\
\hline $19 '$ 'butanoyloxyfucoxanthin & Prymnesiophytes \\
\hline Peridinin & Dinoflagelletes \\
\hline Zeaxanthin & Cyanobacteria, Rhodophytes, Chlorophytes \\
\hline
\end{tabular}

To avoid the complexity in estimating community structure from pigments, algorithms have been developed based on the ratios of different pigments, found in representative phytoplankton cultures, to determine the percent chlorophyll a contributed by different algal groups (Letelier et al., 1993; Mackey et al., 1996; 1998, Wright et al., 2000). Although, no transfer function is available for BATS one developed for the 
oligrophic Pacific by Letelier et al. (1993) has been used previously for the BATS site (Boyd and Newton, 1999). The use of these equations (Table 2.4) is limited because it assumes that the ratios of different pigments remain constant within algal groups and in organisms under different growth conditions. Also, the equations are based on shade adapted cultures (light equivalent to roughly $75 \mathrm{~m}$ ), and they assume that all organisms in a given group have ratios of pigments similar to those used to develop the equations shown in table 2.4 (for example, it is known that one type of diatom uses 19'butanoyloxyfucoxanthin) (Letelier et al., 1993). Because of these assumptions, we will use these equations to provide only a rough approximation of what the changes in pigment concentrations mean in terms of community structure.

Table 2.4. Relationships among diagnostic pigment markers for various algal groups used in the development of an algorithm to attribute measured $\mathrm{Chl}$ a into taxonomic categories (Letelier et al., 1993). To distinguish between (19-but) chrys in chrysophytes

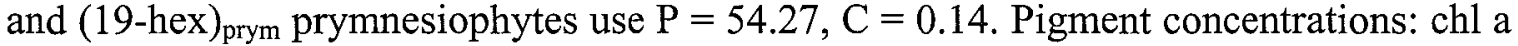
$=$ chlorophyll $\mathrm{a}, \mathrm{chl} \mathrm{b}=$ chlorophyll $\mathrm{b}, 19$-but $=19$-butanoyloxyfucoxanthin, 19-hex $=19$ hexanoyloxyfucoxanthin, fuco $=$ fucoxanthin, zea $=$ zeaxanthin, prasino $=$ prasinoxanthin, and perid $=$ peridinin. For organisms: cyano $=$ cyanobacteria $($ except pros), pros $=$ prochlorococcus , chrys $=$ chrysophyte, bacil $=$ bacillariophyte, dino $=$ dinoflagellate, and pras $=$ prasinophyte .

\begin{tabular}{|c|c|c|}
\hline Algal Group & Algorithm & Source \\
\hline $\begin{array}{l}\text { Prochlorococcus } \\
\text { sp. }\end{array}$ & $(\text { Chl a })_{\text {pros }}=0.91^{*}\left[(\mathrm{chl} \mathrm{b})-2.5^{*}(\right.$ prasino $\left.)\right]$ & $\begin{array}{l}\text { Goericke and } \\
\text { Repeta, } 1992\end{array}$ \\
\hline $\begin{array}{l}\text { Cyanobacteria } \\
\text { (except pros) }\end{array}$ & $(\mathrm{Chl} \mathrm{a})_{\text {cyano }}=2.1(\mathrm{zea})-0.07[(\mathrm{Chl} b)-2.5$ (prasino) $]$ & $\begin{array}{l}\text { Kana et al., } \\
1988\end{array}$ \\
\hline $\begin{array}{l}\text { Prymnesiophytes } \\
\text { (includes } \\
\text { coccolithophorids) }\end{array}$ & $\begin{array}{l}(\text { Chl a })_{\text {prym }}=1.3(19-\text {-hex })_{\text {prym }} \\
(19-\text { hex })_{\text {prym }}=[P /(P-C)][(19-\text {-hex })-(19-\text { but }) C]\end{array}$ & $\begin{array}{l}\text { Emiliania } \\
\text { huxleyi } \\
\text { (CCMP 337) }\end{array}$ \\
\hline Prasinophytes & $(\text { Chl a })_{\text {pras }}=2.1$ (prasino) & $\begin{array}{l}\text { Pycnococcus } \\
\text { provasolii } \\
\text { (CCMP 1203) }\end{array}$ \\
\hline Chrysophytes & $\begin{array}{l}(\mathrm{Chl} \text { a })_{\text {chrys }}=0.9(19-\text { but })_{\text {chrys }} \\
(19 \text {-but })_{\text {chrys }}=[\mathrm{P} /(\mathrm{P}-\mathrm{C})][19 \text {-but }-(19-\text {-hex }) / \mathrm{P}]\end{array}$ & $\begin{array}{l}\text { Clone 1934-1 } \\
\text { (CCMP 1145) }\end{array}$ \\
\hline Dinoflagellates & $(\mathrm{Chl} a)_{\text {dino }}=1.5$ (perid) & $\begin{array}{l}\text { Amphidinium } \\
\text { sp. }\end{array}$ \\
\hline $\begin{array}{l}\text { Bacillariophytes } \\
\text { (diatoms) }\end{array}$ & $\begin{array}{l}(\text { Chl a })_{\text {bacil }}=0.8\left[(\text { fuco })-0.2(19-\text { hex })_{\text {prym }}+0.14(19-\right. \\
\left.\text { but })_{\text {chrys }}\right]\end{array}$ & $\begin{array}{l}\text { Phaeodactylum } \\
\text { tricornutum } \\
\text { (CCMP 1327) }\end{array}$ \\
\hline
\end{tabular}




\section{Methods}

\subsection{Satellite Altimetry and Eddy Field Animations}

\subsubsection{Objective Analysis}

Satellite altimetry measurements provide sea level observations that can be used to detect mesoscale features. To allow us to interpret the altimetry measurements in terms of the presence of mesoscale eddies they were processed using a careful mathematical and statistical analysis. First, non-eddy related trend surfaces were removed from the data following the methods of Bernada (1993) using the Center for Space Research ocean tide model (CSR3.0) (Eanes and Bettadpur, 1995). This adjustment provided residual sea surface height. A long-term mean of this data was determined and then subtracted to yield sea level anomaly (SLA). The SLA data in this study was provided by Archiving, Validation, and Interpretation of Satellite Data in Oceanography (AVISO, 1997). The data of ERS and T/P was merged by AVISO staff using the global minimization algorithm of LeTraon, et al. (1995) and LeTraon and Ogor (1998) which provides compatible error characteristics in the data. An accuracy of $\sim 2$ cm was achieved (AVISO, 1997).

Satellite ground tracks provide limited spatial and temporal coverage; therefore, field estimates of SLA were obtained by objective analysis of the SLA data. Objective analysis is a statistical data treatment that provides the best local estimate of the mean value of a field variable. The method used to generate these field estimates includes time and position. Each image was formed based on a combination of the current SLA and knowledge of the previous and future SLA data adjusted using a calculated westward propagation. Details of this method are given in Carter and Robinson (1987) and Siegel et al. (1999). Objectively analyzed fields were made on a $\sim 25 \mathrm{~km}$ grid in a domain spanning latitude of 28 to $38^{\circ} \mathrm{N}$ and longitude of 75 to $45^{\circ} \mathrm{W}$. An estimated error for these images was generated using T/P along-track data and hydrographic data measured at BATS. By including ERS altimetry the error values in the eddy fields of SLA were never greater than $50 \%$. In the absence of ERS data, error levels of SLA were often greater than $50 \%$ for much of the domain. Unfortunately, no ERS data was available for 1994, therefore, the eddy fields during that time are less accurate but are still considered reliable when a T/P satellite track went right over the eddy's center. 


\subsubsection{Eddy Field Animations}

Eddies were identified from the period between 1993-1995 using eddy field animations generated by the group of Dr. D. J. McGillicuddy at the Woods Hole Oceanograpic Institution. These animations were prepared for October 27, 1992 to September 22, 1999 and are available online at the following website: http://science.whoi.edu/users/mcgillic/tpd/anim.html. Features were selected using these animations based on several criteria. First, coherent features with maximum sea level displacements exceeding $10 \mathrm{~cm}$ were selected. The error of the SLA analysis along tracks is $\sim 2 \mathrm{~cm}$ and greater in the areas where data is interpolated; features with a magnitude below $10 \mathrm{~cm}$ were not viewed as significantly different from background levels. SLA was corroborated by dynamic height measurements from the BATS site. Additional confirmation of a feature was made using contour plots of potential density, i.e. a displacement of the isopycnals with depth indicates the presence of an eddy. In cases when satellite coverage was poor the error on the SLA generated eddy field is high, therefore, potential density and dynamic height are considered better indicators of an eddy's presence during poor satellite coverage. Contour plots of sigma theta and additional information on temperature and velocity were also used where available (Bermuda Testbed Mooring results, Dickey et al., 1998).

\subsection{Thorium-234}

\subsubsection{Thorium-234 Flux Calculation}

Problems with sediment trap collection efficiencies have led us to select the alternative method of estimating particle export using ${ }^{234} \mathrm{Th}$ activity in seawater. This method provides estimates of flux from surface waters on timescales of days to weeks (Buesseler, 1991). ${ }^{234} \mathrm{Th}\left(\mathrm{t} 1 / 2=24.1\right.$ days) is the daughter of ${ }^{238} \mathrm{U}$ decay. Because thorium is very particle reactive it is removed from a parcel of water in only two ways, through decay and through particle flux. Therefore, an activity balance can be used to determine its flux:

$$
\delta^{234} \mathrm{Th} / \delta \mathrm{t}=\left({ }^{238} \mathrm{U}-{ }^{234} \mathrm{Th}\right) \lambda-\mathrm{P}+\mathrm{V}
$$


where ${ }^{238} \mathrm{U}$ is the uranium activity in sea water, determined from its conservative relationship with salinity according to Chen et al. (1986), ${ }^{234} \mathrm{Th}$ is the measured activity sampled in the water column, $\lambda$ is the decay constant for ${ }^{234} \mathrm{Th}, \mathrm{P}$ is the net export flux of ${ }^{234} \mathrm{Th}$ on sinking particles, and $\mathrm{V}$ is the sum of advective and diffusive ${ }^{234} \mathrm{Th}$ fluxes. In this work we have applied a steady state assumption, which implies that the flux has been constant over several weeks preceding the measurement. Recent large export events should be clearly reflected in this measurement, but due to radioactive in-growth of ${ }^{238} \mathrm{U}$ decay, it is impossible to tell a large flux event which occurred several weeks previously from a long period of low flux. The use of a non-steady state model was applied by Buesseler et al. (1992a) for the North Atlantic bloom experiment; however, we do not have the necessary time-series data to apply a non-steady state model here. We were able to estimate the error from the non-steady state assumption by using two subsequent monthly measurements taken within the center and edge of the same eddy. The activity of ${ }^{234} \mathrm{Th}$ was $2.35 \mathrm{dpm} / 1$ in July 1995 and $2.3 \mathrm{dpm} / 1$ in August 1995. The measurements differed by 39 days and thus an estimated $\delta^{234} \mathrm{Th} / \delta \mathrm{t}$ of $190 \mathrm{dpm} / \mathrm{m}^{2} / \mathrm{d}$ results, giving an approximate $15 \%$ error in the August 1995 flux.

Another area of uncertainty when using equation (1) is the advective and diffusive fluxes, which are usually assumed to be small compared to the other terms (Buesseler, 1998). The evidence proposed in the discussion on carbon imbalances can be used to support the assumption of neglecting horizontal advection. In vertical advection there is both upwelling and downwelling to consider. In the case of upwelling, as with a cyclone or mode-water eddy, the calculated flux would be lower than the actual flux. We estimate the error in the ${ }^{234} \mathrm{Th}$ flux to be as high as $\sim 20 \%$ due to the upwelling in an eddy. This estimate is based on an upwelling rate of $1 \mathrm{~m} / \mathrm{d}$ and a deep water ${ }^{234} \mathrm{Th}$ activity in secular equilibrium with ${ }^{238} \mathrm{U}$. In the case of downwelling, assuming replacement through lateral inputs at the surface, and as long as there is not significant horizontal heterogeneity, the ${ }^{234} \mathrm{Th}$ flux would not be effected. All advective and diffusive terms were ignored in these thorium flux calculations. 


\subsubsection{Thorium-234 Activity Measurements}

The ${ }^{234} \mathrm{Th}$ activity measurements were made in accordance with Buesseler et al. (1994). The purpose of the data collection was to compare measured ${ }^{234} \mathrm{Th}$ predicted flux to measured values taken from $150 \mathrm{~m}$ sediment traps. Therefore the samples were vertically integrated between the surface and $150 \mathrm{~m}$. Water was collected at 12 evenly spaced depths and combined. From each depth 2-L samples were dispensed into a clean polycarbonate bottle. The accuracy of this volume measurement was $+/-0.3 \%$. The 12 2-L samples were dispensed into a 25 -L poly-ethylene collapsible container (cubitainer) and mixed well. Next, $1 \mathrm{ml}$ of 6 disintegrations per minute $(\mathrm{dpm}) / \mathrm{ml}{ }^{230} \mathrm{Th}$ used as a yield monitor, $5 \mathrm{ml}$ of $\mathrm{FeCl}_{2}$ in $\mathrm{HCl}(50 \mathrm{mg} / \mathrm{mL})$, and $30 \mathrm{~mL}$ concentrated $\mathrm{HNO}_{3}$ were added. Each sample equilibrated for 24-60 hours on the ship and was returned to Bermuda Biological Station for Research (BBSR) within 60 hours of collection.

At Bermuda Biological Station for Research (BBSR) each sample was weighed and the $\mathrm{pH}$ was adjusted to a value of 8 using concentrated $\mathrm{NH}_{4} \mathrm{OH}$. An Fe precipitate formed and served to scavenge the thorium and other particle reactive substance from solution. This Fe precipitate was collected on a GF/F filter and mailed to Woods Hole Oceanographic Institution (WHOI) for further analysis. The Fe precipitate was next dissolved in concentrated HCL and treated to ion exchange purification procedures to separate ${ }^{234} \mathrm{Th}$ from the other beta emitters (Fleer, 1991; Buesseler et al., 1992b). Within 4-17 days of collection, the ${ }^{234} \mathrm{Th}$ was separated from its parent ${ }^{238} \mathrm{U}$ by passing it through an ion exchange column in $8 \mathrm{~N} \mathrm{HCL}(10 \mathrm{ml}$ volume, BioRad AG1x8 100-200 mesh resin). A second ion exchange column (5 ml, AG1x8 resin 100-200 mesh in $8 \mathrm{~N} \mathrm{HNO}_{3}$ form) was then used to purify the thorium from other beta emitters.

The final purified thorium was electroplated onto a stainless steel planchette for low-level beta counting. Each sample was first alpha counted for $48-96$ hours for ${ }^{230} \mathrm{Th}$ to determine the overall chemical yield. Subsequently, each planchette was mounted with a $9 \mathrm{mg} / \mathrm{cm}^{2}$ foil cover, to reduce any low-energy beta emissions, and counted by a gas flow proportional counter. The beta detectors used had an average background count rate of 0.4-0.5 cpm (Noshkin and DeAgazio, 1966). Blanks were run to ensure that there was no thorium -234 beta activity in the yield monitor or reagents. ${ }^{234} \mathrm{~Pa}$, a daughter product of ${ }^{234} \mathrm{Th}$, has a much stronger beta signal, and it is the primary beta particle used 
to quantify the activity of ${ }^{234} \mathrm{Th}$ in each sample. The detectors were also calibrated using the ${ }^{238} \mathrm{U}$ to salinity relationship of Chen et al. (1986) and by comparing deep waters $\left(>100 \mathrm{~m}\right.$ ) where ${ }^{234} \mathrm{Th}$ activity equals the ${ }^{238} \mathrm{U}$ activity (Buesseler et al., 1994). For improved precision and accuracy, each sample was counted 5-6 times on the same detector for three 500-min cycles over a period of 50-60 days. A decaying activity curve was then fit to these measurements to determine the ${ }^{234} \mathrm{Th}$ activity at $\mathrm{t}_{0}$ and the total background activity. Measurements requiring large in-growth corrections due to the decay of the ${ }^{238} \mathrm{U}$ parent in the sample, and/or measurements having poor recovery of the daughter were not considered statistically accurate and were neglected in this study.

There are several possible sources of error in this data set of ${ }^{234} \mathrm{Th}$. Because the particle flux in the Sargasso Sea is generally very low, the flux values represent small differences in two large numbers, the ${ }^{234} \mathrm{Th}$ and ${ }^{238} \mathrm{U}$ activities, and thus generate larger error in the flux estimate than on the individual measurement themselves (Coale and Bruland, 1987). Also, because the samples were taken at BATS and analyzed at WHOI, there were several days before processing; thus the in-growth from ${ }^{238} \mathrm{U}$ carried in the $\mathrm{Fe}$ precipitate was increased and the net ${ }^{234} \mathrm{Th}$ signal was reduced. Logistical constraints required the combination of the water samples between the surface and $150 \mathrm{~m}$, so the difference between ${ }^{234} \mathrm{Th}$ and ${ }^{238} \mathrm{U}$ was decreased again since ${ }^{234} \mathrm{Th}$ is generally lowest in the upper 50-100 m. Also, there are inherent errors in the steady state approximation and in neglecting advection and diffusion. Counting statistics alone result in an error of $+/$ 200-300 dpm $/ \mathrm{m}^{2} / \mathrm{d}$. In some cases, multiple measurements were taken on a cruise and these values were averaged to determine one estimate for each cruise. By considering the errors listed above, we estimate the total error on the high flux values to be approximately $+/-500 \mathrm{dpm} / \mathrm{m}^{2} / \mathrm{d}$. Given the average value of $540 \mathrm{dpm} / \mathrm{m}^{2} / \mathrm{d}$ for the time period between 1993 and 1995, we have selected flux values of greater than $1000 \mathrm{dpm} / \mathrm{m}^{2} / \mathrm{d}$ as representing significantly elevated export values.

\subsection{Bermuda Atlantic Time-series Study (BATS) Measurements}

General procedures followed at BATS for measurements of Nitrate + Nitrite, primary productivity, and HPLC pigments are presented here. Further details of the sampling scheme, analytical methods and quality control procedures are available in the 
BATS Methods Manual (Knap et al.., 1993) and in the literature (Lohrenz et al.., 1992; Michaels et al., 1994a; Michaels, 1995).

The quality control procedures used at BATS are outlined in the chapter four of the BATS Methods Manual (Knap et al., 1993). Outliers are identified and flagged. Values out of the realm of possibility are discarded. For other outliers, the procedures are checked for error. In the event of bottle leakage, all samples from that bottle are discarded. Other values are compared to a quality control (QC) window, which is based on the first eight years of the time-series.

\subsubsection{Nitrate and Nitrite measurements}

Samples of nitrate + nitrite were withdrawn from the Niskin bottles through inline $0.8 \mu \mathrm{m}$ Nucleopore filters. They were then frozen for later analysis. The frozen samples were analyzed within two weeks using a Technicon Nutrient Autoanalyzer (Knap et al.., 1993) which has been in use at BATS since 1991. The detection limit of this measurement is $0.03 \mu \mathrm{mol} / \mathrm{kg}$.

\subsubsection{Productivity measurements}

Primary production was measured by the uptake of ${ }^{14} \mathrm{C}$ in dawn to dusk in situ incubations. Samples were filtered onto Whatman GF/F glass fiber filters. All the sampling and sample processing was conducted using trace-metal clean procedures (Fitzwater et al., 1982). Incubations were conducted in situ at eight standard depths (usually $20 \mathrm{~m}$ vertical spacing) in the upper $140 \mathrm{~m}$. At each depth, three light bottles and 1 dark bottle were used. The coefficient of variation for replicate samples is $\leq 10 \%$ (Richardson, 1991). No standard calibration method is available, therefore, the QC window is used to identify outliers.

\subsubsection{Chlorophyll samples / Pigment measurements}

Photosynthetic pigment samples were filtered onto Whatman GF/F glass fiber filters, frozen in liquid nitrogen, and analyzed by both fluorometric and HPLC techniques. Pigment measurements at BATS have undergone a number of changes that affect the accuracy of the samples. Since October 1990, BBSR personnel have 
performed both the Turner and the HPLC methods to measure pigments (Bidigare, 1991). The limit of detection is $1 \mathrm{ng}$. In 1994, BATS added the Wright method to their analysis techniques (Wright et al.., 1991). For consistent comparisons throughout the 1993 to 1995 data set the pigment measurements presented here are all from the Bidigare HPLC method. Zeaxanthin cannot be separated from lutein using the traditional HPLC method, however, comparison with the Wright method data shows that zeaxanthin was the majority of the pigment recovered at that peak. In this thesis we have considered zeaxanthin + lutien to be comparable to zeaxanthin alone.

\subsubsection{Plotting procedures}

All the BATS measurements were downloaded from the BATS web site at http://www.bbsr.edu/users/ctd/batdatex.html. The values of sigma theta were taken from CTD measurements of salinity and temperature at approximately $2 \mathrm{~m}$ intervals. For 0 $250 \mathrm{~m}$, a contour plot containing values from both core and bloom cruises was produced based on a spline fit to the CTD measurements at a grid interval of $5 \mathrm{~m}$. For $0-700 \mathrm{~m}$, the same procedure was performed using only the deep casts on the core cruises. For nitrate+nitrite measurements, values from both bloom and core cruises were linearly interpolated at a $5 \mathrm{~m}$ interval. Mixed layer depth was determined from the profiles of sigma theta based on a 0.05 deviation in sigma theta from the value at $5 \mathrm{~m}$. Primary productivity taken at $20 \mathrm{~m}$ intervals to $240 \mathrm{~m}$. These values were integrated and a bar plot was produced. The pigment concentrations were treated the same way except they were linearly interpolated onto a $5 \mathrm{~m}$ grid and then integrated. All interpolated values

were plotted as individual profiles to ensure that the results accurately represent the measurements. 


\section{Results and Discussion}

\subsection{Introduction}

The data recorded at BATS represents a comprehensive data set that allows us to compare indicators of biological activity to examine the impacts of the passage of mesoscale eddies between 1993 and 1995. As each eddy passes the BATS site, its impacts on the monthly to semi-monthly measurements taken at the site are based on many variable factors. These include the seasonal cycle at BATS, other mixing events (such as storms), the direction of isopycnal displacement, the life cycle of the eddy, and the path of the eddy's center with respect to the location of BATS. Nine eddy events are presented and discussed below (summarized in table 4.1). First, mode-water eddies are discussed, followed by cyclones, and then anticyclones. These nine events were selected because they coincide with BATS sampling (i.e. we omitted eddies that passed the site between BATS sampling periods) and we discuss only those features where the maximum displacement of the sea surface in the center of the eddy (not necessarily at the BATS site) was greater than $10 \mathrm{~cm}$.

To aid in our discussion and analysis of the observations from each eddy we developed a conceptual model depicting the sequence of events and impacts of eddy upwelling (figure 4.1). We tested this model by comparing it with the observations of each eddy event. The model depicts the sequence of events expected to occur in a modewater eddy or cyclone in conjunction with upwelling (stages $1-7$ ). When the eddy is first forming, little effect is expected (stage 1). On continued intensification, significant amounts of nutrients are upwelled (stage 2) into the euphotic zone. This nutrient injection is likely to be followed by increased primary productivity, pigment concentrations, and/or other possible biological responses (stage 3). After some variable period of time, the biological response is expected to stimulate increased export (stage 4). Then, as the eddy begins to decay, the nutrient injection should stop (stage 5). At some point nutrients will be exhausted, productivity decreases and/or grazing increases, and the high export signal in ${ }^{234}$ Th remains in the absence of productivity (stage 6). Finally, even the thorium signal is expected to disappear as the eddy continues to decay (stage 7). 
Table 4.1. A Summary of the observations for nine eddy events occurring at BATS between 1993 and 1995. Arrows indicate increasing or decreasing, dashes are no significant change from average value, and N/A is no measurement available. ID\# corresponds to the labels on the figures of biogeochemistry. Eddy type - mw- modewater, c - cyclone, anti - anticyclone. Com. shift refers to shifts from the typical community structure at BATS with diat - diatoms, dino - dinoflagelletes, and cyano cyanobacteria (excluding Prochlorococcus). Int - intensity of eddy, prod - productivity, pig - pigment concentrations, Th - thorium-234 flux, nut - nitrate+nitrite, age - age of eddy at BATS followed by the total age of the eddy in parenthesis with a + symbol meaning the eddy extended beyond the available data period or region, model - represents the position in figure 4.1, and "?" indicates uncertainty in the position.

\begin{tabular}{|c|c|c|c|c|c|c|c|c|c|c|}
\hline ID\# & $\begin{array}{l}\text { Eddy } \\
\text { Type }\end{array}$ & Date & $\begin{array}{l}\text { Com. } \\
\text { Shift }\end{array}$ & Int & $\mathrm{Nu}$ & Prod & Pig & Th & Age & Model \\
\hline \multirow[t]{2}{*}{ Jul95 } & $\mathrm{mw}$ & July 1995 & diat + dino & $\uparrow$ & $\uparrow$ & $\uparrow$ & $\uparrow$ & $\uparrow$ & $1.5(8)$ & 4 \\
\hline & $\mathrm{mw}$ & Aug 1995 & -- & $\downarrow$ & -- & -- & -- & $\uparrow$ & $3(8)$ & 6 \\
\hline \multirow[t]{2}{*}{ May93 } & $\mathrm{mw}$ & April 1993 & diat + dino & $\uparrow$ & $\uparrow$ & -- & $\uparrow$ & N/A & $1(5)$ & 3 \\
\hline & $\mathrm{mw}$ & May 1993 & diat + dino & $\uparrow$ & $\uparrow$ & $\uparrow$ & $\uparrow$ & -- & $1.5(5)$ & 3 \\
\hline \multirow[t]{2}{*}{ Oct95 } & $\mathrm{mw}$ & Sept 1995 & -- & $\downarrow$ & $\uparrow$ & -- & -- & -- & $3(10)$ & $?$ \\
\hline & $\mathrm{mw}$ & Oct 1995 & -- & $\uparrow ?$ & $\uparrow$ & -- & -- & -- & $4(10)$ & 7 \\
\hline \multirow[t]{2}{*}{ Ju193 } & $\mathrm{c}$ & June 1993 & cyano & $\downarrow$ & -- & -- & -- & $\uparrow \uparrow$ & $3(8)$ & 6 \\
\hline & $\mathrm{c}$ & July 1993 & cyano & $\downarrow$ & -- & -- & -- & -- & $4(8)$ & 7 \\
\hline \multirow[t]{2}{*}{ Aug94 } & c & July 1994 & cyano & $\uparrow$ & $\uparrow$ & -- & -- & -- & $2(5)$ & 3 \\
\hline & c & Aug 1994 & $\begin{array}{c}\text { cyano }+ \\
\text { dino }\end{array}$ & $\downarrow$ & -- & -- & $\uparrow$ & $\uparrow$ & $3(5)$ & 5 \\
\hline Nov93 & $\mathrm{c}$ & Nov 1993 & $\begin{array}{l}\text { slight } \\
\text { cyano }\end{array}$ & $\downarrow$ & $\downarrow$ & -- & -- & N/A & $10(11)$ & 7 \\
\hline \multirow[t]{2}{*}{ Jan93 } & c & Jan 1993 & cyano & $\uparrow$ & -- & -- & -- & $\uparrow$ & $3+(9+)$ & 5 or $6 ?$ \\
\hline & c & Feb 1993 & cyano & $\uparrow$ & $\uparrow$ & -- & -- & $\downarrow$ & $4+(9+)$ & $?$ \\
\hline \multirow[t]{2}{*}{ Sep94 } & anti & Sept 1994 & -- & $\downarrow$ & -- & -- & -- & N/A & $5(8)$ & N/A \\
\hline & anti & Oct 1994 & -- & $\downarrow$ & -- & -- & -- & -- & $6(8)$ & N/A \\
\hline Mar94 & anti & Mar 1994 & diat & $\downarrow$ & $\uparrow$ & $\downarrow$ & $\downarrow$ & -- & $9(12)$ & N/A \\
\hline
\end{tabular}




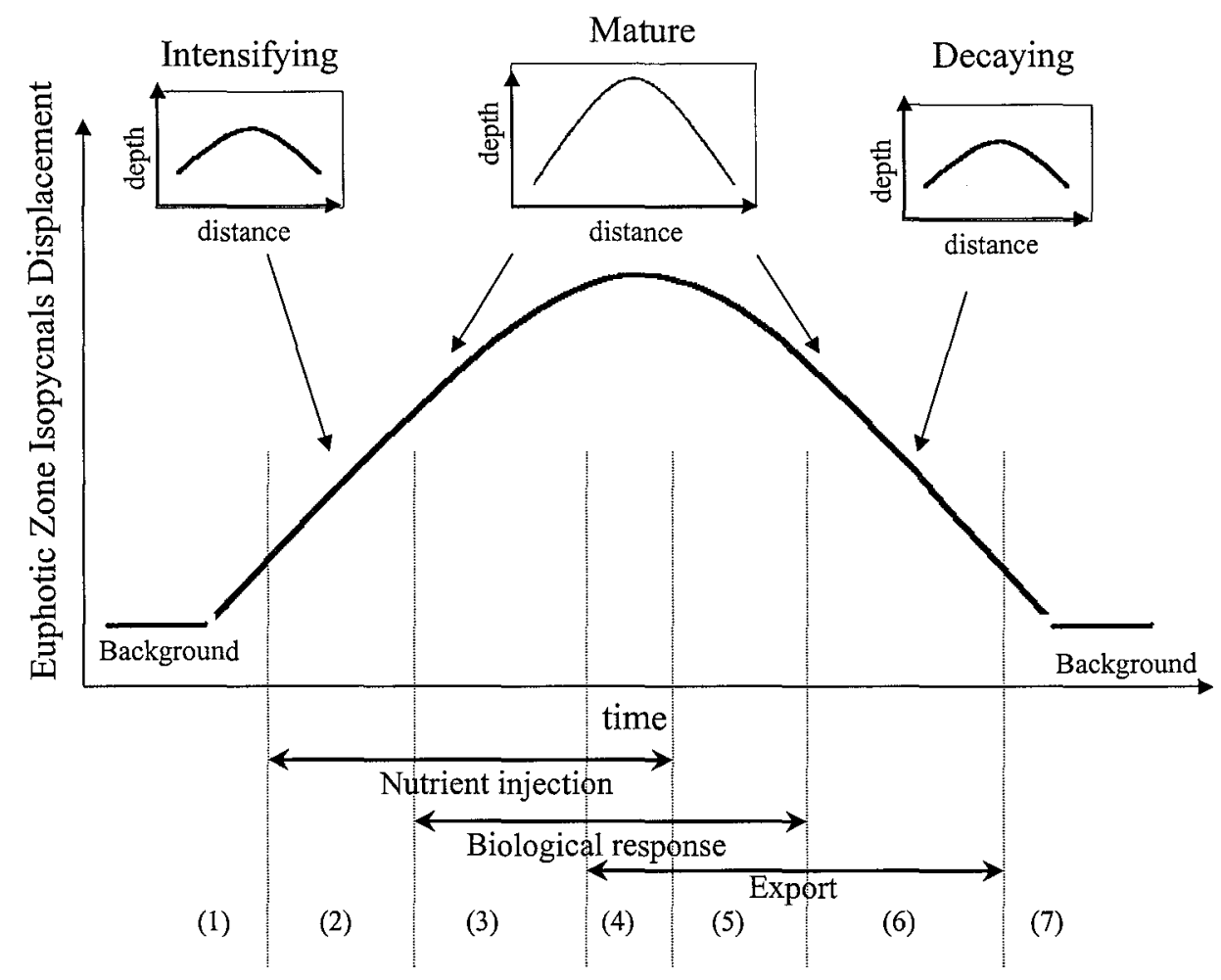

Figure 4.1. Conceptual image depicting the effects of a mode-water eddy or cyclonic eddy with time. The numbers $(1-7)$ on the bottom of this figure correspond to stages in an eddy's life cycle.

To observe the effects of the passage of each eddy, a group of figures depicting physical, chemical, and biological information are presented showing the biogeochemical indicators from January 1993 to December 1995 (figures 4.2 - 4.7). These figures are marked with colored bars that correspond to the passage of an eddy; light-blue for cyclones, pink for mode-water, and red for anticyclones. In addition, green bars are used to indicate a peak in productivity that is not eddy related. Of these, March 1993 and 1995 are spring blooms and May 1995 is a weather related deep mixing event (pers. comm., Dr. S. Doney). To compare the monthly measurements and to help establish typical conditions at BATS during this time period we calculated the average values of integrated primary productivity, thorium flux, and phytoplankton community composition (table 4.2). During our three-year period, the phytoplankton community appears to be dominated by prymnesiophytes and Prochlorococcus. The variability in 

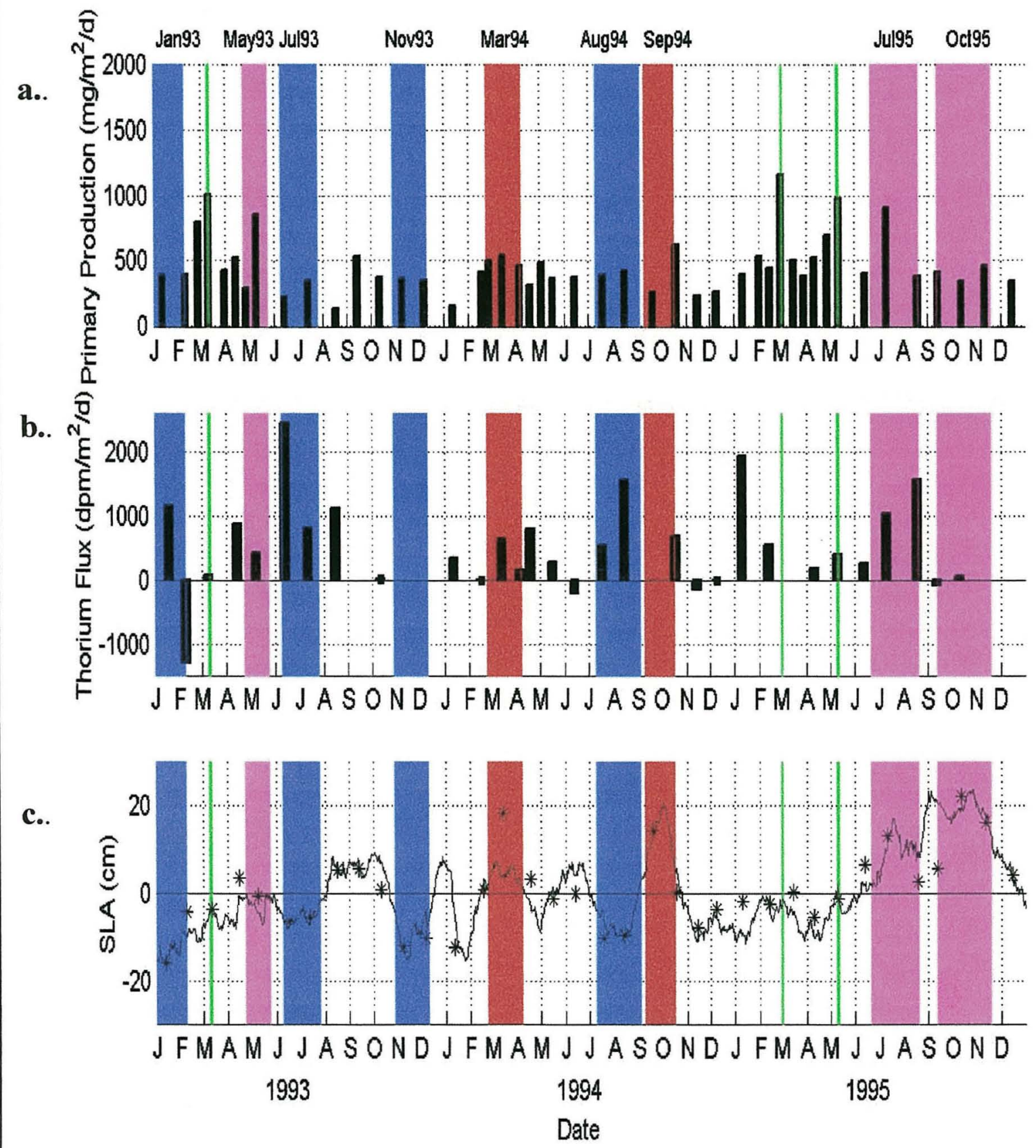

Figure 4.2. Integrated primary productivity $\left(\mathrm{mg} / \mathrm{m}^{2} / \mathrm{d}\right)(\mathrm{a}),{ }^{234} \mathrm{Th}$ flux $\left(\mathrm{dpm} / \mathrm{m}^{2} / \mathrm{d}\right)$ (b), and SLA $(\mathrm{cm})$ - black line with dynamic height $(\mathrm{cm})$ - stars (c). Colored bars indicate eddies; light blue cyclone, pink - mode-water, and red - anticyclone. Green vertical bars indicate non-eddy related increases in primary productivity. 


\section{Sigma Theta(kg/ $\left.\mathrm{m}^{3}\right)$}

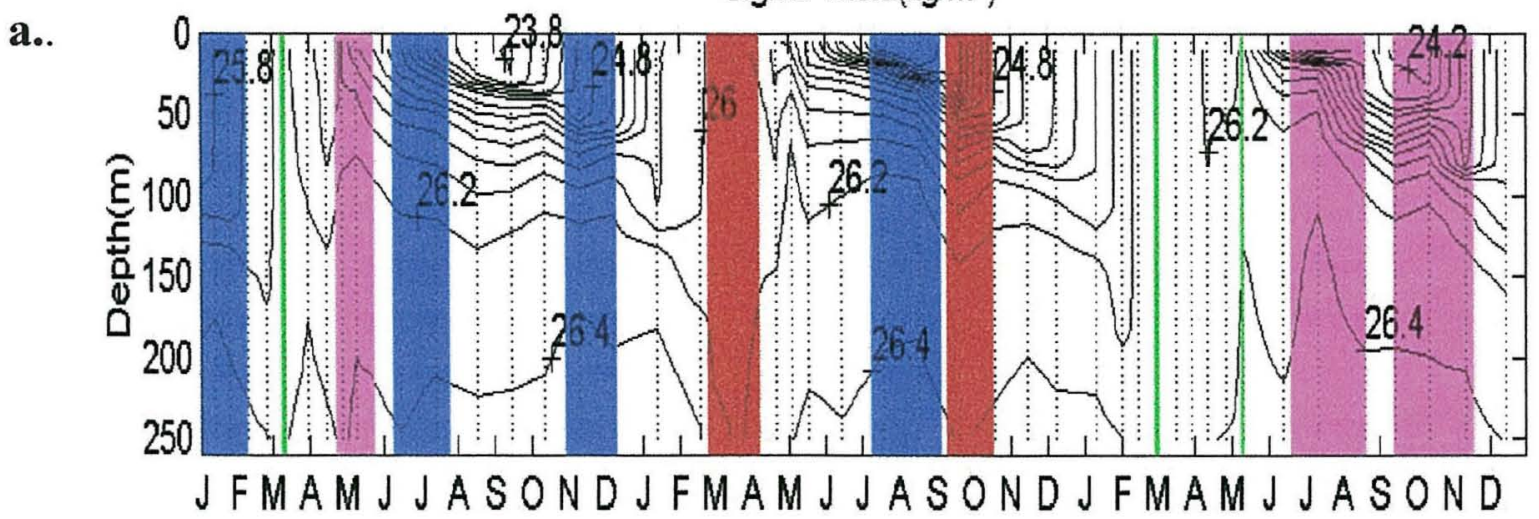

b.

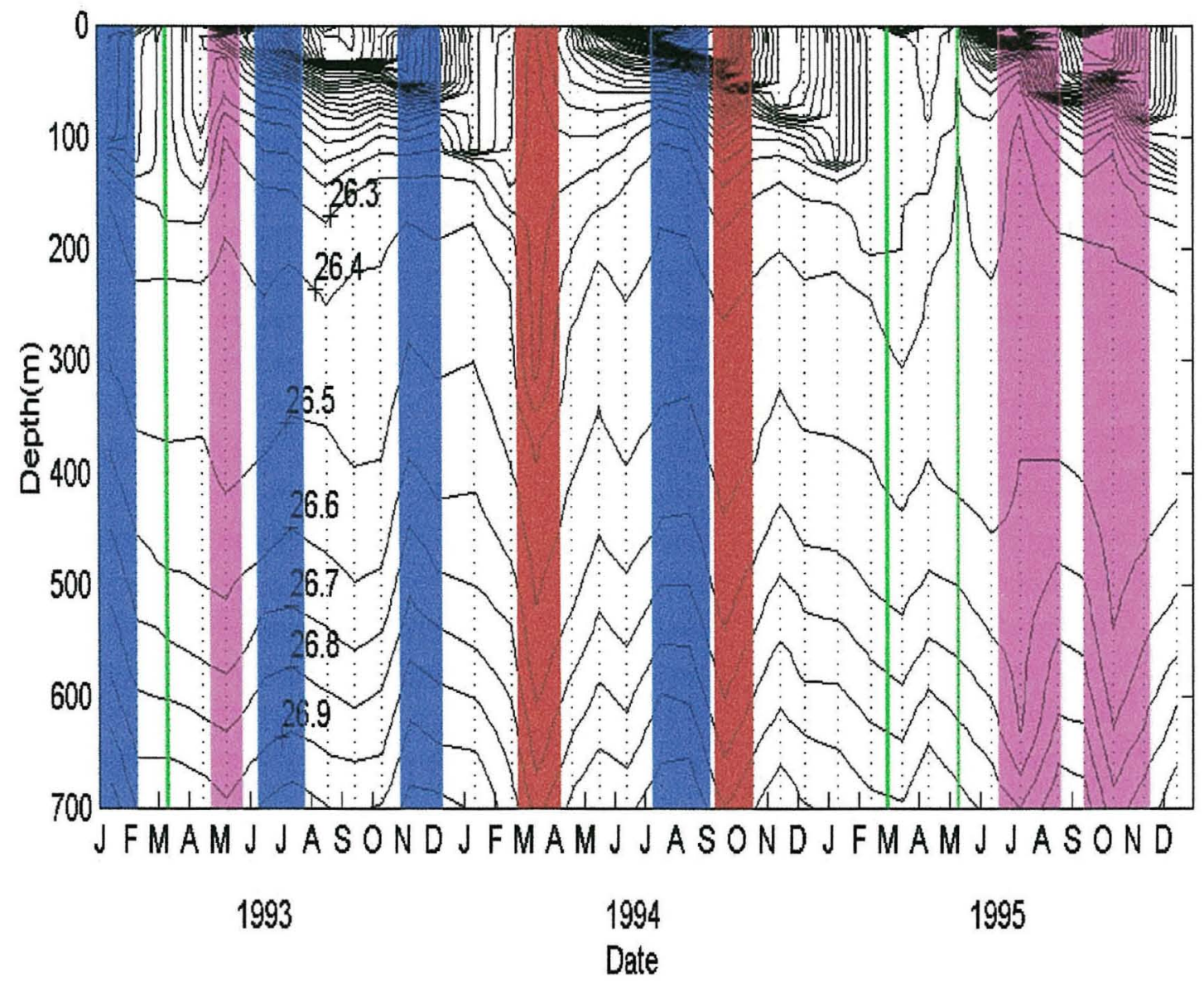

Figure 4.3. Sigma theta $\left(\mathrm{kg} / \mathrm{m}^{3}\right)$ in the top 250 meters (a) based on BATS "bloom" and "core" cruises and sigma theta from zero to $700 \mathrm{~m}$ (b) based on bats "core" cruises only. Colored bars indicate eddies; light blue - cyclone, pink - mode-water, and red - anticyclone. Green vertical bars indicate non-eddy related increases in primary productivity. Dots indicate the dates measurements were taken. 
a.

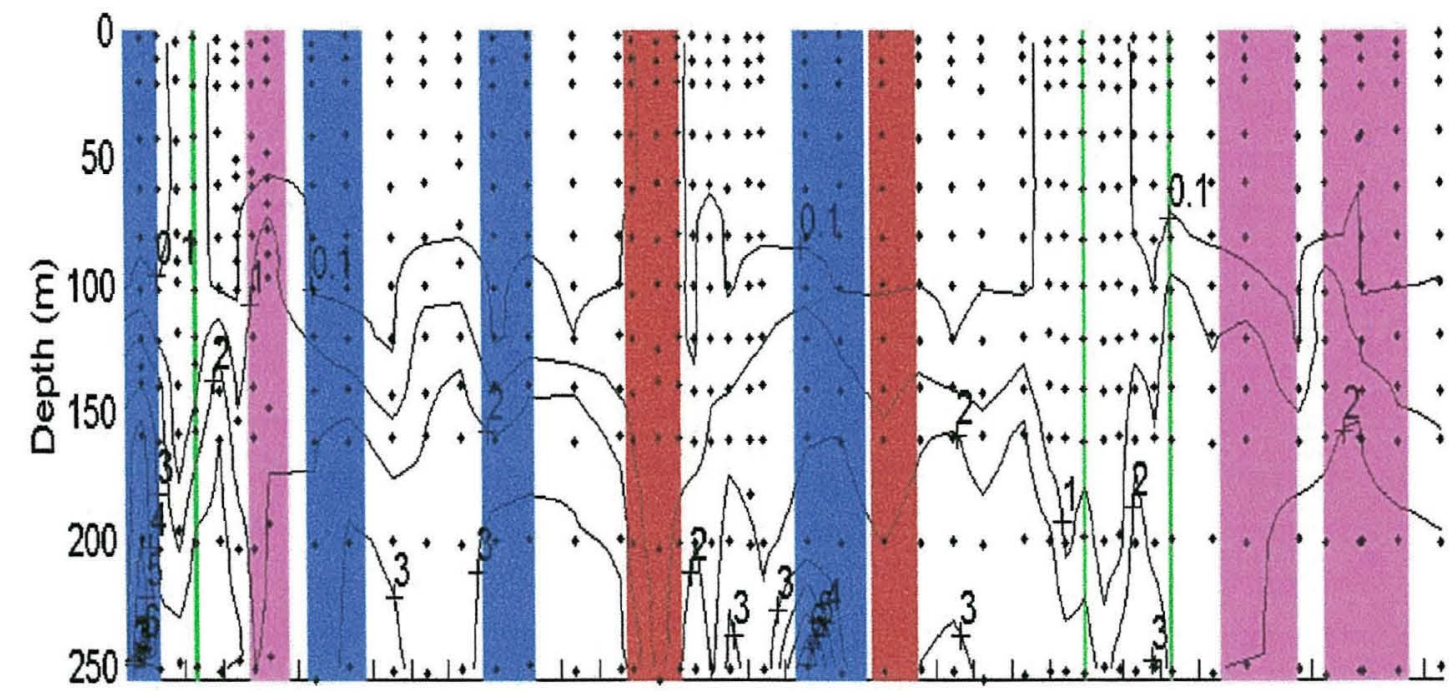

FMAMJ JASONDJFMAMJ JASONDJFMAMJ JASOND

b.

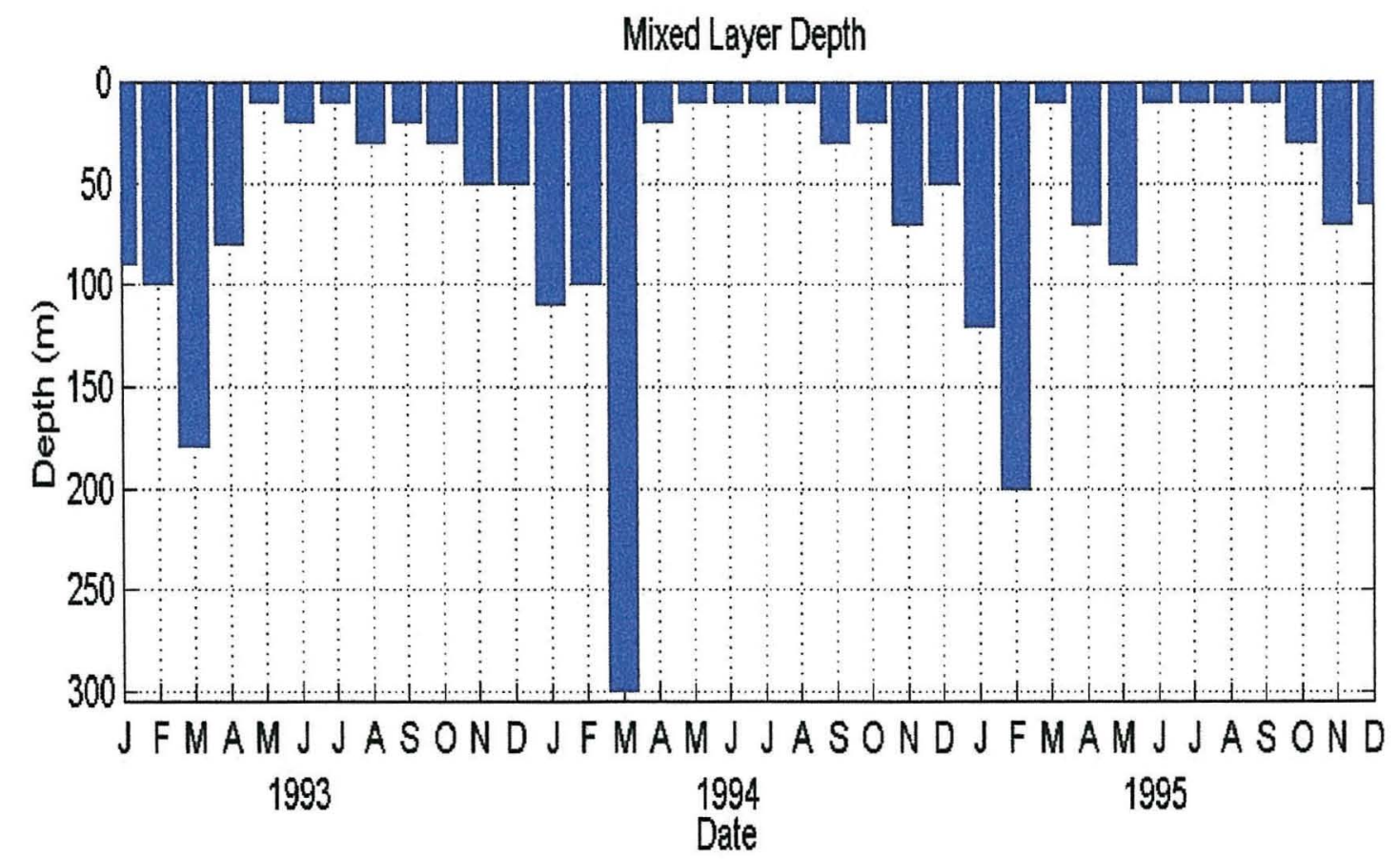

Figure 4.4. Nitrate+nitrite ( $\mu$ moles $/ \mathrm{kg}$ ) in the top $250 \mathrm{~m}$ (a) and mixed layer depth (m) (b). Colored bars indicate eddies; light blue - cyclone, pink - mode-water, and red - anticyclone. Green vertical bars indicate non-eddy related increases in primary productivity. Dots in figure $4.4 \mathrm{a}$ indicate the locations of measurements. The depth of the mixed layer is shown in figure $4.4 \mathrm{~b}$ and was selected using a change of 0.05 in sigma theta from the surface. 


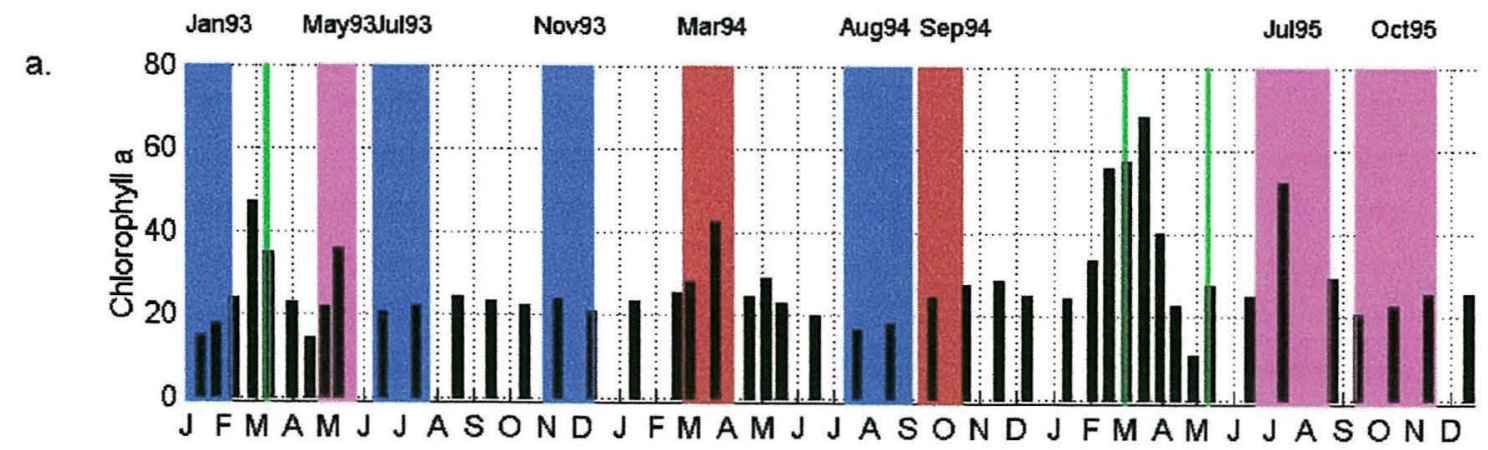

b.

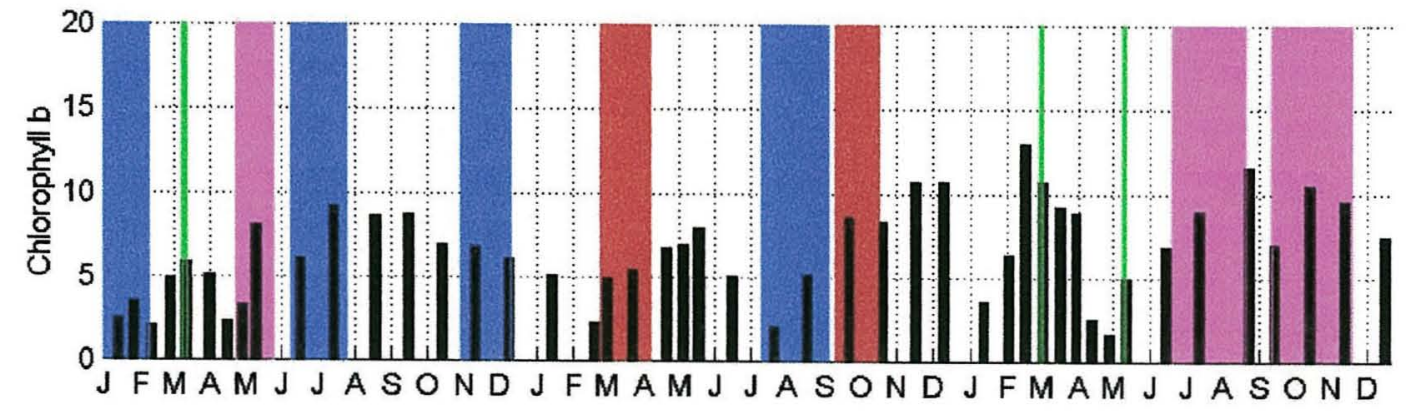

c.

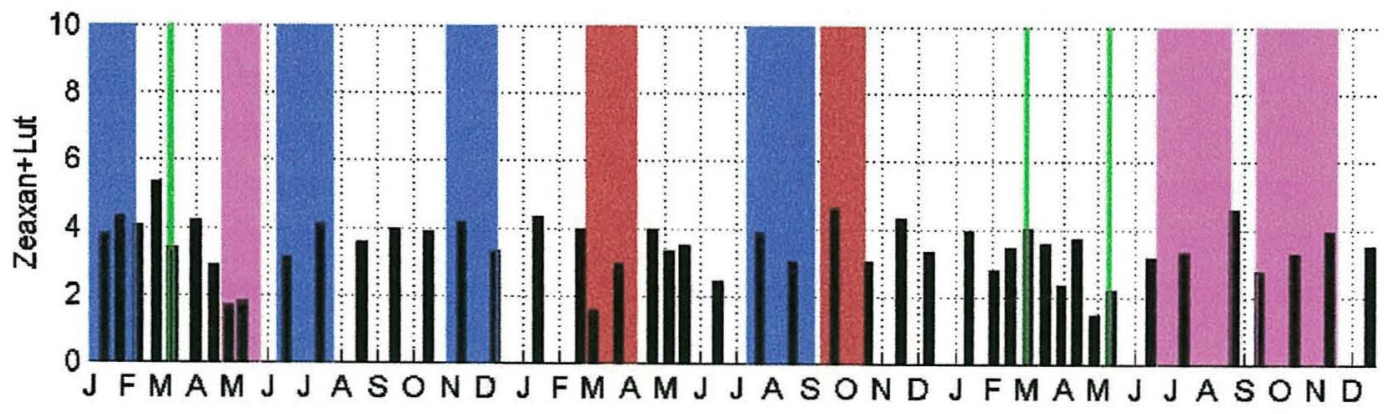

d.

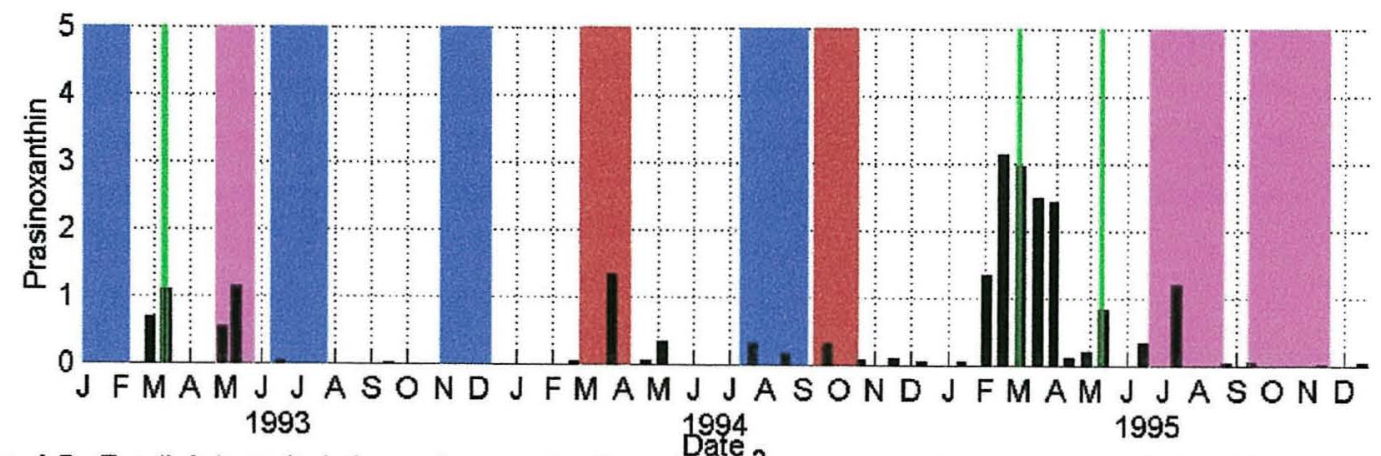

Figure 4.5. Depth integrated pigment concentrations $\left(\mathrm{mg} / \mathrm{m}^{2}\right)$ - chlorophyll a (a), chlorophyll b (b), zeaxanthin+lutein (c), and prasinoxanthin (d). Colored bars indicate eddies; light blue - cyclone, pinkmode-water, and red - anticyclone. Green vertical bars indicate non-eddy related increases in primary production. 
a.

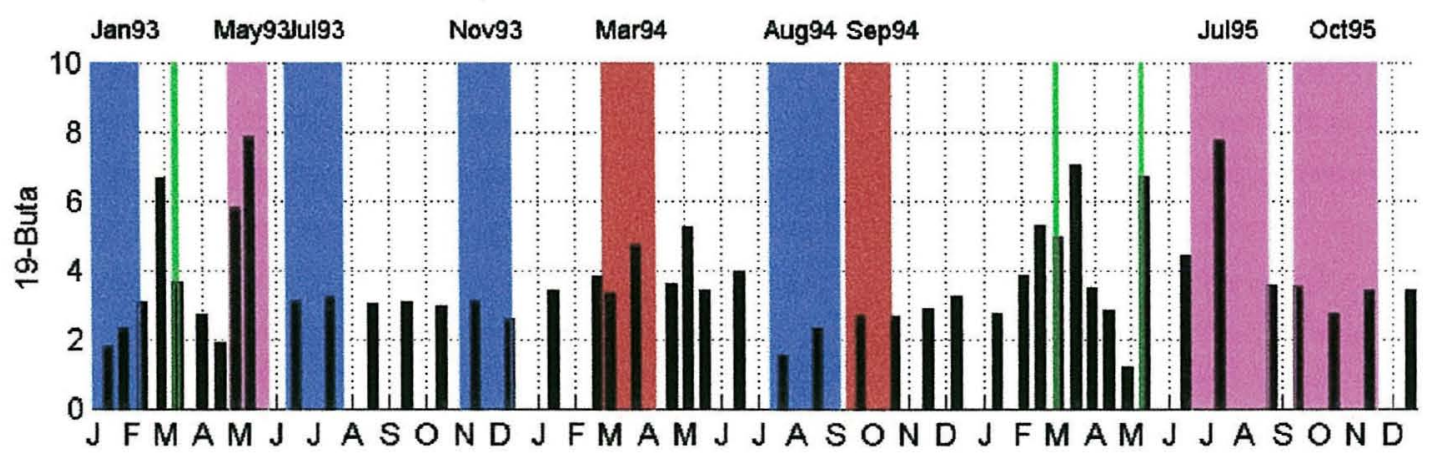

b.

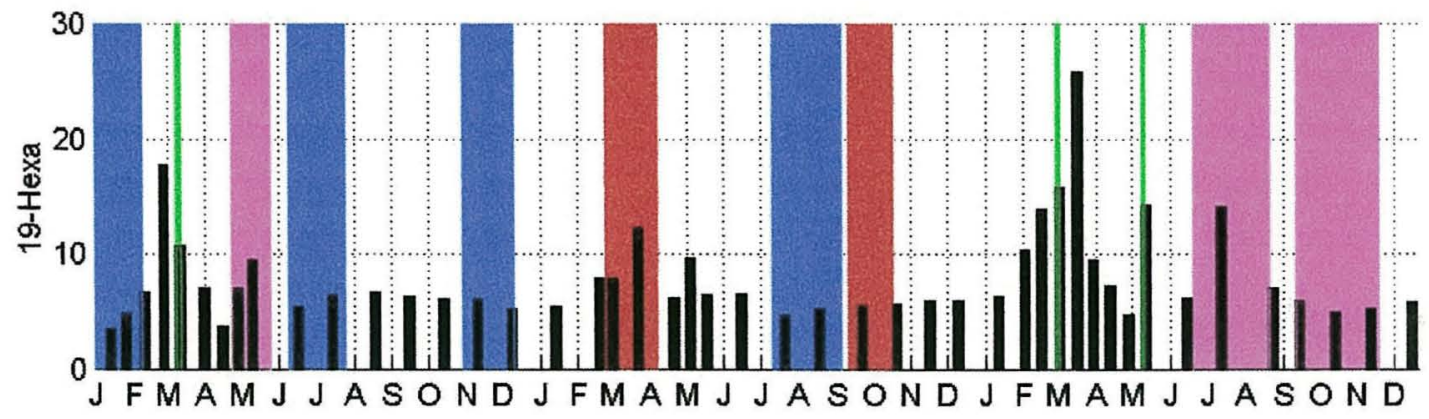

c.

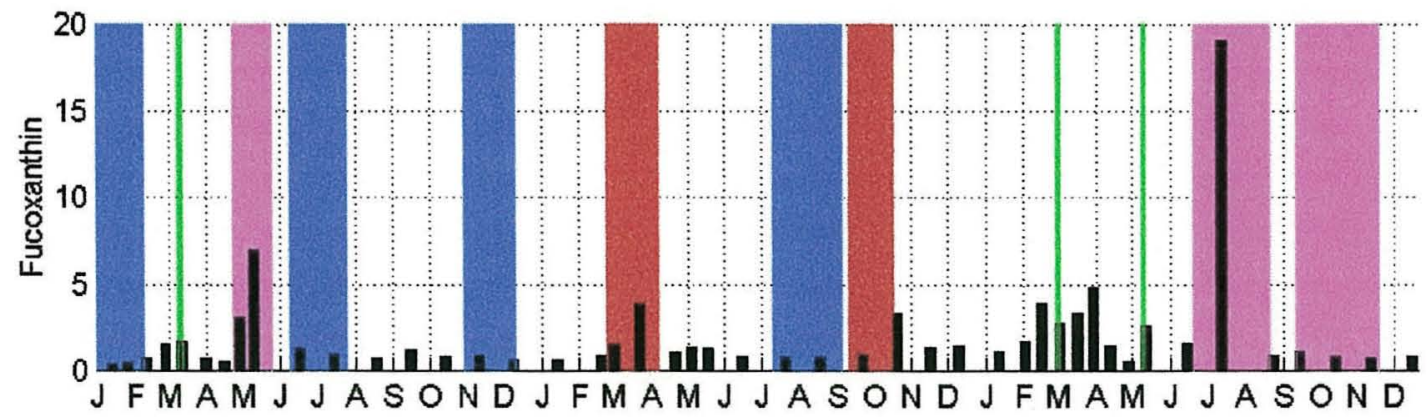

d.

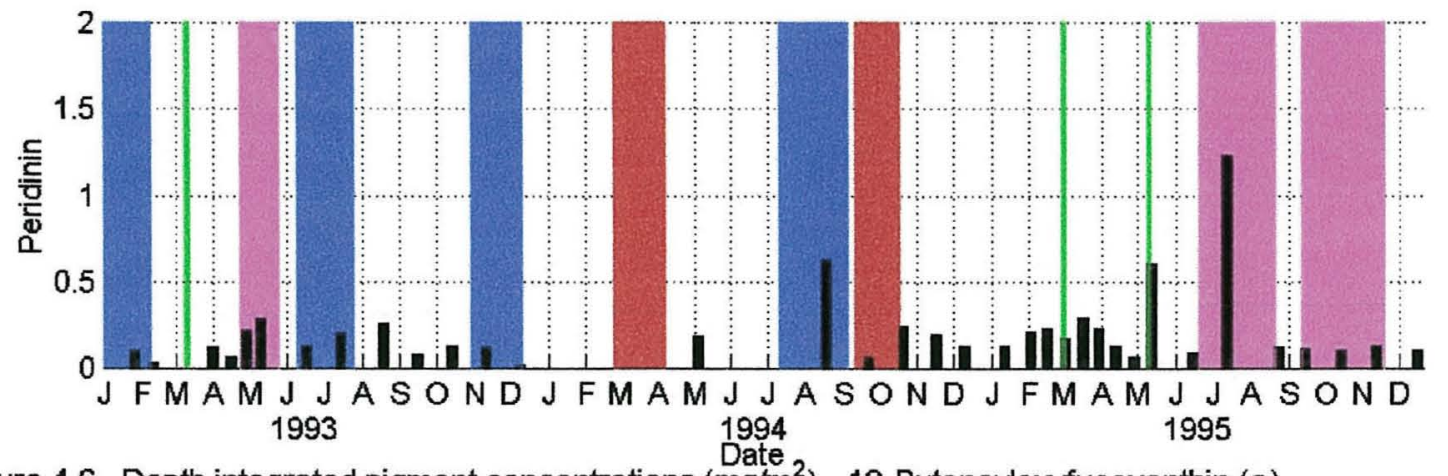

Figure 4.6. Depth integrated pigment concentrations $\left(\mathrm{mg} / \mathrm{m}^{2}\right)-19-$-Butanoyloxyfucoxanthin (a),

19-Hexanoyloxyfucoxanthin (b), fucoxanthin (c), and peridinin (d). Colored bars indicate eddies; light blue cyclone, pink - mode-water, and red - anticyclone. Green vertical bars indicate non-eddy related increases in primarv production. 
a. $60^{\text {Jan93 }}$ May93Jul93 Nov93 Mar94 Aug94 Sep94

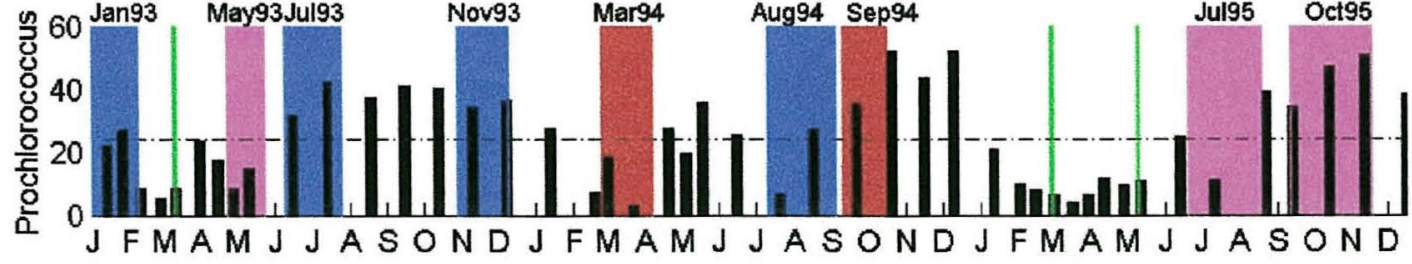

b.

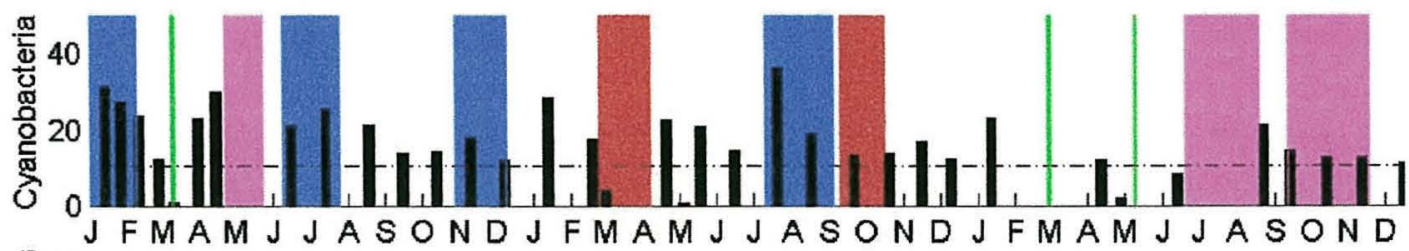

c.

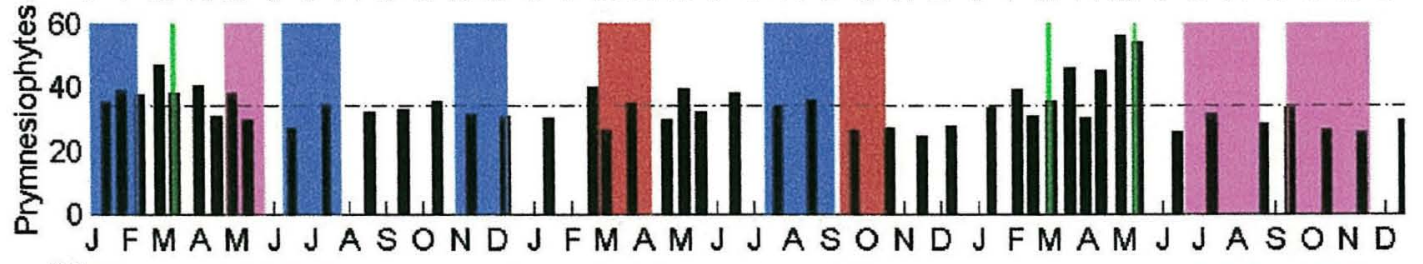

d.

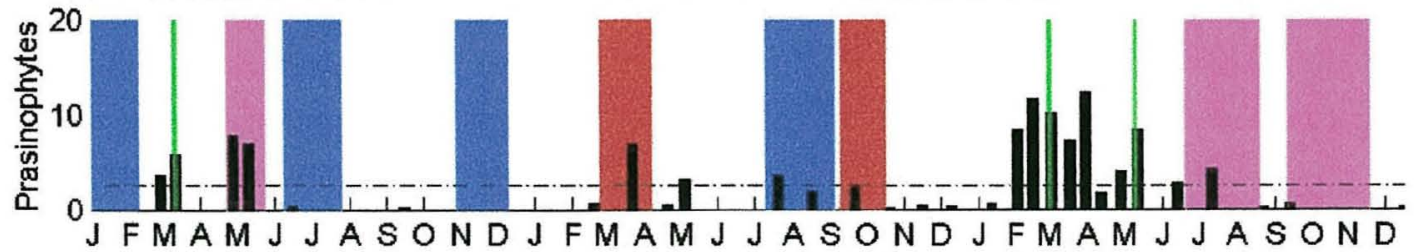

e.

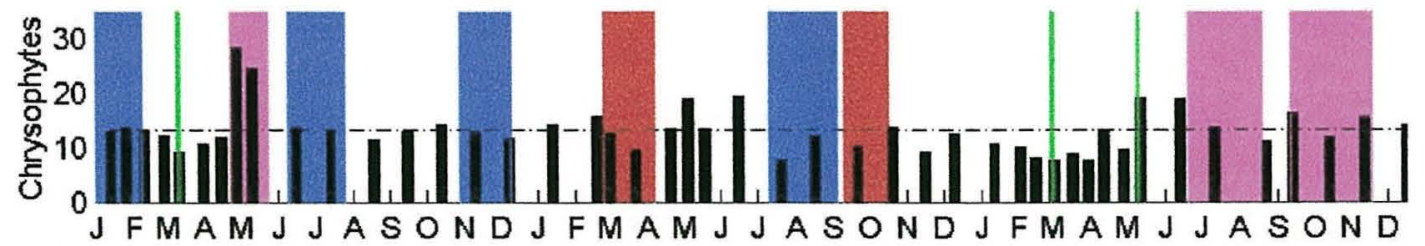

f.

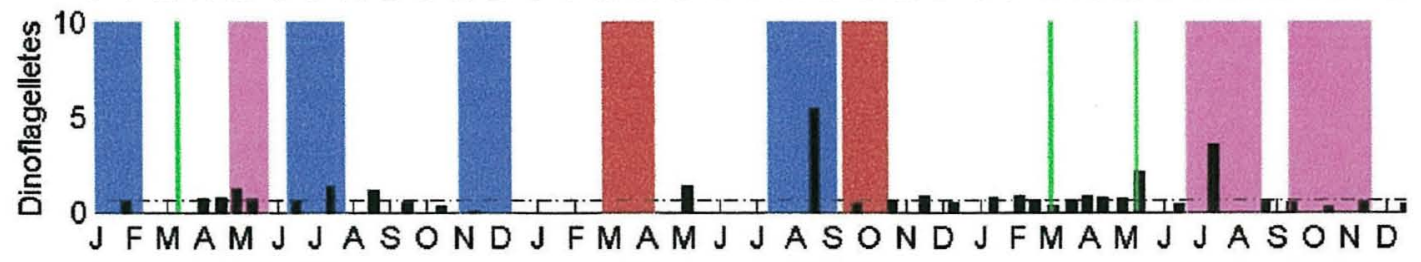

g.

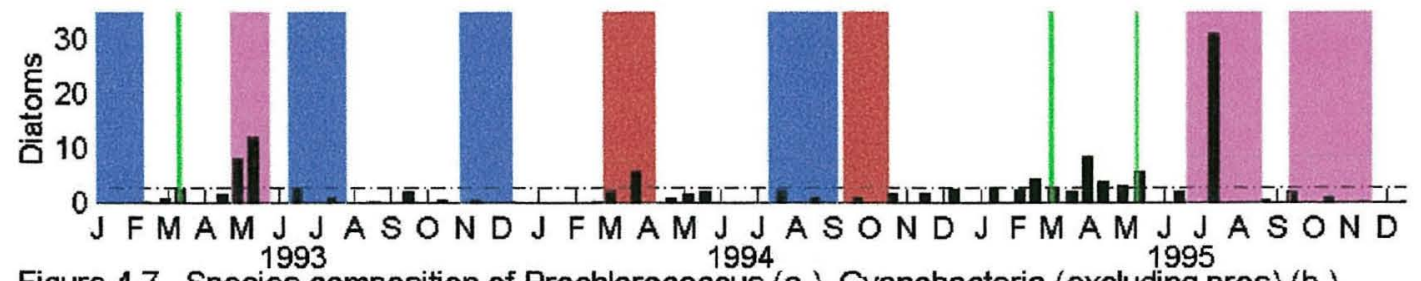

Figure 4.7. Species composition of Prochlorococcus (a.), Cyanobacteria (excluding pros) (b.),

Prymnesiophytes (c.), Prasinophytes (d.), Chrysophytes (e.), Dinoflagelletes (f.), and Diatoms (g.). Colored bars indicate eddies; light blue - cyclone, pink-mode-water, and red - anticyclone. Green vertical bars indicate non-eddy related increases in primary production. 
the prymnesiophytes contribution to chl a is small; the value remains close to its average throughout the time-series and does not respond to the passage of eddies (figure 4.7c). In the case of Prochloroccocus, the variability is seasonally dependent being high in the fall and low during spring blooms. This result matches the findings of DuRand et al. (in press) that observed a seasonal cycle of Prochloroccus in cell concentration and percent phytoplankton carbon. It should be noted, however, that the values shown in figure 4.7 are percent chl a which does not necessarily reflect changes in cell concentration, percent phytoplankton carbon, or percent primary production.

Table 4.2. Average values of biogeochemical indicators at BATS, 1993-1995.

\begin{tabular}{|l|c|}
\hline Indicator & Average Value \\
\hline Primary Productivity $\left(\mathrm{mg} \mathrm{C} / \mathrm{m}^{2} / \mathrm{d}\right)$ & 230 \\
\hline Thorium-234 Flux $\left(\mathrm{dpm} / \mathrm{m}^{2} / \mathrm{d}\right)$ & 540 \\
\hline Diatoms $(\% \mathrm{Chl}$ a) & 3 \\
\hline Dinoflagelletes (\% Chl a) & 1 \\
\hline Chrysophytes (\% Chl a) & 13 \\
\hline Prasinophytes (\% Chl a) & 2.5 \\
\hline Prymnesiophytes (\% Chl a) & 35 \\
\hline $\begin{array}{l}\text { Cyanobacteria (\% Chl a) } \\
\text { (except prochlorococcus sp.) }\end{array}$ & 11 \\
\hline Prochlorococcus sp. (\% Chl a) & 25 \\
\hline
\end{tabular}

\subsection{Eddy Events}

Each of the nine eddy events that coincide with BATS sampling contributed useful information about the impacts of mesoscale eddies (table 4.1). We tested our conceptual model by comparing it to the detailed observations associated with each event, starting first with mode-water eddies, then cyclones, and finally anticyclones.

\subsubsection{Mode-Water Eddies}

Mode-water eddies form lens shaped isopycnals, have an anticyclonic rotation, and a positive SLA. They displace the seasonal thermocline upwards, causing upwelling at the surface, and depress the main thermocline. This process increases the thickness of the $18^{\circ} \mathrm{C}$ mode-water, defined by Siegel et al. (1999) as the distance between the $17.5^{\circ}$ 
and $18.5^{\circ}$ isotherms. Mode-water eddies also have a surface cold water anomaly and a depressed salinity. There were three mode-water eddies observed in this time series. These events are discussed below in an order based on the degree with which the observations of the events allow us to test the conceptual model: July 1995, May 1993 then October 1995.

\section{July 1995 - Mode-water Eddy}

The July 1995 mode-water eddy passed over the site during the same time that sampling by the Bermuda Testbed Mooring (BTM) was occurring (Dickey et al., 1998). The resulting pulse of nutrients and the increased biological response have been documented by McNeil et al. (1999). The eddy was directly over the site from July 10-13, 1995 when BATS sampling occurred (figure 4.8) and at that time the eddy was approximately 1.5 months old (table 4.1 ). The displacement of the sea surface in the center of the eddy at that time was approximately $12 \mathrm{~cm}$ (figure 4.8). The eddy was intensifying as it passed the site and reached its peak of around $32 \mathrm{~cm}$ prior to the August 18-22, 1995 BATS cruise when only the edge of the eddy remained at the BATS site.

The presence of this eddy was corroborated in the isopycnals, which were lens shaped in the July measurement (figure 4.3b), allowing us to distinguish this feature from an anticyclone. The eddy was also observed by Seigel et al. (1999) in their analysis of the thickness of $18{ }^{\circ} \mathrm{C}$ water (see Siegel et al. (1999) figure 10). In July, upwelling of nitrate+nitrite was not observed in the BATS measurements (figure 4.4a), but McNeil et al. (1999) documented that the BTM nitrate measurements taken at $80 \mathrm{~m}$ were over $2 \mu \mathrm{M}$ for much of the time period between July 6 and 17 (see McNeil et al. (1999) plate 3). The failure to observe this in the BATS measurements is likely due to inertial oscillations occurring in the water column which depressed the depth of nutrients during the single July BATS measurement (McNeil et al., 1999). In August, the isopycnals subsided and the nutrient concentrations were decreased. 

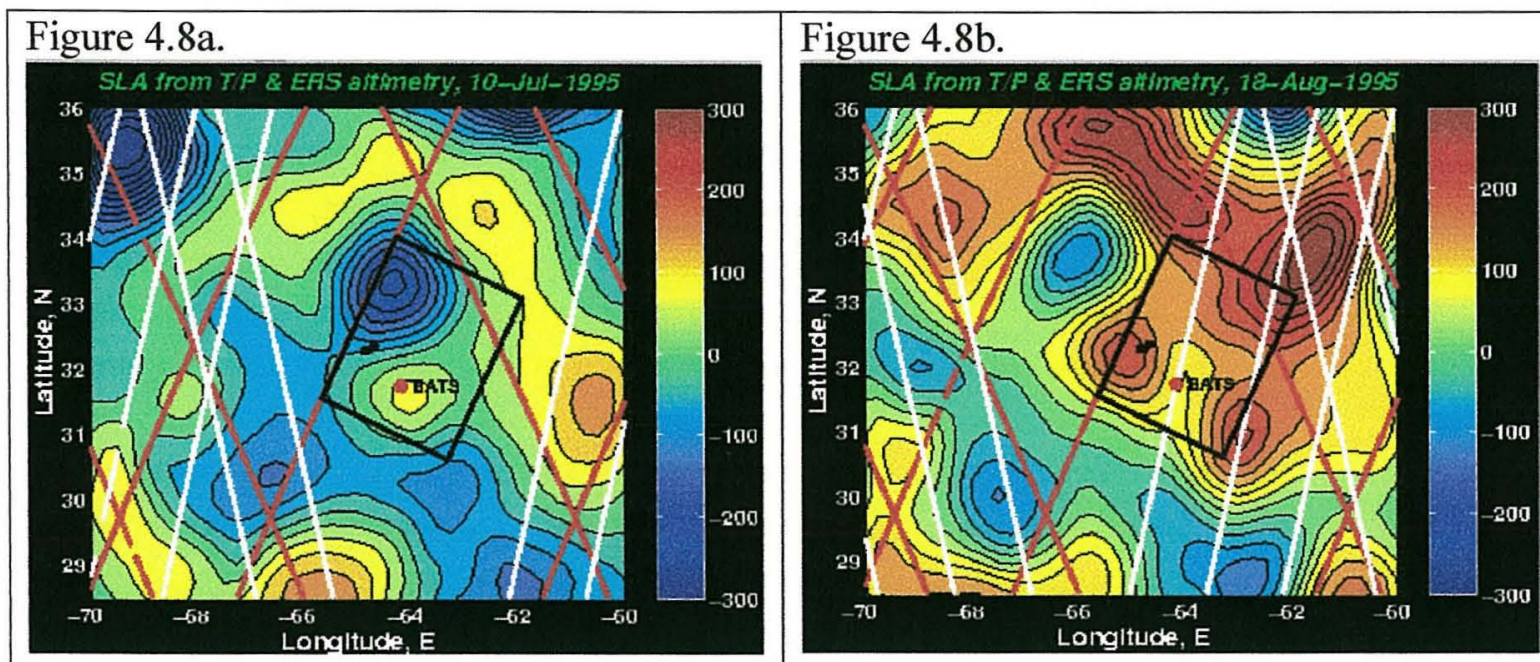

Figure 4.8c.

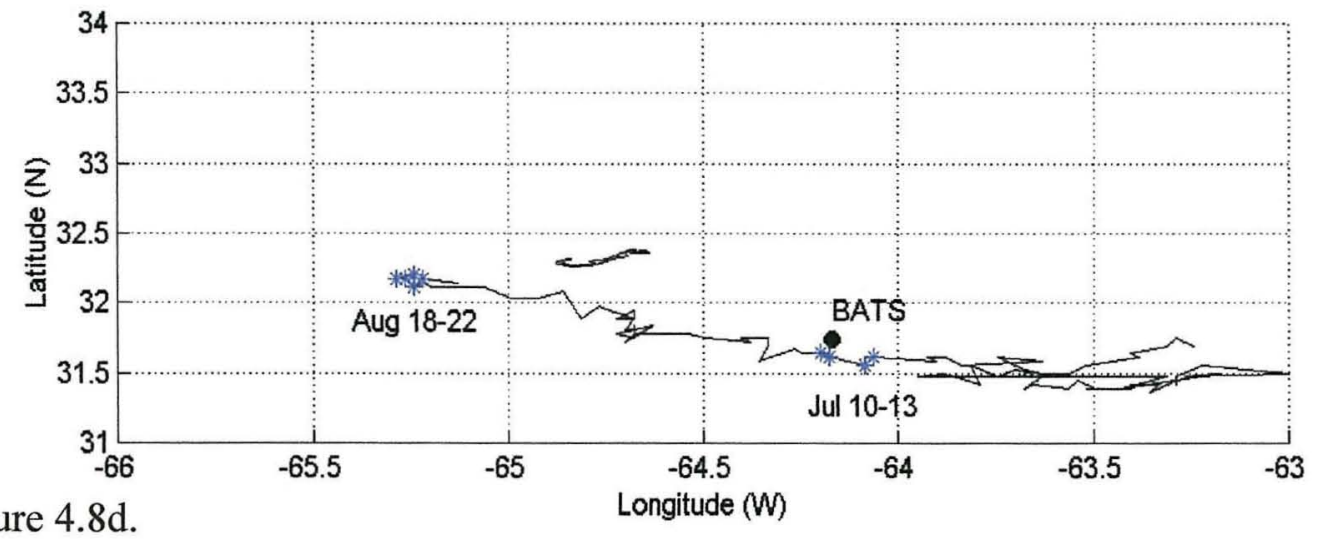

Figure 4.8d.

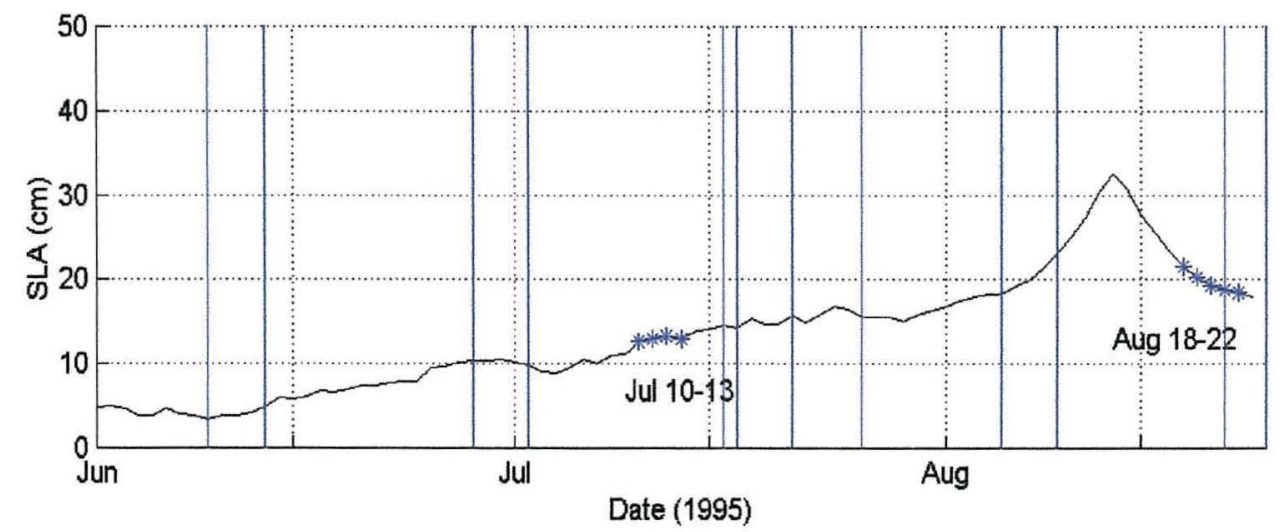

Figure 4.8. Eddy history for July 1995 mode-water eddy. Images on July 10 (a) and August 18 (b) depicting sea level anomaly $(\mathrm{mm})$ with scale from $+/-300 \mathrm{~mm}$, red and white lines represent satellite passes. Plot of eddy trajectory (c) and SLA (d) with blue stars indicating sampling and blue vertical lines indicating satellite passes through eddy center. 
There was a strong biological response to this eddy in July 1995. A peak in primary production of almost $980 \mathrm{mg} / \mathrm{m}^{2} / \mathrm{d}$ (figure 4.2a), over four times the average value, and was accompanied by elevated concentrations of all photosynthetic pigments except chlorophyll b and zeaxanthin (figure 4.5 \& 4.6). Most notable was the elevated fucoxanthin of almost $20 \mathrm{mg} / \mathrm{m}^{2}$, representing a value nearly 3 times greater than the next highest value. Diatoms made up ten times their average contribution to chlorophyll a $(\sim 30 \%)$ and dinoflagelletes were over 4 times their average ( 4\%) (figure 4.7$)$. In addition, the contribution of cyanobacteria to chlorophyll a during this bloom is reduced to nearly zero. Finally, the July ${ }^{234} \mathrm{Th}$ flux was among the highest measurements in the time series at over $1000 \mathrm{dpm} / \mathrm{m}^{2} / \mathrm{d}$. This scenario corresponds to stage 4 of the conceptual model (figure 4.1) and represents an example of a significant diatom bloom resulting from an eddy that the work of Goldman $(1988 ; 1993)$ indicates could represent significant new production.

Following this bloom, the August measurements of biological indicators had all returned to their normal levels. The BATS station was on the edge of the eddy, which was beginning to decay. The August ${ }^{234} \mathrm{Th}$ flux was $1575 \mathrm{dpm} / \mathrm{m}^{2} / \mathrm{d}$, the third highest flux event of the time series. This flux could be a result of the July bloom of large phytoplankton, stage 6 on the conceptual model; this would represent a case where multiple sampling events captured high primary productivity, a community shift, and subsequent particle export. The August flux could also represent an "edge effect" as the samples were taken in the eddy's edge.

\section{May 1993 - Mode-water Eddy}

The May 1993 event, also a mode-water eddy, was not captured well in the satellite generated images because during the period of April to early May the eddy was between satellite passes. When a satellite track did pass over this eddy on May 7, 1993 it passed the west edge of the feature, the far side from BATS, making it difficult to be sure of the eddy's exact location (Figure 4.9). However, other available evidence supports the eddy's presence at the BATS site during May sampling. First, the isopycnals in May were lens shaped and there was upwelling of nutrients to near $50 \mathrm{~m}$ (figures $4.3 \mathrm{~b}$ and $4.4 a$, respectively). With mode-water eddies the surface water upward displacement 
Figure 4.9a.

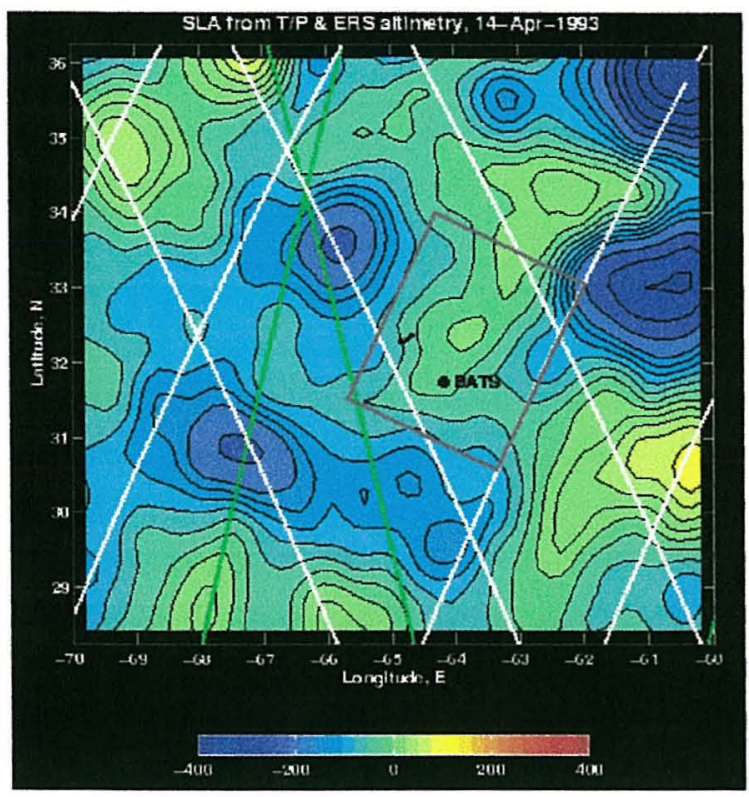

Figure $4.9 \mathrm{~b}$.

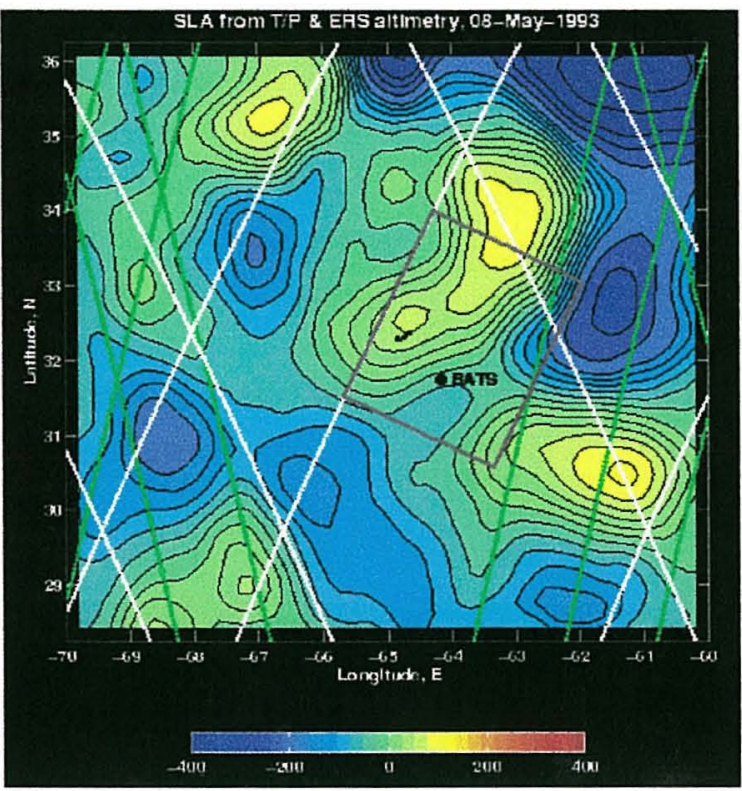

Figure 4.9c.

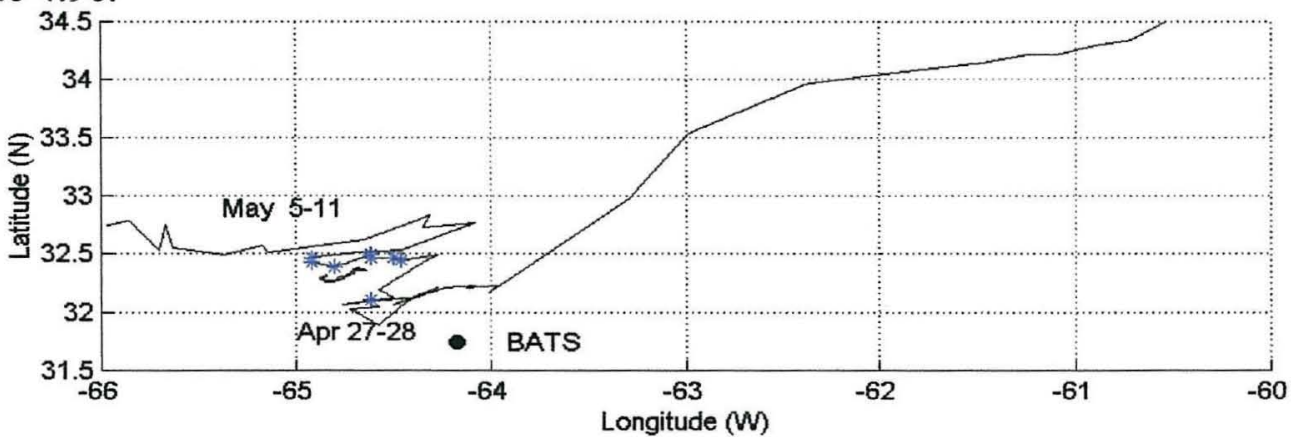

Figure 4 sd.

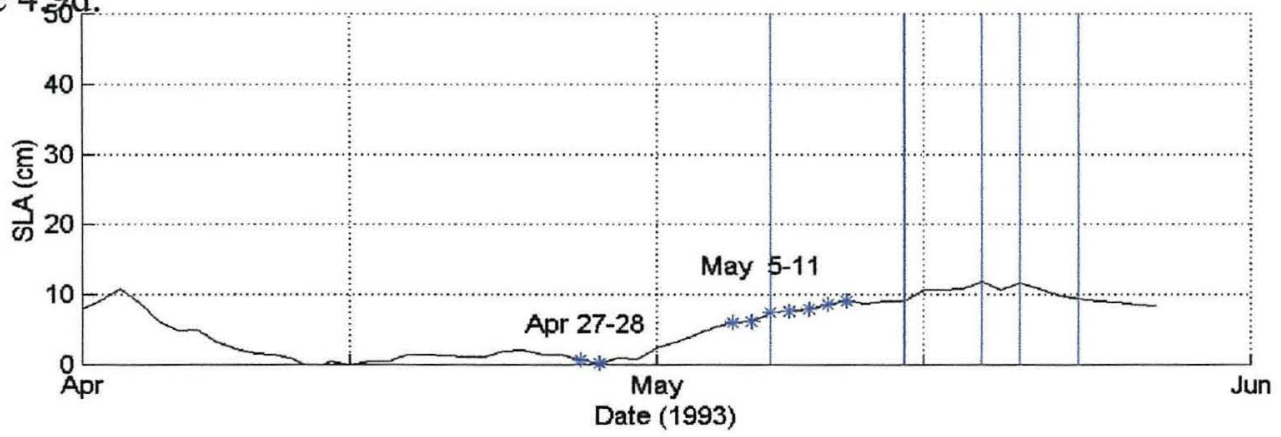

Figure 4.9. Eddy history for May 1993 mode-water eddy. Images on April 14 (a) and May 8 (b) depicting sea level anomaly $(\mathrm{mm})$ with scale from $+/-400 \mathrm{~mm}$, green and white lines represent satellite passes. Plot of eddy trajectory (c) and SLA (d) with blue stars indicating sampling and blue vertical lines indicating satellite passes through eddy center. 
in part counteracts the effect of the deepwater downward displacement, thus reducing the eddy's effect on sea level anomaly and dynamic height measurements (figure 4.2c). The presence of this eddy was also observed by Seigel et al. (1999) in their analysis of the thickness of $18{ }^{\circ} \mathrm{C}$ water and the concentration of nitrate at the BATS site (see Siegel et al. (1999) figure 10). Despite the poor satellite coverage the eddy was located near the site for both the April 27-28, 1993 (bloom cruise) when it was approximately one month old and approximately two weeks later during the May 5-11, 1993 BATS cruises; it was intensifying during this time period.

As with the July 1995 mode-water eddy, there was a noticeable biological response to the passage of this intensifying feature. The rate of primary productivity reached $850 \mathrm{mg} / \mathrm{m}^{2} / \mathrm{d}$ in May, the fifth highest data point (figure 4.2a). Chlorophyll a and b, fucoxanthin, 19'-Butanoyloxyfucoxanthin, 19'-Hexanoyloxyfucoxanthin, prasinoxanthin, and peridinin were all elevated (figures 4.5 \& 4.6). Also, as with the July 1995 eddy, the phytoplankton community composition was quite different from the typical conditions at BATS; chrysophytes were twice their usual percentage of chlorophyll a, while cyanobacteria (excluding Prochloroccocus) again dropped to nearly zero (figure 4.7). Large phytoplankton also increased; diatoms reached their second highest level in the time series (over 8\%) and dinoflagelletes were elevated over their average as well. This shift was observed in both the April bloom and May core cruises.

The thorium measurement taken May $9^{\text {th }}$ did not show an increased particle flux (figure 4.2b). As the eddy was intensifying when it passed the site and was less than 2 months old, it is likely that the bloom was just beginning when the measurements were taken and the subsequent high flux resulted in days following the May core cruise. This corresponds to stage 3 in the conceptual model (figure 4.1). This event represents a second example of an increased biological response to the passage of an intensifying mode-water eddy and again highlights the potential importance of blooms of larger phytoplankton, stimulated by mesoscale eddies, to the $\mathrm{C}$ and $\mathrm{N}$ budgets (Goldman, 1988; 1993). 
October 1995 - Mode-water eddy

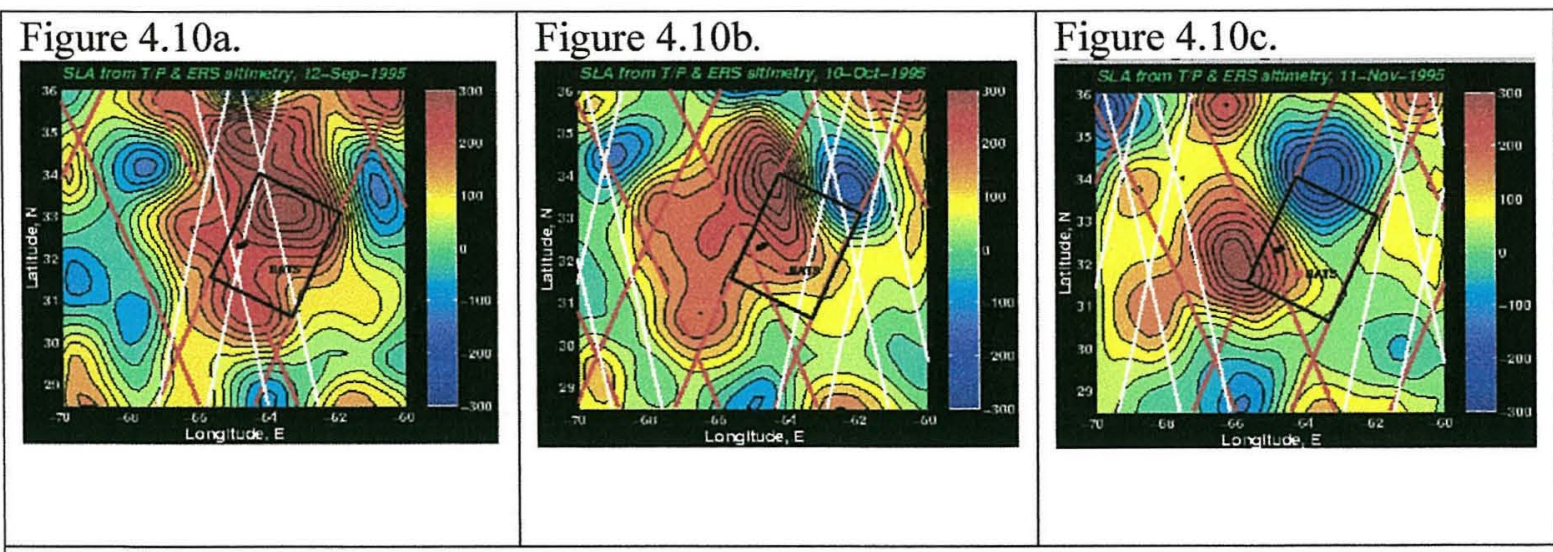

Figure $4.10 \mathrm{c}$.

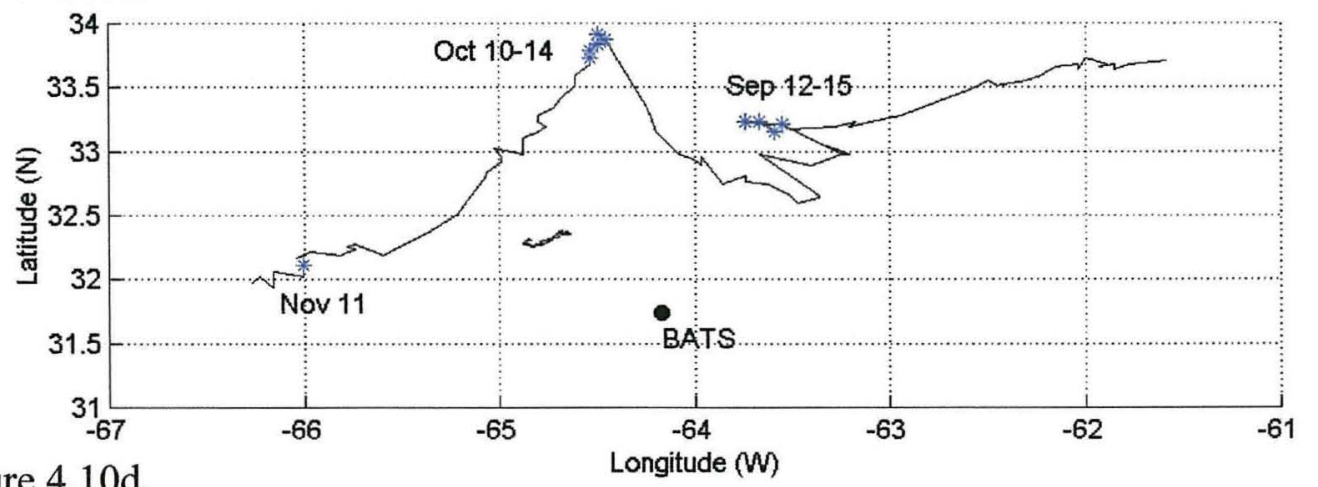

Figure 4.10d.

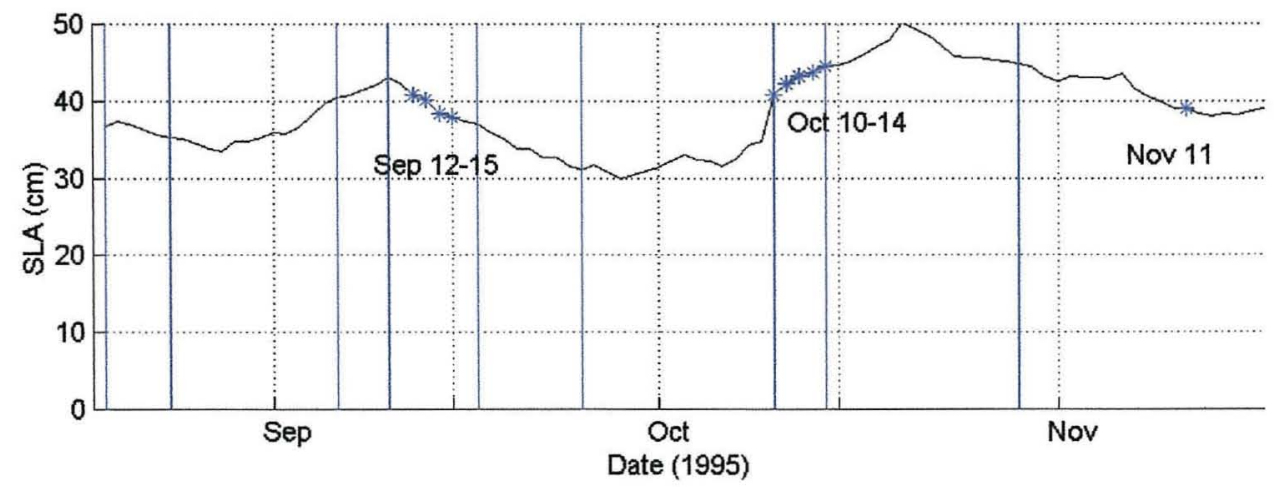

Figure 4.10. Eddy history for October 1995 mode-water eddy. Images on September 12 (a), October 10 (b), and November 11 (c). Plot of eddy trajectory (d) and SLA (e) with blue stars indicating sampling and blue vertical lines indicating satellite passes through eddy center.

\section{October 1995 - Mode-water Eddy}

The mode-water eddy that occurred in October 1995 (figure 4.10) was older than the other two mode-water eddies (approximately four months old in October). This eddy 
was associated with the largest displacement of the sea surface observed in the time series, both at the actual BATS site, where its maximum displacement was approximately $25 \mathrm{~cm}$, and in the eddy's center, where it reached $50 \mathrm{~cm}$. It was also a very large feature in spatial extent. This observation is complicated, however, by the presence of four interacting features near BATS during this time. In the images, the eddy appears to be over the BATS site for three BATS cruises on September 12-15, 1995, October 10-14, 1995, and November 11, 1995 (figure 4.10), but again several interacting features complicate this determination. Figure 4.11 (data contributed by Dr. T. Dickey), shows the eddy clearly at the site from at least October 7 to October 19, coinciding with the time of October sampling. The October measurements were taken in the edge of this eddy while it appeared to be intensifying, however, again it was older than the previous two mode-water eddies by several months.

Even though the eddy's center was far from the site, it was very large and the isopycnals are lens shaped in October (figure 4.3). In addition, the dynamic height measurements corroborate the SLA (figure 4.2c). This eddy was also apparent as an increase in $18{ }^{\circ} \mathrm{C}$ water (Siegel et al., 1999 figure 10). Additional information obtained from the BTM shows the feature had a cold expression in the upper ocean, further supporting the belief that it is a mode-water eddy (figure 4.11).

Although elevated nitrate+nitrite in the $60-80 \mathrm{~m}$ depth interval is depicted in figure 4.4 in October 1995, the contour is based on the October $10^{\text {th }}$ measurement at 100 $\mathrm{m}$ showing $0.3 \mu \mathrm{mol} / \mathrm{kg}$ Nitrate. There are no measurements between 50 and $100 \mathrm{~m}$ in this cast, thus it is impossible to tell how much nitrogen was available within this part of the euphotic zone. There was another cast on October $13^{\text {th }}$ which showed low concentrations of nutrients present at $0.1 \mu \mathrm{mol} / \mathrm{kg}$ in the base of the Euphotic zone $(100 \mathrm{~m})$ and none above that depth. By looking at these measurements in detail, we see that the availability of nutrients during this event is unclear. Nutrients may have been present but the measurements do not clearly indicate this, despite the contour in figure 4.4. The September measurement indicated nutrients of $0.1 \mu \mathrm{mol} / \mathrm{kg}$ extending up to 80 $m$ when the BATS site may have been in the edge of this feature. 

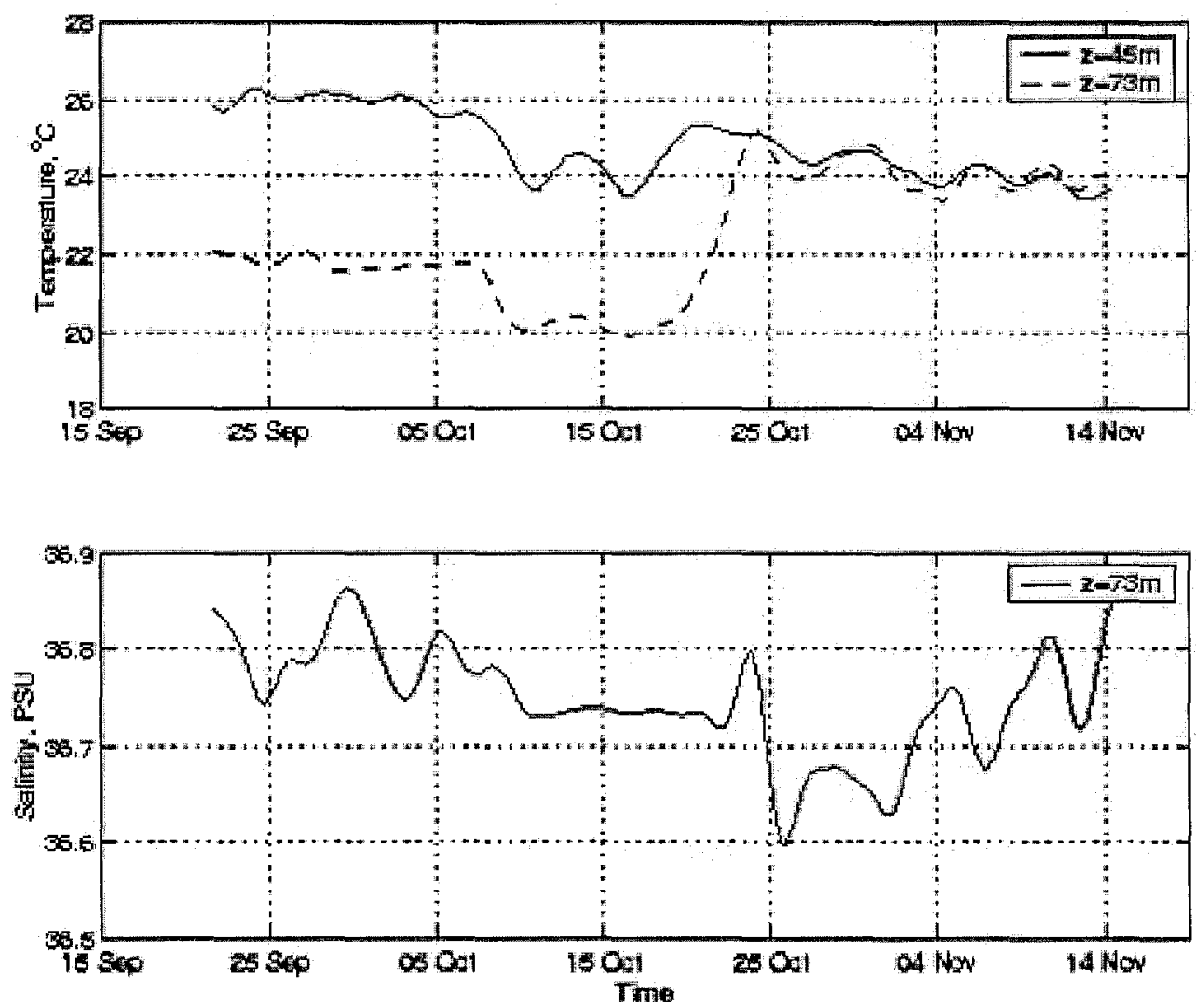

Figure 4.11 October 1995 mode-water eddy; measurements of temperature measured at $45 \mathrm{~m}$ and $73 \mathrm{~m}$ (a) and Salinity measured at $73 \mathrm{~m} \mathrm{(b)}$ as function of time at BATS (provided by Dr. T. Dickey from BTM measurements).

There were no increased pigment concentrations or productivity observed in September through November. In addition, there is no increased particle export, however a measurement of ${ }^{234} \mathrm{Th}$ flux is not available for November 1995, which, as mentioned above; the November measurement may not have sampled water from this feature anyway. The community structure appeared unchanged from typical conditions dominated by picoplankton. It is possible that the situation corresponds to stage 7 in the conceptual model (figure 4.1). In the previous two mode-water eddies the biological response occurred in the first two months of the eddy's life. This feature is 3 months old in September and 4 months old in October; it is plausible that the biological response occurred in the first two months of the eddy's life and was missed by our sampling. In 
other features, thorium flux was observed in month 3 , however, this feature had no elevated flux. Therefore, the September measurement may have failed to sample the water within the eddy and the high flux signal may have been gone in October. In summary, despite the significant magnitude of this eddy, its passage did not result in an observed biological response or flux and may indicate that an eddy's biological impact occurs primarily in the first two months of life.

\subsubsection{Cyclones}

Cyclonic eddies are cold water anomalies that displace the isopycnals upwards and can upwell nutrients into the euphotic zone. There were four cyclones that passed the BATS site during our time series. They are discussed below in an order based on the degree with which the observations allow us to test the conceptual model: June 1993, July 1995, November 1993, and January 1993.

\section{July 1993 - Cyclone}

In June and July 1993 a cyclonic eddy passed by the BATS site (figure 4.12). The edge of the eddy passed the BATS site during sampling on the June 12-15, 1993 (feature was approximately 3 months old) and July 12-16 BATS cruises (approximately 4 months old). This eddy was relatively intense, reaching a peak of $32 \mathrm{~cm}$ around June $5^{\text {th }}$. The eddy was already beginning to decay on June $13^{\text {th }}$ and continued to decay after that point. Although an upward displacement of the isopycnals was evident in the July $12^{\text {th }}$ measurements (figure 4.3b), it was not intense, perhaps because the BATS site was in the eddy's edge. No noticeable elevation in nutrients was observed; this is expected due to the eddy's age and the fact that it was decaying during the sampling period, corresponding to stage 6 in the conceptual model (figure 4.1). 


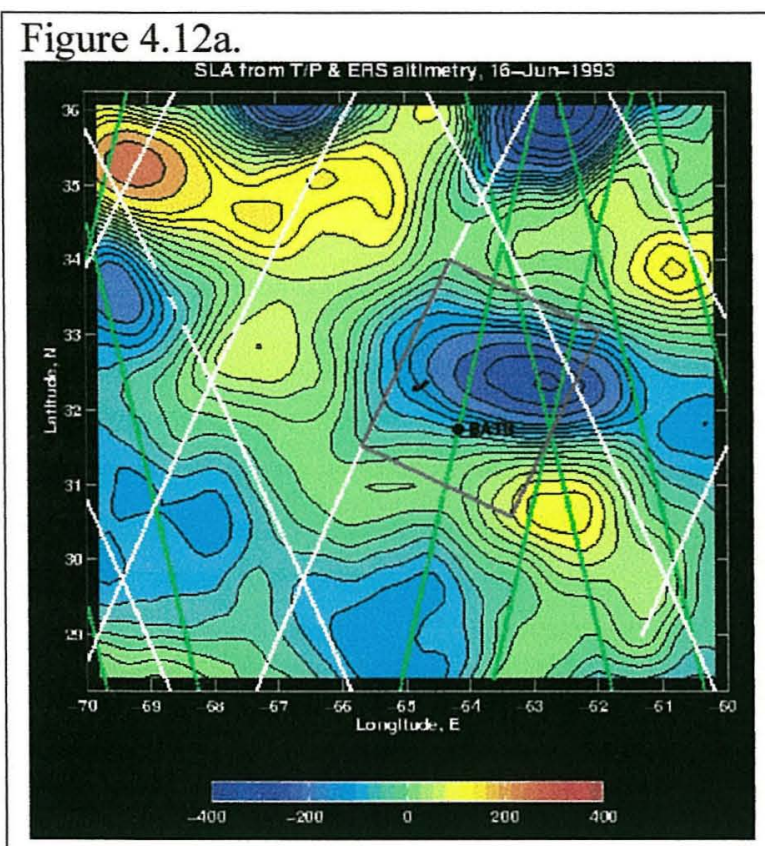

Figure 4.12b.

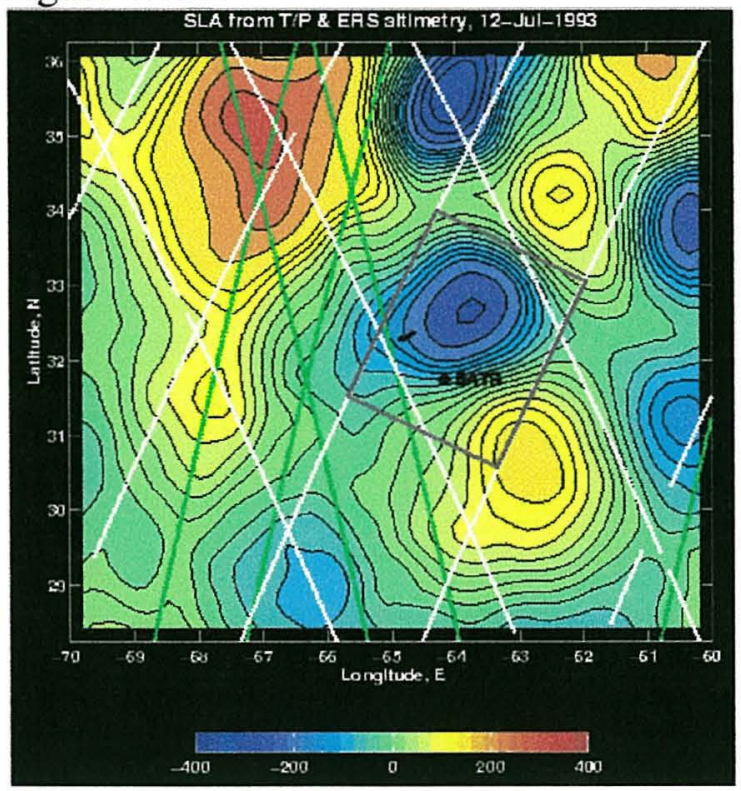

Figure 4.12c.

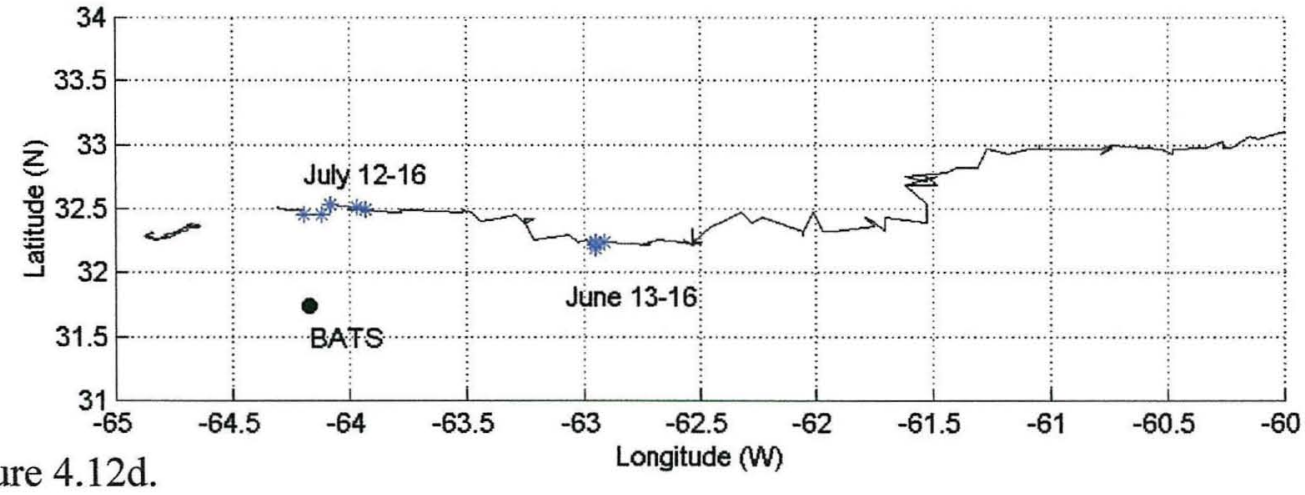

Figure 4.12d.

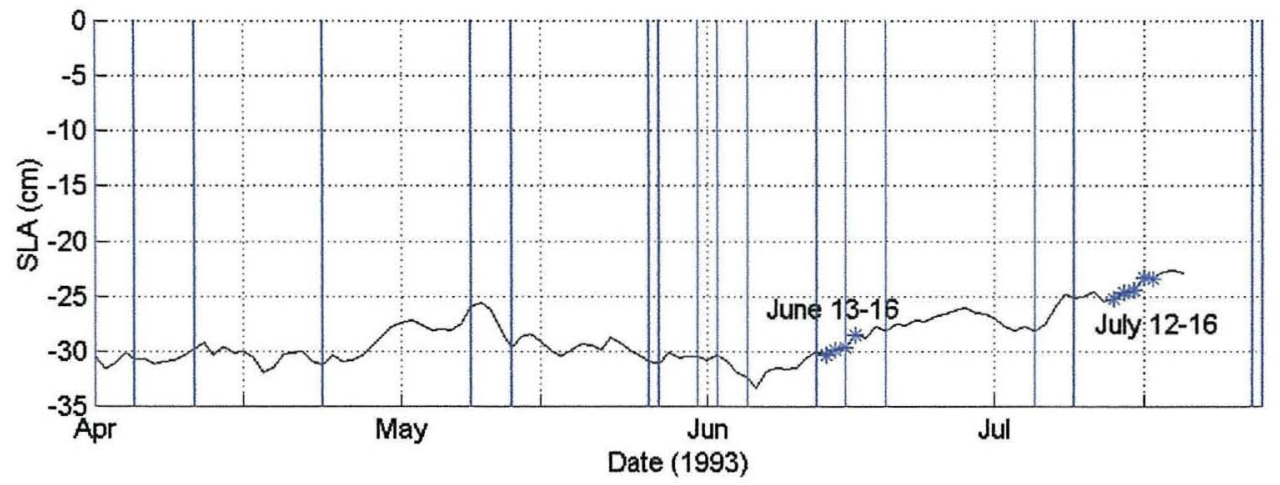

Figure 4.12. Eddy history for July 1993 cyclone. Images on June 16 (a) and July 12 (b). Plot of eddy trajectory (c) and SLA (d) with blue stars indicating sampling and blue vertical lines indicating satellite passes through eddy center. 
There was no observed increase in primary productivity or pigment concentrations; however, the thorium flux on June 16, 1993 was the highest of the record at $2450 \mathrm{dpm} / \mathrm{m}^{2} / \mathrm{d}$ (figure $4.2 \mathrm{~b}$ ). We may have captured the resulting flux from a previous bloom that occurred as the eddy intensified prior to reaching the sampling site. The phytoplankton community composition showed a shift to greater percentages of cyanobacteria (excluding Prochloroccocus) (figure 4.7). Based on the eddy's age and the high thorium flux, the observations correspond to position 6 in the conceptual model in July and position 7 in August. In addition, since both the June and July measurements were taken in the eddy's edge we could be observing increased flux from a bloom stimulated as part of eddy edge effects.

\section{August 1994 - Cyclone}

The July and August 1994 eddy event is comparable to the June / July 1993 event because they were both summer events and there was a high thorium flux observed during both features. The sampling location was on the edge of the eddy during the July 18-21, 1994 BATS cruise when the eddy was approximately 2 months old and near the eddy center one month later in the August 15-19, 1994 cruise (Figure 4.13). This eddy was near a peak of $15 \mathrm{~cm}$ in July with a decline to $10 \mathrm{~cm}$ in August, when it began to increase slightly again as it passed most near the site. The isopycnals showed an upward displacement in both months (figure 4.3), and the July nutrient profile indicated nitrogen was present in the euphotic zone at $80 \mathrm{~m}$ (figure 4.4). In July, the percentage of chlorophyll a contributed by cyanobacteria (excluding Prochlorococcus) was the highest in the record (figure 4.7$)$, over three times the average value $(\sim 36 \%)$. This community structure shift and available nutrients in July 1994 corresponds to stage 3 in the conceptual model in July 1994, however, it differs from the observations in mode-water eddies in that the community shift in the early period of those eddies was to larger phytoplankton. This could indicate that we are not sampling the water mass impacted by this feature, because we are in the eddy's edge, or we could be observing a difference in the impacts of mode-water eddies and cyclones. 


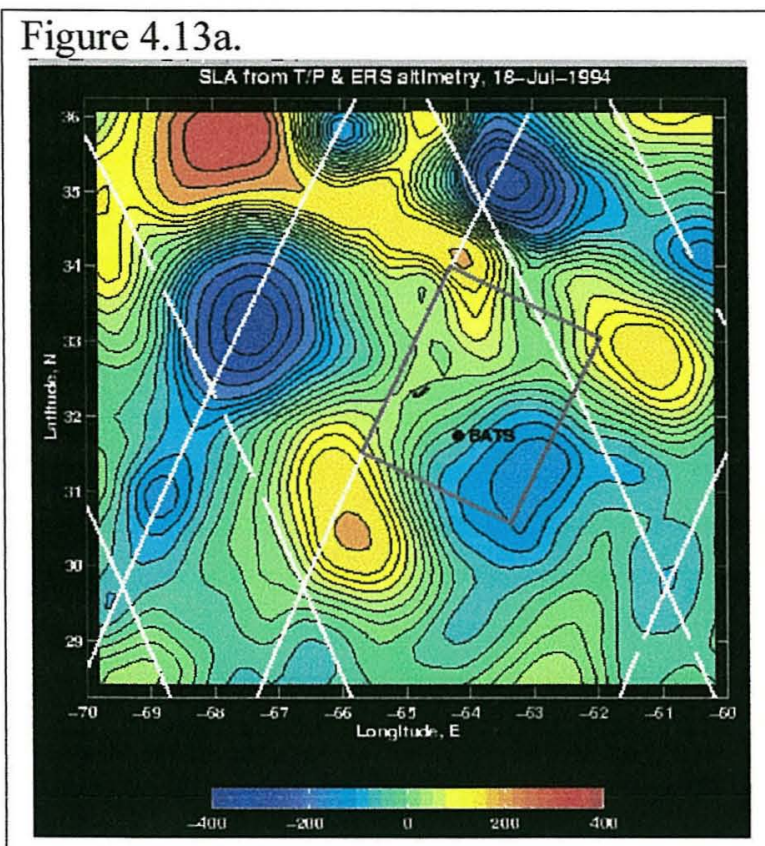

\section{Figure $4.13 \mathrm{~b}$.}

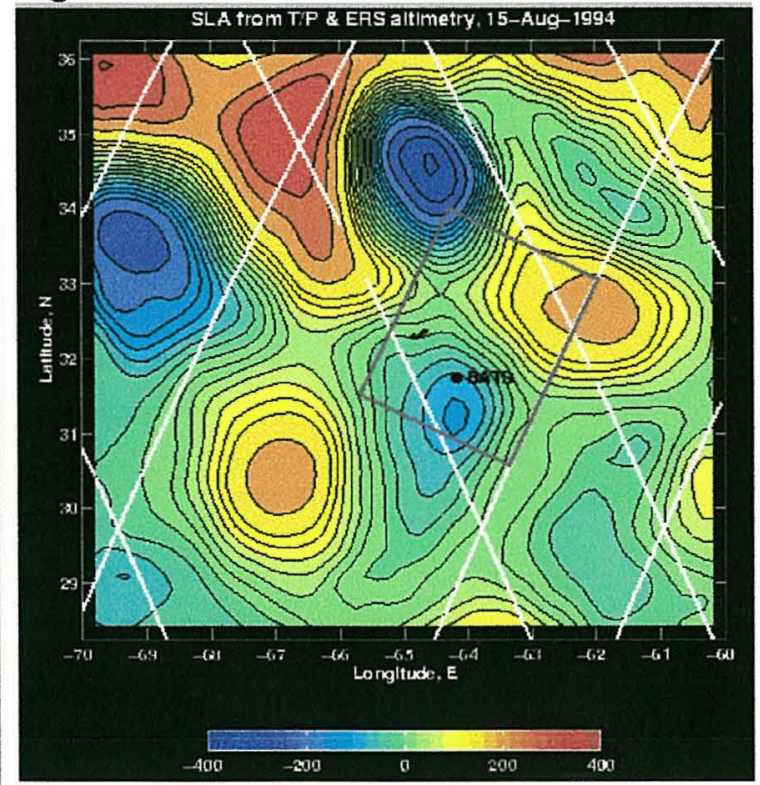

Figure $4.13 \mathrm{c}$.

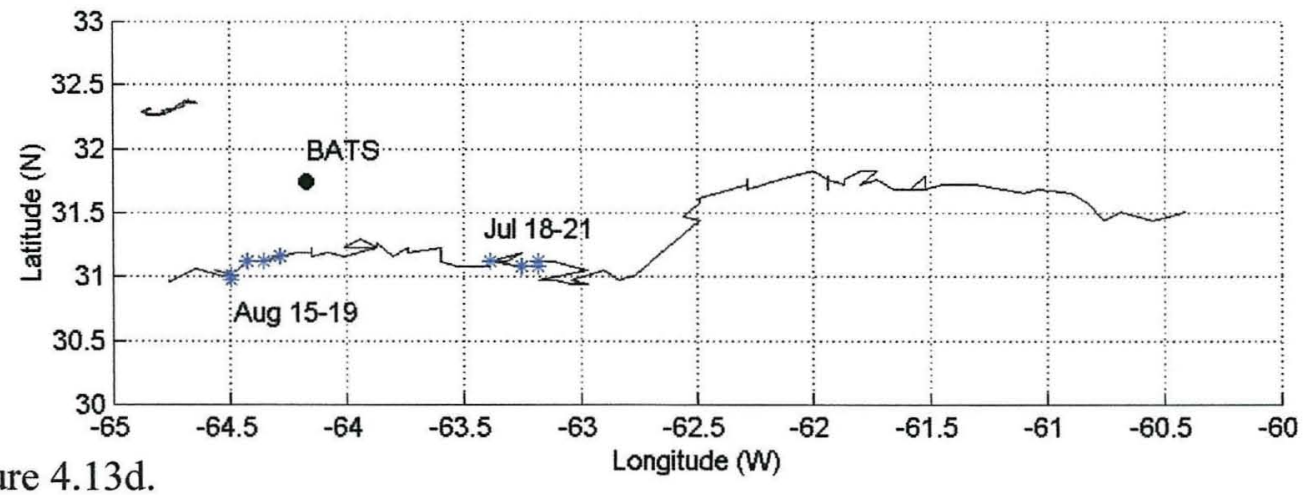

Figure 4.13d.

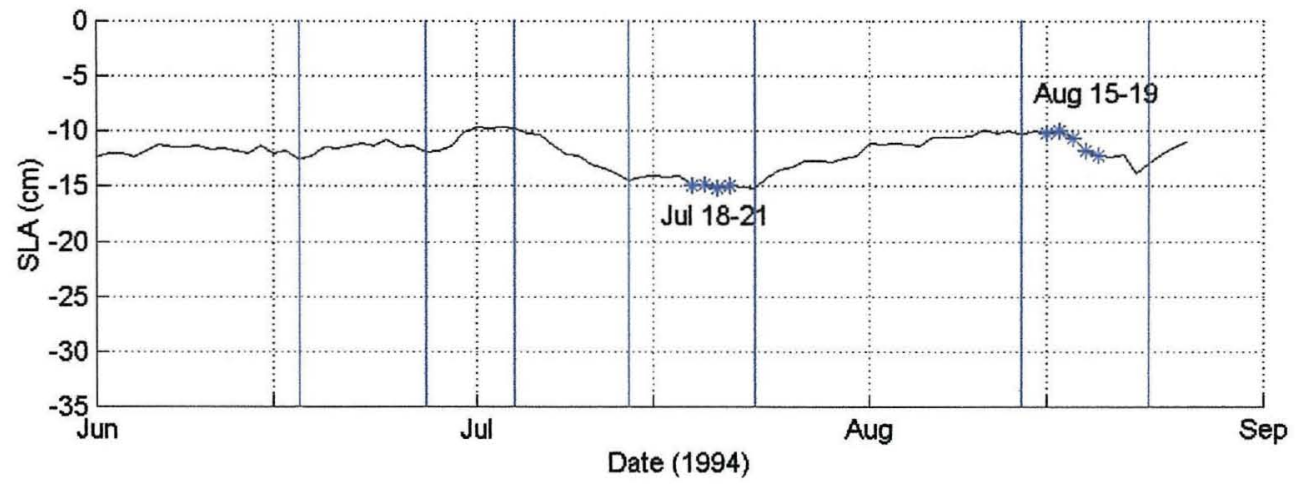

Figure 4.13. Eddy history for August 1994 cyclone. Images on July 16 (a) and August 15(b). Plot of eddy trajectory (c) and SLA (d) with blue stars indicating sampling and blue vertical lines indicating satellite passes through eddy center. 
There was a bloom of dinoflagelletes in August 1994 associated with the passage of this eddy (figure 4.6d and 4.7f). The pigment peridinin was at its second highest concentration in the record at a value of $0.6 \mathrm{mg} / \mathrm{m}^{2}$ (figure $4.6 \mathrm{~d}$ ) and dinoflagelletes are estimated to comprise over 5 times their average percentage of chlorophyll a $(\sim 5 \%)$, the highest percentage in the time record (figure 4.7f). This bloom was accompanied by an increased ${ }^{234} \mathrm{Th}$ flux measurement of $1573 \mathrm{dpm} / \mathrm{m}^{2} / \mathrm{d}$ (figure $4.2 \mathrm{~b}$ ). The increased dinoflagellete presence and high flux in the absence of measurable nutrients indicates stage 5 in the conceptual model during the August BATS cruise. This August measurement was made relatively close to the eddy's center and thus is not likely to be an edge effect.

\section{November 1993 - Cyclone}

Another cyclonic eddy went past the BATS site in November 1993 (figure 4.14). Note that the December 1993 image (figure 4.14b) shows a second cyclone North of the site that interacted with the first, and that the November feature has disappeared. It intensifies slightly prior to sampling but then begins to decay during sampling until it disappears in December. Also, the eddy was already 10 months old when it passed the site. It was not a prominent feature, reaching a maximum displacement of around $14 \mathrm{~cm}$. The elevation of the isopycnals was evident in the November 8, 1993 measurement, with elevations much more pronounced at depth and diminishing at the surface (figure 4.3b). Nitrate concentrations were actually depressed to below $100 \mathrm{~m}$ with the passage of this eddy (figure 4.4a). There is no increased productivity or pigment concentrations (figures 4.2a, 4.5, and 4.6). As with the two previous cyclones, there is a slight increase in the percentage of cyanobacteria (excluding Prochlorococcus) associated with this eddy. No conclusion can be drawn about export because the ${ }^{234} \mathrm{Th}$ flux measurement is not available. With the assumption that this eddy is towards the end of its life and is decaying, it represents stage 7 of the conceptual model (figure 4.1). The depressed nitrogen levels, long age of this feature, and the fact that it was no 


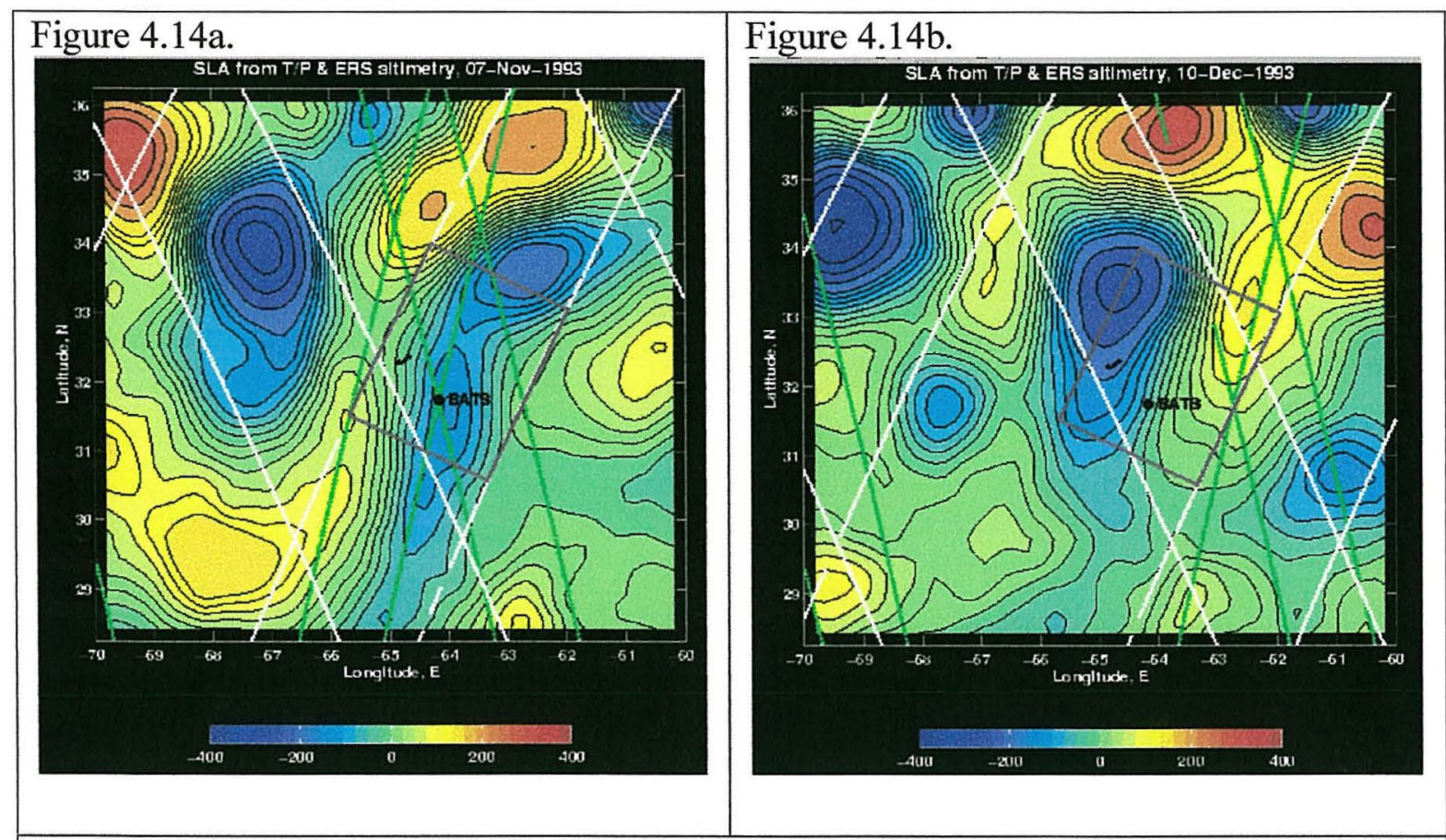

Figure 4.14b.

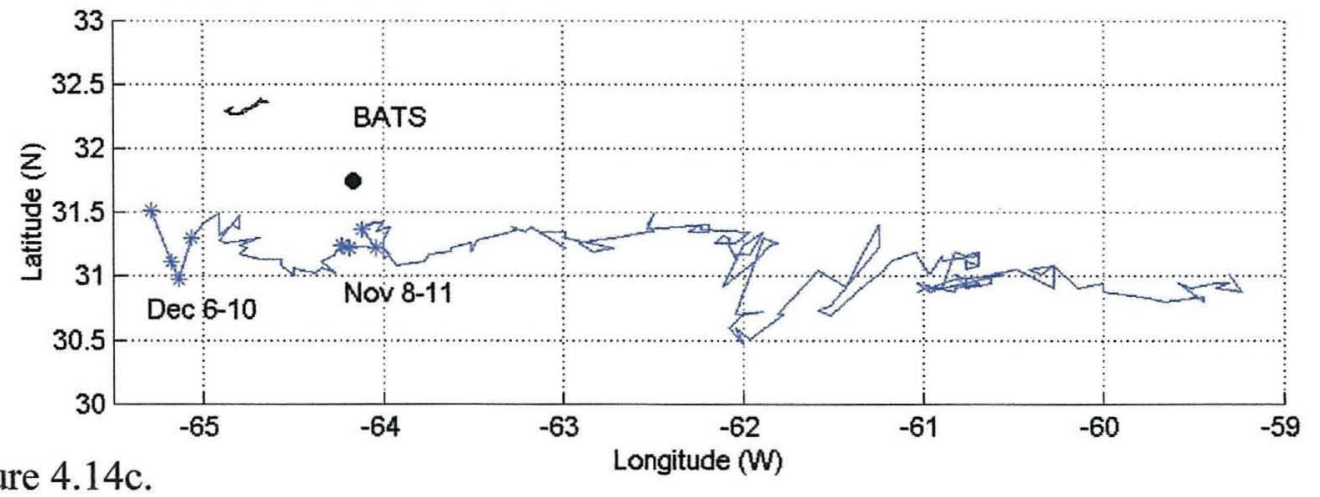

Figure 4.14c.

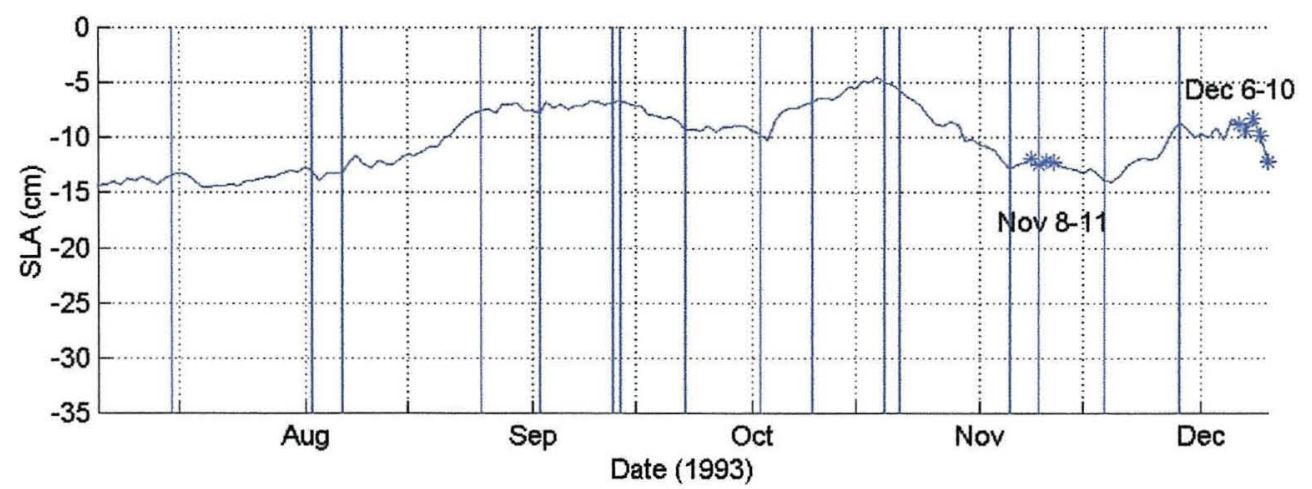

Figure 4.14. Eddy history for November 1993 cyclone. Images on November 7 (a) and December 10 (b). Plot of eddy trajectory (c) and SLA (d) with blue stars indicating sampling and blue vertical lines indicating satellite passes through eddy center. 
longer present in December support this hypothesis. It is also possible that the phytoplankton might not benefit from any injected nutrients in the fall due to the deeper mixed layer depth.

\section{January 1993 - Cyclone}

The January 1993 cyclone's history is shown in figure 4.15; it passed over the site during the January 12-15, 1993 cruise. The thorium measurement was made on January 18, 1993 and a BATS bloom cruise occurred on January 25, 1993. The February 8-11 BATS measurements are in the eddy's edge. The exact age of this feature is unknown because it formed prior to the start of available eddy field images of SLA (prior to October 1992); the feature is over three months old in January. The eddy is intensifying from around $-10 \mathrm{~cm}$ to around $-20 \mathrm{~cm}$ in late February 1993 as it passes the site.

The January and February observations are complicated by deepening of the mixed layer (figure 4.3 and $4.4 \mathrm{~b}$ ) that occurs just prior to the deepest winter mixing in February or March. Specifically, mixing can increase nutrient concentrations and decrease thorium flux estimates, since the mixing can cause the addition of thorium rich waters from below. If particles containing thorium sink to depth and then remineralize, the activity of ${ }^{234} \mathrm{Th}$ can rise above the parent ${ }^{238} \mathrm{U}$, resulting in excess ${ }^{234} \mathrm{Th}$. If this water

upwells, it is possible to have ${ }^{234} \mathrm{Th}$ greater than ${ }^{238} \mathrm{U}$ activity resulting in a negative thorium flux. In February 1993, there was a negative thorium flux measurement of -1290 $\mathrm{dpm} / \mathrm{m}^{2} / \mathrm{d}$ (figure $4.2 \mathrm{~b}$ ). This negative flux is most likely due to the remineralization of particles from a prior particle export event. Because the January 1993 cyclone occurred during deepening of the mixed layer, it is difficult to test the conceptual model with this event. 


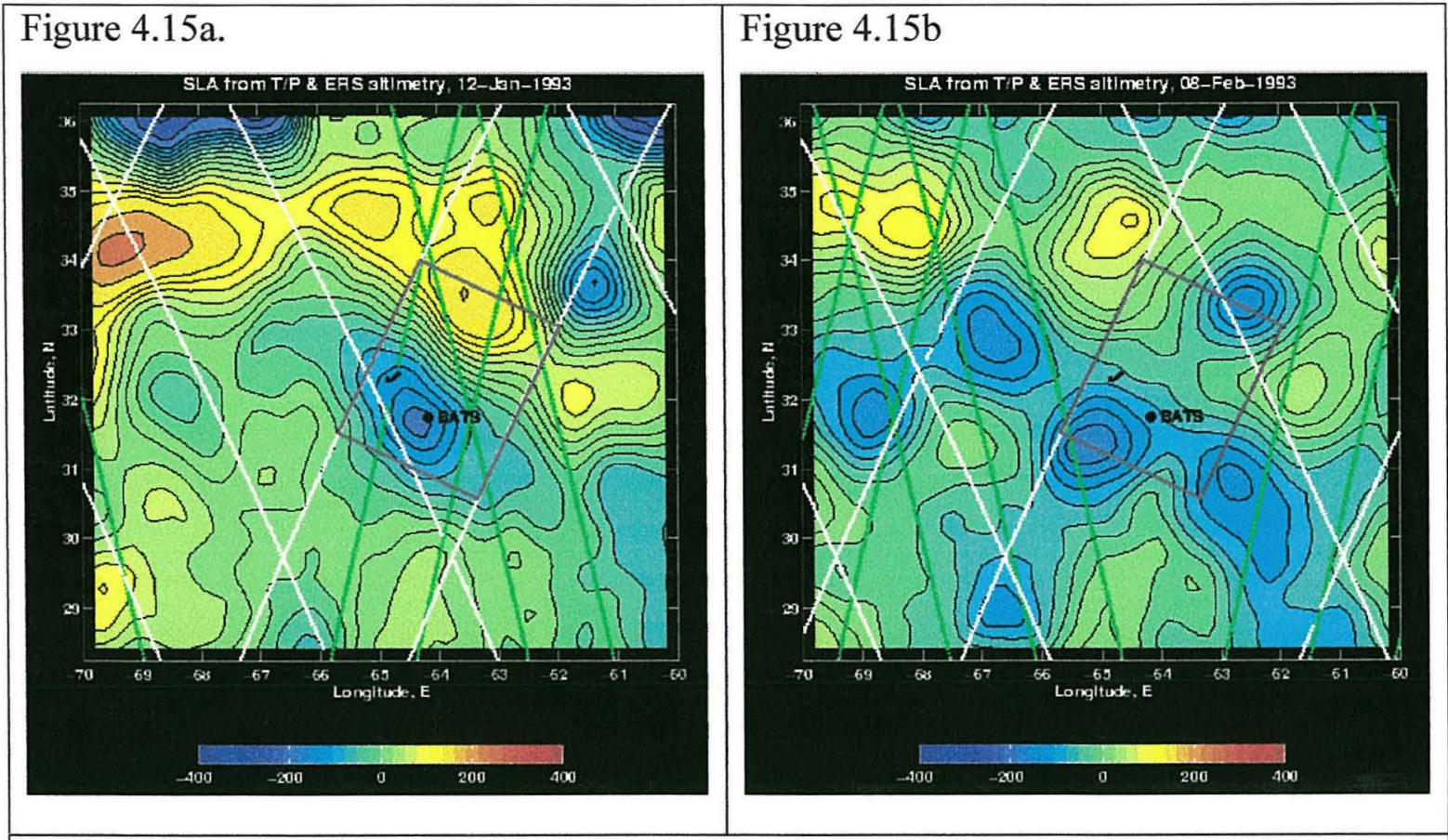

Figure $4.15 \mathrm{c}$.

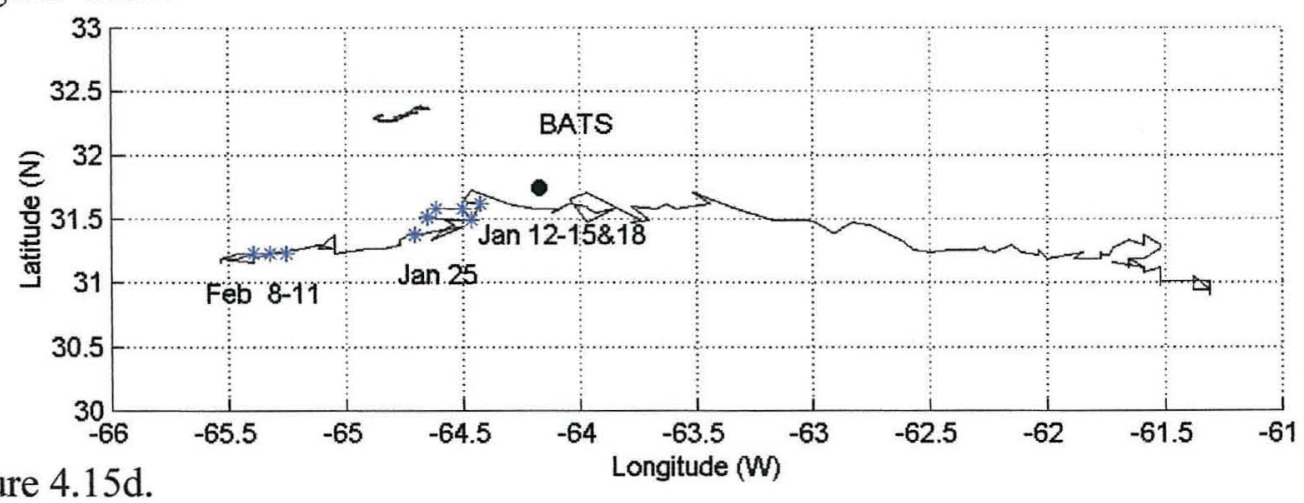

Figure $4.15 \mathrm{~d}$.

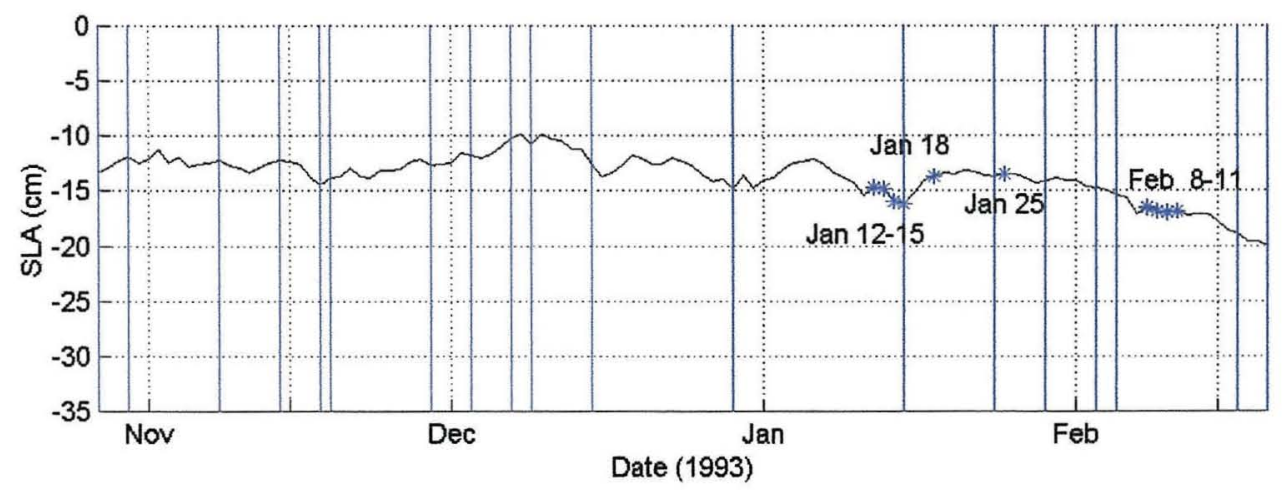

Figure 4.15. Eddy history for January 1993 cyclone. Images on January 12 (a) and February 8 (b). Plot of eddy trajectory (c) and SLA (d) with blue stars indicating sampling and blue vertical lines indicating satellite passes through eddy center. 
Despite this limitation, the following observations about the January 1993 cyclone were made. There is a biological response in January and February 1993 (3 measurements) of the cyanobacteria (excluding Prochloroccoccus) community; they have increased their percentage to chlorophyll a by more than twice the average value (figure 4.7c). This percentage increase in the cyanobacteria community is unlikely to directly influence the export, however, there is a high thorium flux of.1160 dpm $/ \mathrm{m}^{2} / \mathrm{d}$ (figure 4.2b) on January 18,1993 . This indicates position 4 to 5 on the conceptual model in January (figure 4.1); however, it is impossible to tell if the eddy or the onset of winter mixing stimulates this biological response. Note that figure $4.2 \mathrm{~b}$ shows high flux in January 1995, in the absence of an eddy. In addition, community shifts to more cyanobacteria occurred every January in the record, though not as intense as 1993. It is possible the eddy amplified the already existing cycle by stimulating a larger community response in January 1993. It is just as plausible that the eddy had little impact due to the winter entrainment. To determine this, more detailed study of the fluxes, including consideration of three dimensional flows, is needed.

\subsubsection{Anticyclones}

An anticyclone is a warm water anomaly that depresses the isopycnals and is expected to downwell surface water. It therefore is not expected to cause an increase in biological activity. Below two anticylone events are discussed in the following order: September 1994 and March 1994.

\section{September 1994}

In September and October 1994 an anticyclone passed the BATS site (figure 4.16). The trajectory shows that it passed during September 19-22, 1994 and October 1822, 1994 cruises. The feature reached a peak around September 2 of over $25 \mathrm{~cm}$ and was decaying as it passed the site. In September the isopycnals were deepening (figure 4.3). The upwelling of nutrients was not observed (figure 4.4a). As expected, no biological response was observed to the passage of the eddy. 


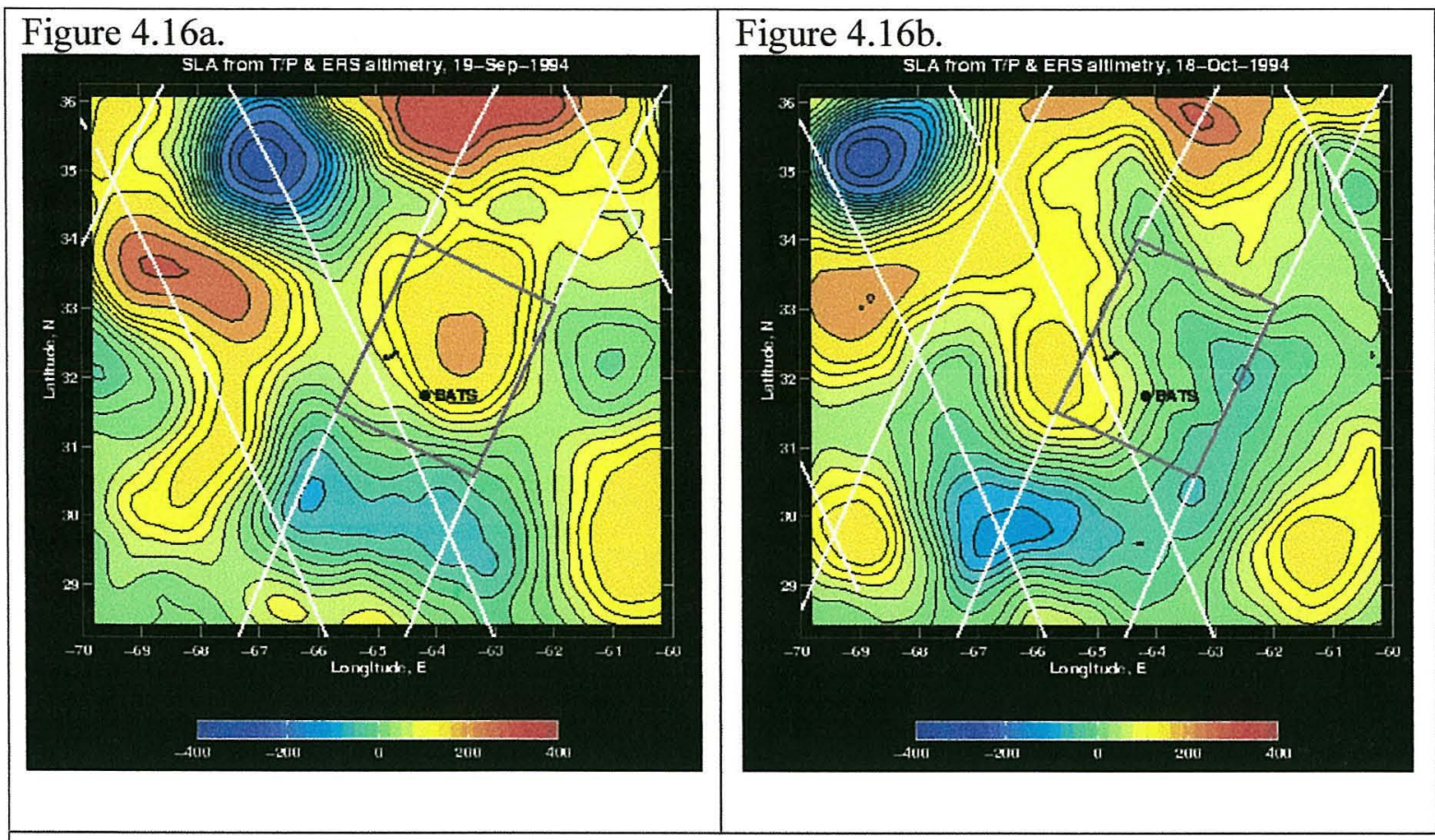

Figure 4.16c.

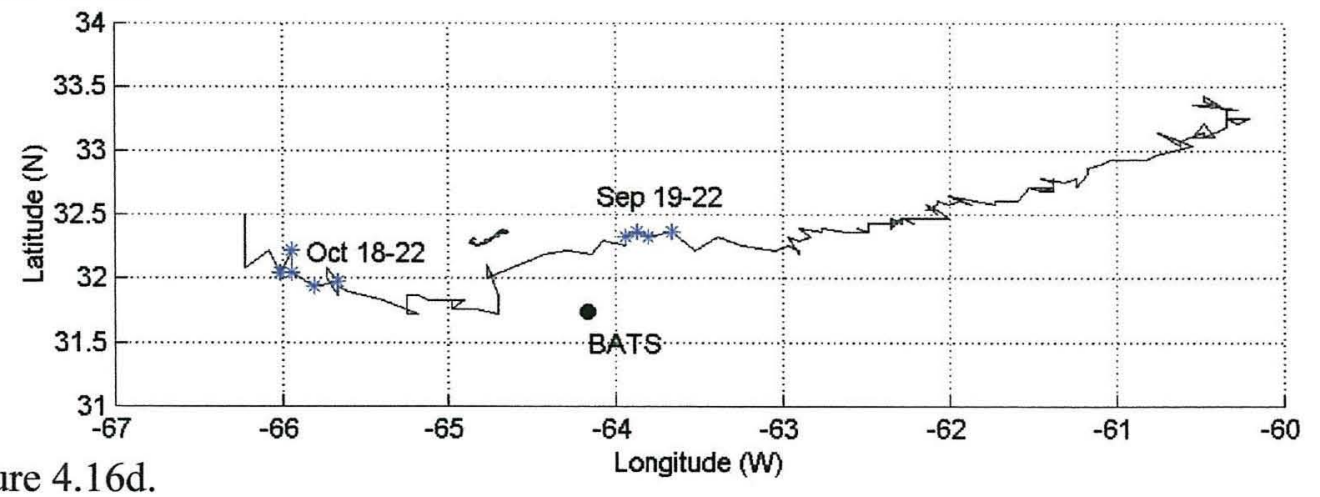

Figure 4.16d.

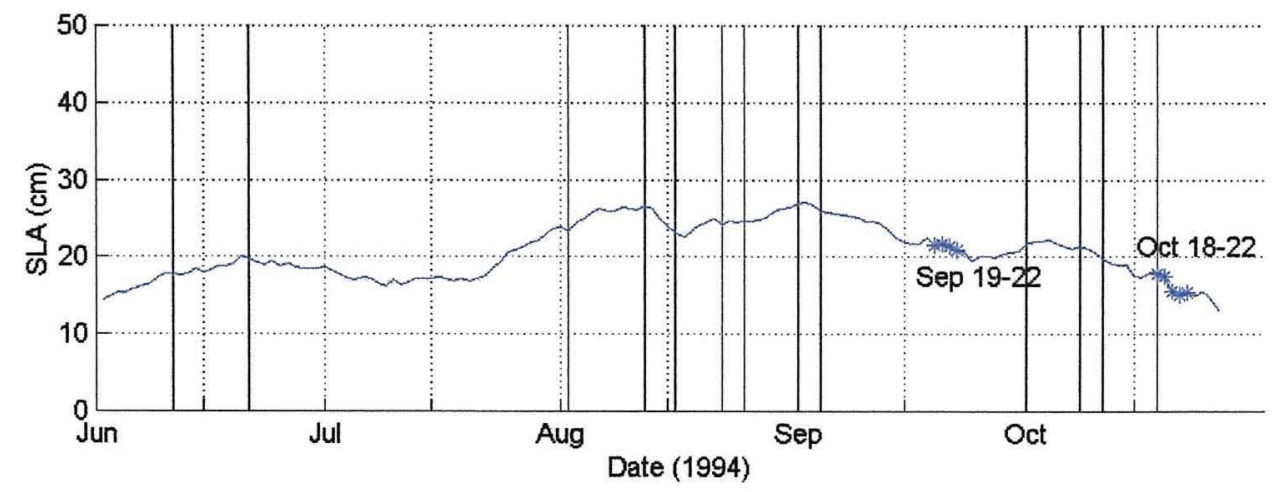

Figure 4.16. Eddy history for September 1994 anticyclone. Images on September 19 (a) and October 18 (b). Plot of eddy trajectory (c) and SLA (d) with blue stars indicating sampling and blue vertical lines indicating satellite passes through eddy center. 


\section{March 1994}

The event that occurred in March 1994 is an example of how an anticyclone can effect the biological activity at BATS. This event suppressed the 1994 spring bloom; below the observations in 1994 are presented and compared to the other three spring blooms observed during our study period. For the purpose of this discussion, the spring bloom is the increased primary productivity observed after the seasonal winter entrainment mixing that occurs in the Sargasso Sea. The spring peaks in productivity that occurred during the 1993 and 1995 blooms are marked by narrow green lines in figures 4.2-4.7. Though indicated by a thin line, these blooms last for days to weeks, and probably impact measurements from multiple BATS cruises both before and after the indicated lines.

The anticyclone (figure 4.17) passed the site during the February 28-Mar 1, 1994 bloom cruise and the March 14-21, 1994 core cruise. The feature was decaying from a displacement of around $30 \mathrm{~cm}$ in early February to $20 \mathrm{~cm}$ when it passed near the site. The eddy images indicate the BATS site was in the edge of the eddy, however, this event occurred during a time when ERS satellite information was not available, therefore, the exact location and extent of the feature is uncertain. Other information corroborates that the eddy was present at the site. An intense downward displacement of the isopycnals (figure 4.3) and an unusually deep mixed layer of $300 \mathrm{~m}$ (figure 4.4b) occurred in March. Also, the dynamic height was elevated above the SLA by $15 \mathrm{~cm}$ (figure $4.2 \mathrm{c}$ ). In addition, the nutrients at the site were low at depth and unusually evenly mixed $(\sim 0.5$ $\mu \mathrm{mol} / \mathrm{kg}$ to $300 \mathrm{~m}$ ) (figure $4.4 \mathrm{a}$ ).

Seasonal deep mixing occurred in late February and March of 1993 at the Bermuda site; this is shown in vertical isopycnals in the contour plot of sigma theta (figure 4.3) and in the mixed layer depth of approximately 180-m (figure 4.4b). The nitrate+nitrite levels were also elevated at the surface from late February to early April. The spring bloom that accompanied this deep mixing event was evident in the increased primary production and in the increased photosynthetic pigment concentrations (figures 4.2a, 4.5 and 4.6). The 1995 spring bloom followed the same pattern as 1993 . Vertical isopycnals and deep mixing occurred in February and March, with February deep mixing extending to $200 \mathrm{~m}$ (figure $4.4 \mathrm{~b}$ ). Nitrate+nitrite concentration at the surface was elevated 


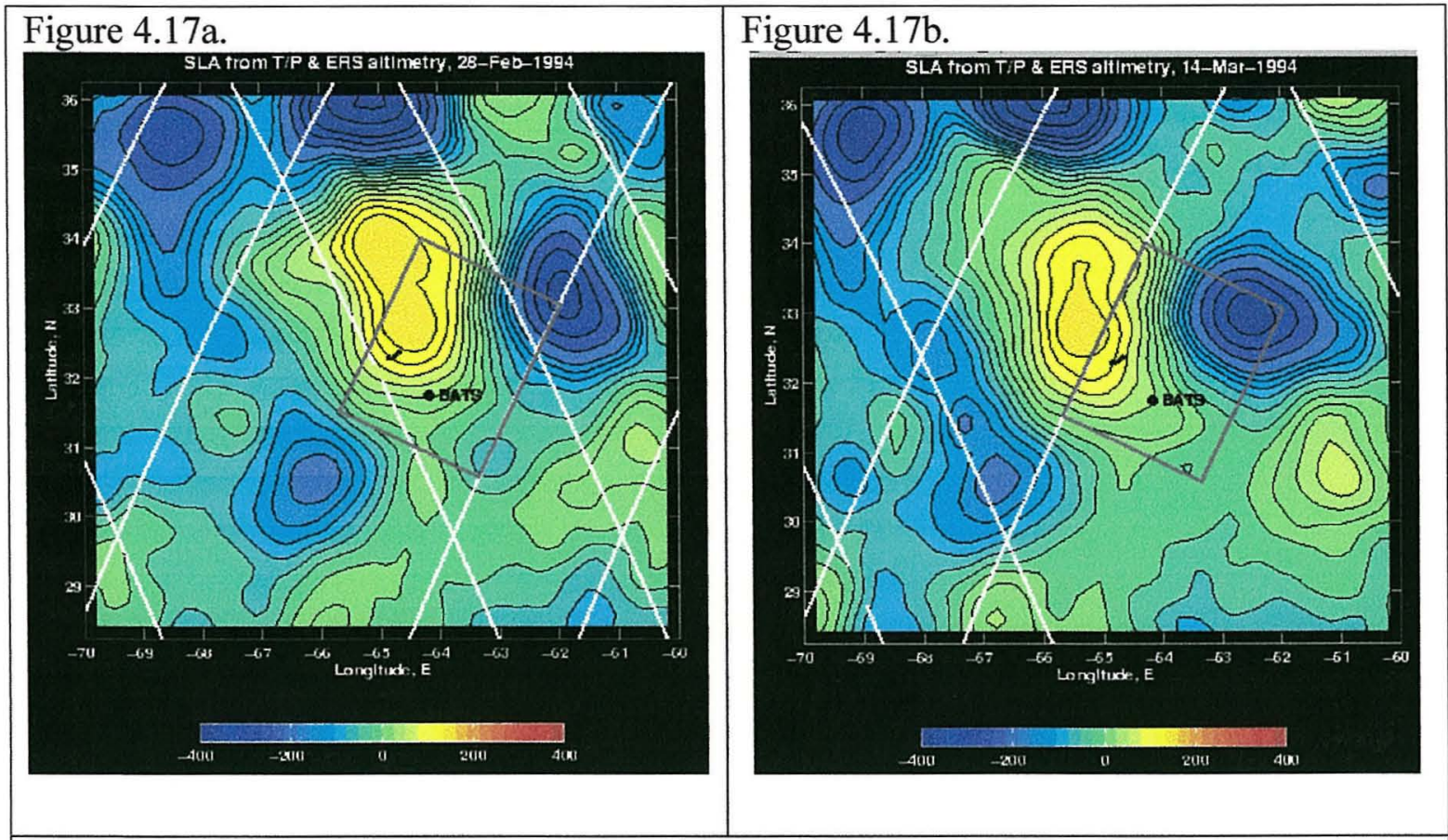

Figure $4.17 \mathrm{c}$.

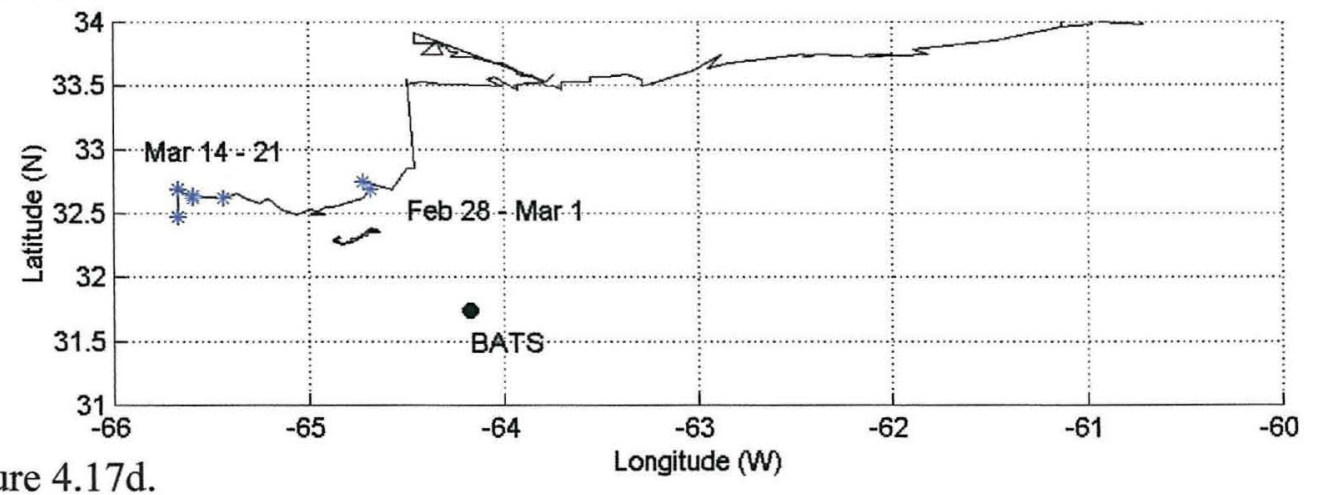

Figure $4.17 \mathrm{~d}$.

Figure 4.17b.

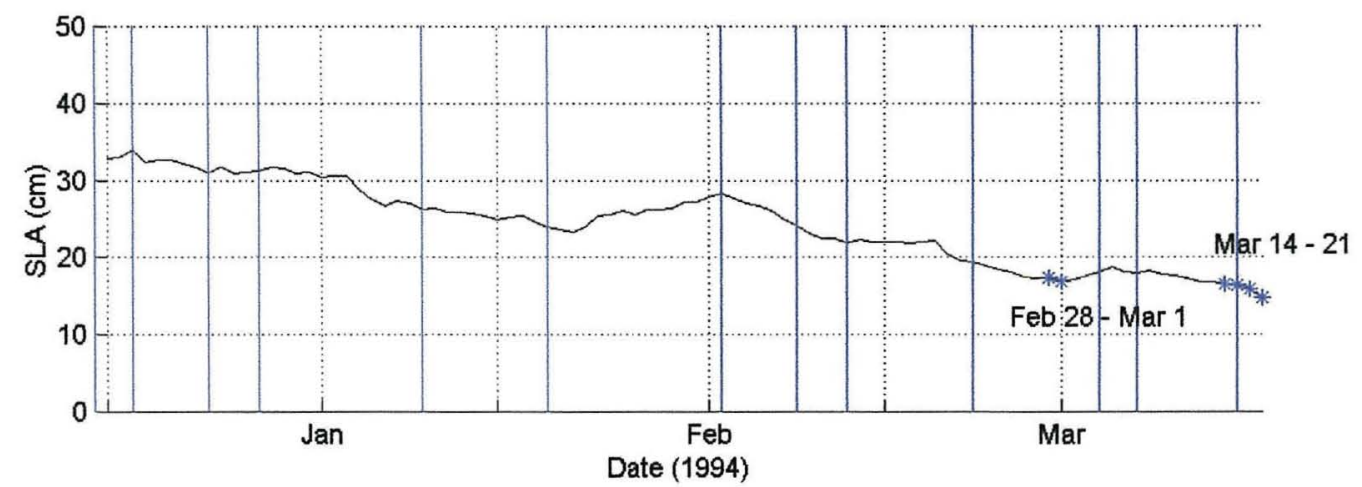

Figure 4.17. Eddy history for March 1994 anticyclone. Images on February 28 (a) and March 14(b). Plot of eddy trajectory (c) and SLA (d) with blue stars indicating sampling and blue vertical lines indicating satellite passes through eddy center. 
from mid-January to early April and concentrations were higher than the 1993 bloom (figure 4.4a). The phytoplankton pigment concentrations were increased from February through the end of March. The deeper mixing in 1995 resulted in more nutrients and was followed by a bloom of longer duration than the 1993 bloom. The species distribution did not shift from a community dominated by nano- and picoplankton, but the prevalence of cyanobacteria (excluding Prochlorococcus) appears to be reduced to near zero during both blooms and prasinophytes seem to thrive under the bloom conditions (figure 4.7). In summary, both 1993 and 1995 blooms showed increased primary productivity, pigment concentrations elevated in chlorophyll a, chlorophyll b, prasinoxanthin, 19Butanoyloxyfucoxanthin, 19-Hexanoyloxyfucoxanthin, fucoxanthin, and peridinin (1995 only), and community structure was dominated by small size class phytoplankton.

In 1994, nutrients were present in the surface but no increased productivity was observed, the productivity during this time being half to one third the value of the 1993 and 1995 blooms (figure 4.4a and 4.2a, respectively). The pigment concentrations of chlorophyll a, fucoxanthin, 19-Hexanoyloxyfucoxanthin, 19-Butanoyloxyfucoxanthin, and prasinoxanthin were all increased (figure 4.5 and 4.6), similar to the 1993 and 1995 blooms. The community structure was also similar in that cyanobacteria (excluding Prochlorococcus) diminished and prasinophytes thrived (figure 4.7). This event was also discussed briefly in Michaels and Knap (1996) as an unusually weak spring bloom given the very deep mixed layer depth. The diminished productivity was likely due to the deep mixing of the organisms out of the euphotic zone during this event; the eddy appears to have amplified mixing preventing stratification, causing light limitation, and reducing the magnitude of the 1994 bloom event. This illustrates that it is possible for an anticylcone to diminish productivity by competing with the seasonal cycle and suppressing a biological response. 


\section{Summary and Significance of Work}

\subsection{Overview}

After discussing the eddy events individually it is useful to look back at the time series as a whole. Figure 4.2 allows us to view both productivity and export in each event. Of the six flux events over $1000 \mathrm{dpm} / \mathrm{m}^{2} / \mathrm{d}$ (figure $4.2 \mathrm{~b}$ ), at least four of them were associated with the passage of an eddy. Also, in the July 95 and May 93 modewater eddies, productivity levels nearly as high as the 1993 and 1994 spring bloom recorded maximums were observed. Young mode-water eddies were characterized by a shift towards large plankton, diatoms and dinoflagelletes (figure 4.7). All four cyclones exhibited increased percent contributions of cyanobacteria (not including Prochlorococcus). This community shift may be a result of the timing of the observations in these features; we were not able to observe a cyclone less than 2 months old. However, there may be other aspects of these eddies (such as temperature and seasonality), in addition to nutrients, that help determine the effect an eddy will have on community structure. In addition, it is possible that the biological response of an eddy may be reduced significantly during times of a deep or deepening mixed layer, however, we were not able to draw conclusions about this due to our limited observations during periods of deep mixed layer. All these generalized observations show the significant biological response to the passage of eddies; the temporal aspects of the features are presented in the conceptual model and discussed below.

\subsection{The Conceptual Model}

The conceptual model of eddy upwelling (Figure 4.1) depicts a mode-water eddy or cyclone as it perturbs an ecosystem. With intensification, nutrients are upwelled into the euphotic zone where they stimulate a biological response; in our observations this occurred in the first two months (Ju195, May93). Enhanced export appeared to occur at least as early as month 1.5 and persisted as long as three months (Jul95, Jul93, Aug94, and maybe Jan93). On decay or relaxation of the eddy, the nutrient addition ends and the biological response diminishes; features greater than 4 months old did not show a biological response (Nov93, Oct95). The factors that effect the timing of these responses are not fully known. This temporal dynamic and its uncertainty complicates the 
interpretation of the BATS observations. However, we have been able to put the BATS observations into a temporal context by using satellite altimetry to estimate the eddy's history and "life cycle" (i.e. intensification or decay).

The observations in all seven of the upwelling eddies can be explained using the conceptual model. As a result of the biweekly to monthly one-dimensional nature of the measurements at a fixed point we often capture only the edge of a feature, failing to capture the intensification and decay. Therefore, it is difficult to distinguish cases in the conceptual model that could be due to temporal dynamics from true differences in the response (for example, in the case of the differences observed in mode-water eddies and cyclones). Because of this, more information is needed to determine if differences between the biological response in cyclones and mode-water eddies exist and if the guidelines for the impacts based on eddy age, made above, are generally true.

Some notable limitations with the simplicity of the conceptual model are worth discussing. First, an eddy's intensity and decay cycle is more complex than depicted in figure 4.1, because eddies can increase and decrease intensity multiple times during their life cycle (refer to figures 4.8-4.16). It is also still unclear how important the age of a feature is to its nutrient injection. Specifically, whether subsequent nutrient injections occur and if consecutive injections diminish the intensity of the nutrients. Further, we may find, through more detailed studies that the impact on the community structure in cyclones and mode-water eddies differ considerably. The use of the transfer functions of Letelier et al. (1993) provides us with a basis to approximate community structure, but it is limited in utility; to determine conclusively the community structure, more detailed observations are required. In addition, the importance, extent, and temporal dynamics of "edge effects" are still not known and are not included in the model.

The impact of winter entrainment and deepening of the mixed layer may also impact the biological response to an eddy. High export flux events occurred in both January 1993 and January 1995 (figure 4.2b). In order to distiguish eddy impacts from seasonal impacts we need a four-dimensional (space and time) analysis of fluxes and a better understanding of the seasonal cycle in throium-234 and community structure at BATS. Finally, consideration of seasonal stratification may be an important aspect currently absent from our model. Because of the reduced response in the November 1993 
cyclone and the absent response in the October mode-water eddy, a general conclusion is that eddy impacts are most intense during times of seasonal stratification and the establishment of strong nutraclines (Dickey et al., 2001). More information is needed to determine the importance of stratification because the temporal aspect of our model makes it likely the timing of sampling has influenced the interpretation of the November 1993 and October 1995 observations.

\subsection{Summary}

The results of this study show that eddies exert significant influence on variations in productivity, community structure, and particle flux in the Sargasso Sea. Here we have observed that 4 out of the 6 flux events over $1000 \mathrm{dpm} / \mathrm{m}^{2} / \mathrm{d}$ during 1993-1995 occurred during the passage of an eddy. The primary productivity was nearly as high as the spring bloom maximum in two of the three mode-water eddies (May 1993 and July 1995). The 1994 spring bloom at BATS was significantly depressed by the passage of an anticyclonic eddy. Also, phytoplankton community shifts in mode-water eddies (larger phytoplankton) and cyclones (cyanobacteria) were specific and distinct suggesting that mode-water eddies and cyclones may impact community structure differently but, until the early impacts of both types of features can be observed, the differences are uncertain. Finally, eddy age seemed to be significant in its impact on the biology. In general, eddies that were one to two months old elicited a large biological response (Ju195 and May93); eddies that were three months may show a biological response (Aug94) and were accompanied by high thorium flux measurements (Jul93, Aug94); eddies that were four months old or older did not show a biological response or high thorium flux (Nov93, Oct95).

The conceptual model of eddy upwelling provides a general description of the type of response expected from the passage of an eddy and can explain the observations in the 7 upwelling events. Improvements such as Lagrangian studies, higher resolution time-series, and/or more spatial coverage will help to provide added details to the model. With a more complete temporal picture of the effects of eddies, including information about fluxes in four-dimensions, we will significantly improve our understanding of the impacts of mesoscale eddies on biogeochemical cycling in the ocean. 
Learning more information about eddy events in the Sargasso Sea will help us to understand much needed information about oligotrophic mid-ocean gyres. Future work can help explain the large observed variability in productivity and particle flux, balance the budgets of carbon and nitrogen, and provide an opportunity to learn more about ecosystem dynamics and controls of community structure. 


\section{References}

Anderson, R. A., Bidigare, R. R., Keller, M. D., and Latasa, M., A comparison of HPLC pigment signatures and electron microscopic observations for oligotrophic waters of the North Atlantic and Pacific Oceans, Deep-Sea Research II, 43, 517-537, 1996.

Archer, D., Upper Ocean Physics as Relevant to Ecosystem Dynamics: a Tutorial, Ecosystem Applications, 5(3), 724-739, 1995

Archer, D., Winguth, A., Lea, D., and Mahowald, N., What caused the glacial / interglacial $\mathrm{pCO}_{2}$ cycles? Reviews of Geophysics, 38, 159-189, 2000.

Archiving, Validation, and Interpretation of Satellite Data in Oceanography (AVISO), AVISO handbook: Sea level anomaly files, Publishing AVI-NT-001-312-CN, $21^{\text {st }}$ ed., 24 pp., (Cent. Nat. d'Etudes Spatiales, Toullouse, France, 1997).

Bernada, R., Merged GDR (TOPEX/POSEIDON) Users Handbook, version 1, Tech. Rep. 11007, (Jet Propulsion Lab, Pasadena, California, 1993).

Bidigare, R., in Spencer and Hurd (eds), The analysis and characterization of Marine particles, (American Geochemical Union, Washington, D.C., 1991).

Boyd, P. W., and Newton, P. P., Does planktonic community structure determine downward particulate organic carbon flux in different oceanic provinces? DeepSea Research I, 46, 63-91, 1999.

Boyd, P., and Newton, P., Evidence of the potential influence of planktonic community structure on the interannual variability of particulate carbon flux, Deep-Sea Research I, 42, 619-639, 1995.

Brzezinski, M. A., Nelson, D. M., The annual silica cycle in the Sargasso Sea near Bermuda, Deep-Sea Research I, 42, 1215-1237, 1995.

Buesseler, K. O., Do upper-ocean sediment traps provide an accurate record of particle flux? Nature, 353, 420-423, 1991.

Buesseler, K. O., Bacon, M. P., Cochran, J. K., and Livingston, H. D., Carbon and nitrogen export during the JGOFS North Atlantic Bloom Experiment estimated from ${ }^{234} \mathrm{Th}:{ }^{238} \mathrm{U}$ disequilibria, Deep-Sea Research, 39, 1115-1137, 1992a.

Buesseler, K. O., Cochran, J. K., Bacon, M. P., Livingston, H. D., Casso, S. A., Hirschberg, D., Hartman, M. C., and Fleer, A. P., Determination of thorium 
isotopes in seawater by non-destructive and radiochemical procedures, Deep-Sea Research, Part A, 39, 1103-1114, 1992b.

Buesseler, K. O., Michaels, A. F., Siegel, D. A., and Knap, A. H., A three dimensional time-dependent approach to calibrating sediment trap fluxes, Global Biogeochemical Cycles, 8, 179-193, 1994.

Buesseler, K., Ball, L., Andrews, J., Benitez-Nelson, C., Belastock, R., Chai, F., Chao, Y., Upper ocean export of particulate organic carbon in the Arabian Sea derived from thorium-234, Deep-Sea Research II, 45, 2461-2487, 1998.

Buesseler, K. O., Steinberg, D. K., Michaels, A. F., Johnson, R. J., Andrews, J. E., Valdes, J. R., and Price, J. F., A comparison of the quantity and composition of material caught in a neutrally buoyant versus surface-tethered sediment trap, Deep-Sea Research I, 47, 277-294, 2000.

Carpenter, E.J., Nitrogen fixation by marine Oscillatoria (Trichodesmium) in the world's oceans (Academic Press, New York, 1983).

Carter, E. F., and Robinson, A. R., Analysis methods for the estimation of oceanic fields, Journal of Atmospheric Oceanic Technology, 4, 49-74, 1987.

Chen, J. H., Edwards, R. L., and Wasserburg, G. J., ${ }^{238} \mathrm{U},{ }^{234} \mathrm{U}$, and ${ }^{232} \mathrm{Th}$ in seawater, Earth and Planetary Science Letters, 80, 241-251, 1986.

Coale, K., and Bruland, K. W., Oceanic stratified euphotic zone as elucidated by ${ }^{234} \mathrm{Th}$ : ${ }^{238} \mathrm{U}$ disequilibria, Limnology and Oceanography, 23, 189-200, 1987.

Dickey, T., Frye, D., Jannasch, H., Boyle, E., Manov, D., Sigurdson, D., McNeil, J., Stramska, M., Michaels, A., Nelson, N., Siegel, D., Chang, G., Wu, J., and Knap, A., Initial results from the Bermuda Testbed Mooring program, Deep-Sea Research, 45, 771-794, 1998.

Dickey, T., Zedler, S., Yu, X., Doney, S. C., Frye, D., Jannasch, H., Manov, D., Sigurdson, D., McNeil, J., Dobeck, L., Gilboy, T., Bravo, C., Siegel, D. A., and Nelson, N. B., Physical and biogeochemical variability from hours to years at the Bermuda Testbed Mooring site: June 1994-March 1998, Deep-Sea Research II, 48, 2105-2140, 2001.

Doney, S., A synoptic atmospheric surface forcing data set and physical upper ocean model for the U.S. JGOFS Bermuda Atlantic Time Series (BATS) site, Journal of Geophysical Research, 101, 25615-25634, 1996.

DuRand, M. D., Olson, R. J., and Chisholm, S. W., Phytoplankton population dynamics at the Bermuda Atlantic time-series station in the Sargasso Sea, Deep-Sea Research II, in press. 
Eanes, R., and Bettadpur, S., The CSR 3.0 global ocean tide model, Tech. Memo, CSRTM-95-06, (Center for Space Research, University of Texas, Austin, 1995).

Fleer, A. P., Updated determination of particulate and dissolved thorium-234, Marine Particles: Analysis and Characterization, Geophysics Monograph Series, 63, (ed. Hurd, D. C., and Spencer D. W.), pp 227-228, (AGU, Washington, D.C., 1991).

Flierl G. and McGillicuddy, D. J. Jr., Mesoscale and sub-mesoscale physical-biological interactions, The Sea, (John Wiley and Sons, New York, In press).

Glover, H. E., Prezelin, B. B., Campbell, L., Wyman, M., and Garside, C., Anitratedependent Synechococcus bloom in surface Sargasso Sea water, Nature, 331, 161-163, 1988.

Goericke, R., and D. J. Repeta, The pigments of Prochloroccus marinus: The presence of divinyl chlorophyll a and $\mathrm{b}$ in a marine prokaryote, Limnology and Oceanography, 37, 425-433, 1992.

Goldman, J. C., Spatial and temporal discontinuities of biological processes in pelagic surface waters, in Toward a theory on biological-physical interactions in the world ocean, (ed. B. J. Rothschild), pp. 273-296, (Kluwer Academic, Dordrecth, 1988).

Goldman, J. C., Potential role of large oceanic diatoms in new primary production, DeepSea Research I, 40, 159-168, 1993.

Gruber, N., and Sarmiento, J. L., Global patterns of nitrogen fixation and denitrification, Global Biocgeochemical Cycles, 11, 235-266, 1997.

Harrison, D. and Heinmiller, R., Upper ocean variability in the Sargasso Sea July 1977July 1978: The POLYMODE XBT program, Journal of Physical Oceanography, $13,859-872,1983$.

Jeffrey, S. W., Mantoura, R.F.C., and Wright, S. W. (Eds.), Phytoplankton pigments in oceanography: guidelines to modern methods, p. 661, (UNESCO Publishing, Paris, 1997)

Jenkins, W. J. and Goldman, J. C., Seasonal oxygen cycling and primary production in the Sargasso Sea, Journal of Marine Research, 43, 465-491, 1985.

Jenkins, W. J., Nitrate flux into the euphotic zone near Bermuda, Nature, 331, 521-523, 1988. 
Jenkins W. J. and Wallace D. W. R., Primary Productivity and Biogeochemical Cycles in the Sea (eds Falkowski, P. G. and Woodhead, A. D.), 299-316, (Plenum, New York, 1992).

Karl, D. M., Letelier, R., Hebel, d., Tupas, I., Dore, J., Christian, J., and Winn, C., Ecosystem changes in the North Pacific subtropical gyre attributed to the 1991$1992 \mathrm{El} \mathrm{Ni} \star_{0}$, Nature, 373, 230-234, 1995.

Karl, D. M., Christian, J. R., Dore, J. E., Hebel, D. V., Letelier, R. M., Tupas, L. M., and Winn, C. D., Seasonal and interannual variability in primary production and particle flux at Station aloha, Deep-Sea Research II, 43, 539-568, 1996.

Kana, T. M., Glibert, P. M., Goericke, R., and Welschmeyer, N. A., Zeaxanthin and $\beta$ carotene in Synechococcus WH7803, Limnology and Oceanography, 33, 1623$1627,1988$.

Knap, A. H., Michaels, A. F., Dow, R. L., Johnson, R. J., Gundersen, K., Sorensen, J. C., Close, A., Howse, F., Hammer, M., Bates, N., Doyle, A., and Waterhouse, T., BATS methods Manual, Version 3, (U.S. JGOFS Planning Office, Woods Hole, MA U.S.A, 1993).

Ledwell, J. R., Watson, A. J. and Law, C. S., Evidence for slow mixing across the pycnocline from an open-ocean tracer-release experiment, Nature, 364, 701-703, 1993.

Letelier, R. M., Bidigare, R. R., Hebel, D. V., Ondrusek, M., Winn, C. D., and Karl, D. M., Temporal variability of phytoplankton community structure based on pigment analysis, Limnology and Oceanography, 38(7), 1420-1437, 1993.

LeTraon, P. Y., Gaspar, P., Bouyssel, F., and Makhmara, H., Using TOPEX/POSEIDON data to enhance ERS-1 data, Journal of Atmospheric Oceanic Technology, 12, 161-170, 1995.

LeTraon, P. Y., and Ogor, F., ERS-1/2 orbit improvement using Topex/Poseidon: The 2$\mathrm{cm}$ challenge, Journal of Geophysical Research, 103, 8045-8050, 1998.

Levy, M., Memery, L., and Madec, G., The onset of the spring bloom in the MEDOC area: mesoscale spatial variability, Deep-Sea Research I, 46, 1137-1160, 1999.

Lewis, M.R., Harrison, W. G., Oakely, N. S., Hebert, D., and Platt, T., Vertical nitrate fluxes in the oligotrophic ocean, Science, 234, 870-873, 1986.

Lipschultz, F., and Owens, N. J. P., An assessment of nitrogen fixation as a source of nitrogen to the North Atlantic Ocean, Biogeochemistry, 35, 261-274, 1996. 
Lohrenz, S. E., Knauer, G. A., Asper, V. L., Tuel, M., Michaels, A. F., and Knap, A. H., Seasonal and interannual variability in primary production and particle flux in the Northwestern Sargasso sea US JGOFS Bermuda Atlantic Time-series Study, Deep-Sea Research, 39, 1373-1391, 1992.

Mackey, D. J., Higgins, H. W., Mackey, M. D., Holdsworth, D., Algal class abundances in the western equatorial Pacific: Estimation from HPLC measurements of chloroplast pigments using CHEMTAX, Deep-Sea Research I, 45, 1441-1468, 1998.

Mackey, M. D., Mackey, D. J., Higgins, H. W., Wright, S. W., CHEMTAX - A program for estimating class abundances from chemical markers: Application to HPLC measurements of phytoplankton, Marine Ecology-Progress Series, 144, 265-283, 1996.

Mahadevan, A. and Archer, D., Modeling the impact of fronts and mesoscale circulation on the nutrient supply and biogeochemistry of the upper ocean, Journal of Geophysical Research, 105, 1209-1225, 2000.

Malone, T. C., Pike, S. E., and Conley, D. J., Transient variations in phytoplankton productivity at the JGOFS Bermuda time-series station, Deep-Sea Research I, 40, 903-924, 1993.

McNeil, J. D., Jannasch, H. W., Dickey, T., McGillicuddy, D., Brzezinski, M., and Sakamoto, C. M., New Chemical, bio-optical and physical observations of upper ocean response to the passage of a mesoscale eddy off Bermuda, Journal of Geophysical Research, 104(C7), 15537-15548, 1999.

McGillicuddy, D. J., and Robinson, A. R., Eddy-induced nutrient supply and new production in the Sargasso Sea, Deep-Sea Research I, 44, 1427-1450, 1997.

McGillicuddy, D. J. Jr., Robinson, A. R., Siegel, D. A., Jannasch, H. W., Johnson, R., Dickey, T. D., McNeil, J., Michaels, A. F., and Knap, A. H., Influence of mesoscale eddies on new production in the Sargasso Sea, Nature, 394, 263-265, 1998.

McGillicuddy, D. J. Jr., R. Johnson, R., Siegel, D. A., Michaels, A. F., Bates, N. R., and Knap, A. H., Mesoscale variations in biogeochemical properties in the Sargasso Sea, Journal of Geophysical Research, 104(C6), 13381-13394, 1999.

Michaels, A. F., and Silver, M. W., Primary production, sinking fluxes and the microbial food web, Deep-sea Research, 35, 473-490, 1988.

Michaels, A. F., Knap, A. H., Dow, R. L., Gundersen, K., Johnson, R. J., Sorensen, J., Close, A., Knauer, G. A., Lohrenz, S. E., Asper, V. A., Tuel, M. and Bidigare, R., 
Seasonal patterns of ocean biogeochemistry at the U.S. JGOFS Bermuda Atlantic Time-series Study site, Deep-Sea Research I, 41, 1013-1038, 1994a.

Michaels, A. F., Nicholas, R. B., Buesseler, K. O., Carlson, C. A., and Knp, A. H., Carbon-cycle imbalances in the Sargasso Sea, Nature, 372, 537-540, $1994 \mathrm{~b}$.

Michaels, A. F., Ocean time series research near Bermuda: The Hydrostation S timeseries and the Bermuda Atlantic Time-series Study (BATS) program, In Ecological Time Series, (Powell, T. M., and Steele, H. J., eds), pp. 181-208, (Chapman and Hall, New York, 1995).

Michaels, A. F. and Knap, A. H., Overview of the U.S. JGOFS Bermuda Atlantic Timeseries Study and the Hydrostation S program, Deep Sea Research II, 43(2-3), 157198, 1996.

Michaels, A. F., Olson, D., Sarmiento, J. L., Ammerman, J., Fanning, K., Jahnke, R., Knap, A. H., Lipshultz, R., and Prospero, J., Inputs, losses and transformations of nitrogen and phosphorous in the pelagic North Atlantic Ocean, Biogeochemistry, 35, 181-226, 1996.

Noshkin, V. E., and DeAgazio, E., Low background beta detector for solid sample assay, Nuclear Instrumental Methods, 39, 265-270, 1966.

Olson, R.J., Chisholm, S. W., Zettler, E. R., Altabet, M. A., and Dusenberry, J. A., Spatial and temporal distributions of prochlorophyte picoplankton in the North Atlantic Ocean, Deep-Sea Research, 37, 1033-1051, 1990a.

Olson, R. J., Chisholm, S. W., Zettler, E.R., and Armbrust, E. V., Pigments, size and distribution of Synechococcus in the North Atlantic and Pacific Oceans, Limnology and Oceanography, 35, 45-58, $1990 \mathrm{~b}$.

Prospero, J. M., Barrett, K., Church, T., Dentener, F., Duce, R. A., Gallaway, J., Levy II, H., Moddy, J., and Quinn, P., Atmospheric deposition of nutrients to the North Atlantic Basin, Biogeochemistry, 35, 27-73, 1996.

Roman, M. R., Dam, H. G., Gauzens, A. L., and Napp, J. M., Zooplankton biomass and grazing at the JGOFS Sargasso Sea time-series station, Deep-Sea Research I, 40, 883-901, 1993.

Roman, M. R., Adolf, H. A., Landry, M. R., Madin, L. P., Steinberg, D. K., and Zhang, $\mathrm{X}$., Estimates of oceanic mesozooplankton production: A comparison between the Bermuda and Hawaii time-series data, Deep-Sea Research II, in press.

Richardson, K., Comparison of ${ }^{14} \mathrm{C}$ primary production determinations made by different laboratories, Marine Ecology Progress Series, 72, 189-201, 1991. 
Richardson, P. L., Eddy kinetic energy in the North Atlantic from surface drifters, Journal of Geophysical Research, 88, 4355-4367, 1983.

Richman, J. G., Wunsch, C., and Hogg, N. G., Space and time scales of mesoscale motions in the western North Atlantic, Reviews of Geophysics, 15, 385-377, 1977.

Savidge, G., Boyd, P. W., Pomroy, A.J., Harbour, D., Joint I., A study of the spring bloom in the N-E Atlantic Ocean in 1990, Deep-Sea Research I, 42, 599-617, 1995.

Sieburth, J. M., and Smetacek, V., Pelagic ecosystem structure: Heterotrophic compartments of the plankton and their relationship to plankton size fractions, Limnology and Oceanography, 23, 1256-1263, 1978.

Siegel, D. A., Itturiaga, R., Bidigare, R., Smith, R. C., Pak, H., Dickey, T.D., Marra J., and Baker, K. S., Meridional variations of the spring time phytoplankton community in the Sargasso Sea, Journal of Marine Research, 48, 379-412, 1990.

Siegel, D. A., McGillicuddy, D. J. Jr, and Fields, E. A., Mesoscale eddies, satellite altimetry, and new production in the Sargasso Sea, Journal of Geophysical Research, 104(C6), 13359-13379, 1999.

Silver, M. W., Gowing, M. M., and Davoll, P. J., The association of photosynthetic picoplankton and ultraplankton with pelagic detritus through the water column (0$2000 \mathrm{~m}$ ), Canadian Bulletin of Fisheries and Aquatic Sciences, 214, 311-341, 1986.

Spitzer, W.S. and Jenkins, W.J., Rates of vertical mixing, gas exchange and new production: estimates from seasonal gas cycles in the upper ocean near Bermuda, Journal of Marine Research, 47, 169-196, 1989.

Takahashi, M., and Bienfang, P. K., Size-structure of phytoplankton biomass and photosynthesis in subtropical Hawaiian waters, Marine Biology, 76, 203-211, 1983.

The MODE Group, The mid-ocean dynamics experiment, Deep-Sea Research, 25, 859910, 1978.

Williams, R. G. and Follows, M. J., The Ekman transfer of nutrients and maintenance of new production over the North Atlantic, Deep-Sea Research I, 45, 461-489, 1998.

Woods, J. D., Mesoscale upwelling and primary production, Toward a Theory on Biological-Physical Interactions in the World Ocean, (ed. Rothschild, B. J.), (D. Reidel, Dordrecht, 1988). 
Wright, S. W., Jeffrey, S. W., Mantoura, F. C., Llewellyn, C. A., Bj*rnland, T., Repeta, D., and Welschmeyer, N., Improved HPLC method for the analysis of chlorophylls and caratenoids from marine phytoplankton, Marine Ecology Progress Series, 77, 183-196, 1991.

Wright, S. W., van den Enden, R. L., Phytoplankton community structure and stocks in the East Antarctic marginal ice zone (BROKE survey, January-March 1996) determined by CHEMTAX analysis of HPLC pigment signatures, Deep-Sea Research II, 47, 2363-2400, 2000. 